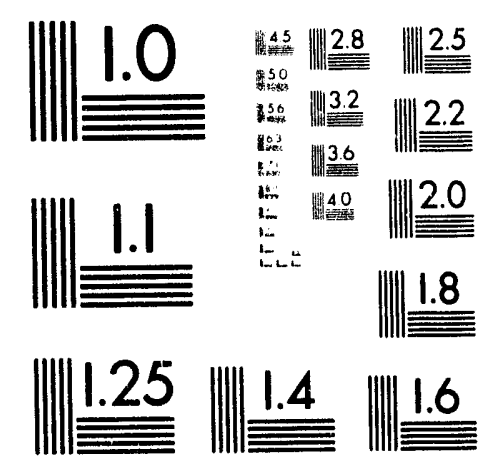



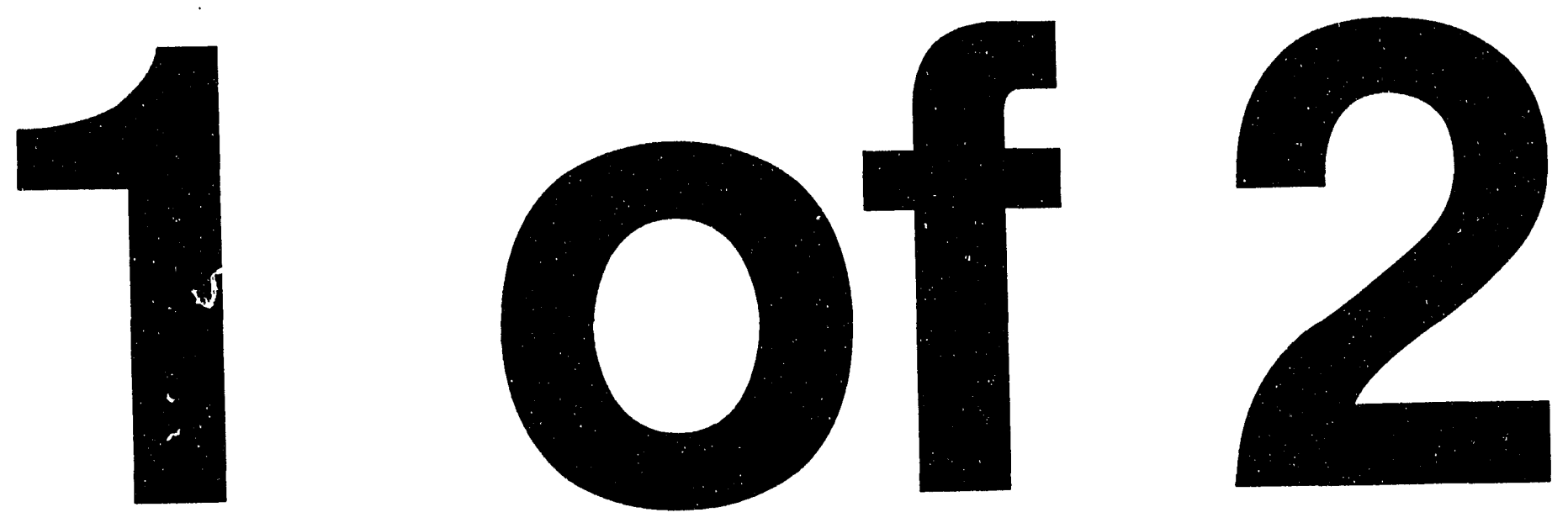
WHC-EP-0522

UC.811

\title{
Hanford Waste Vitrification Plant Project Waste Form Qualification Program Plan
}

\author{
E. H. Randklev
}

Date Published

June 1993

Date Manuscript Completed

April 1992

Prepared for the U.S. Department of Energy Office of Environmental Restoration and Waste Management

\section{(2) Westinghouse P.O. Box 1970 \\ Hanford Company Richland, Washington 99352}

Hanford Operations and Engineering Contractor for the

U.S. Department of Energy under Contract DE-AC06-87RL10930 


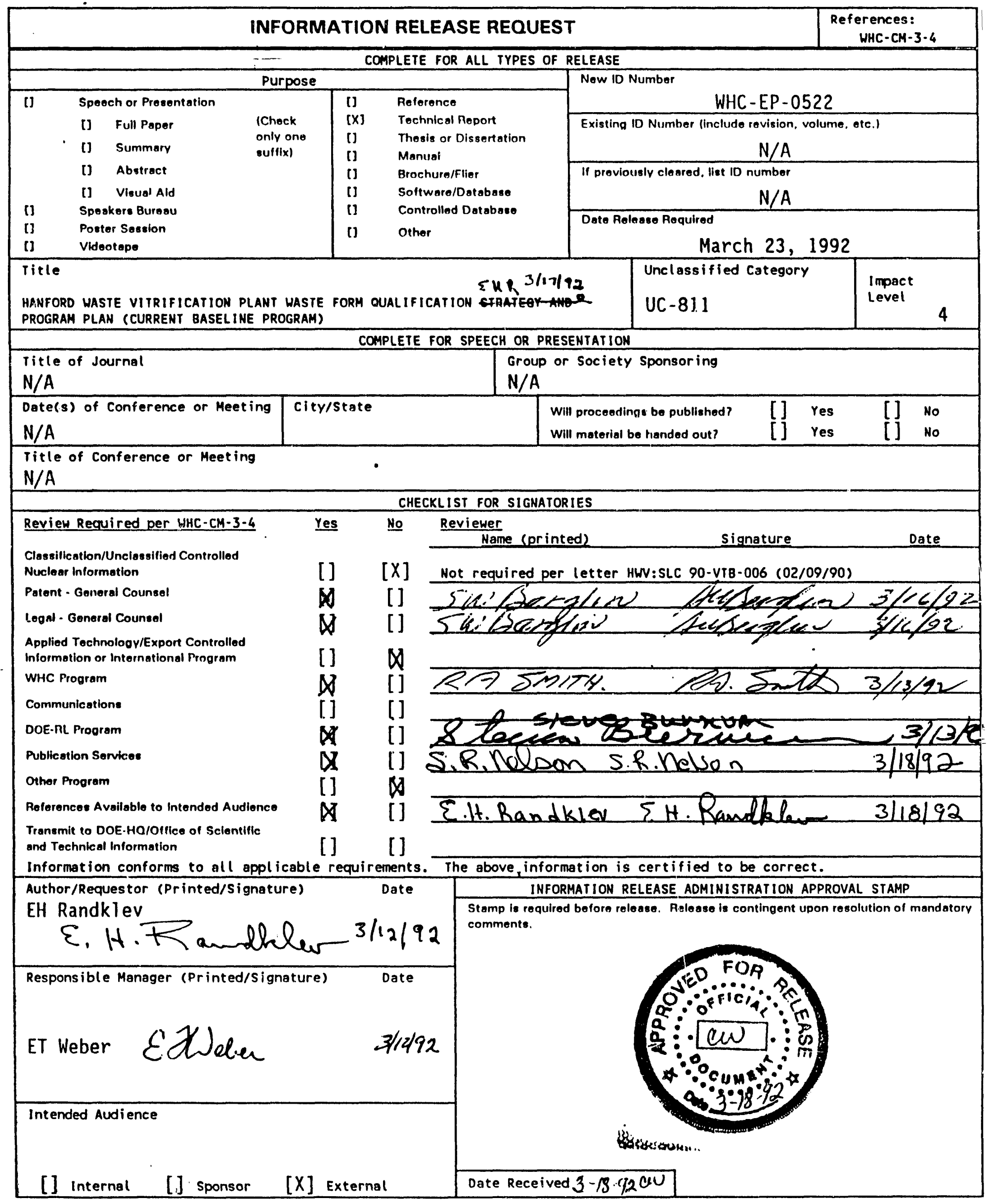




\section{HANFORD WASTE VITRIFICATION PLANT PROJECT WASTE FORM QUALIFICATION} PROGRAM PLAN

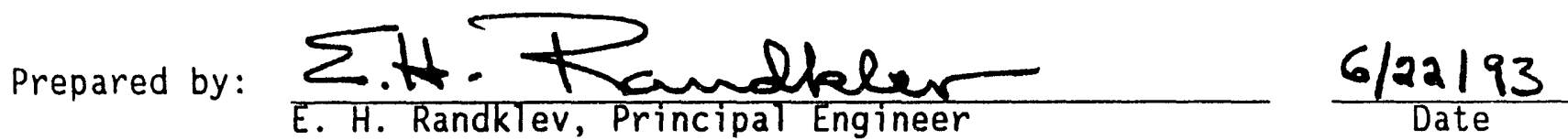
HWVP Technology

Approved by:
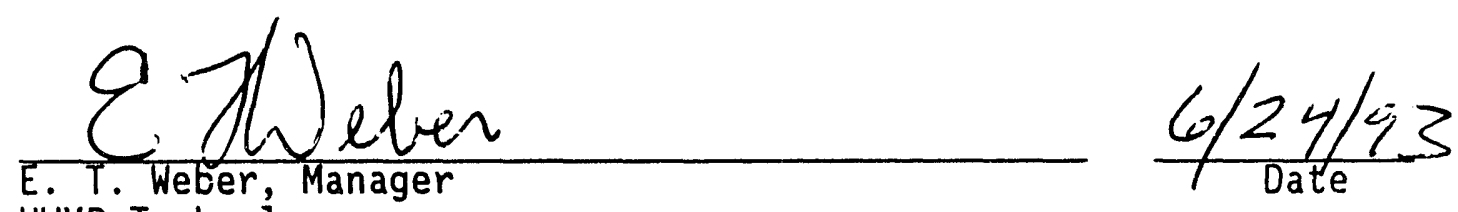
HWVP Technology 
WHC-EP-0522

This page intentionally left blank. 
WHC-EP-0522

\title{
HANFORD WASTE VITRIFICATION PLANT PROJECT WASTE FORM QUALIFICATION PROGRAF PLAN
}

\author{
E. H. RandkTev
}

\section{PREFACE}

In April 1992, a "prepublication draft" of this report was completed. The report addressed the topic of waste form qual ification for the baseline program at that time (i.e., the immobilization of high-level tank wastes from the Hanford Site double-shell storage tanks). The report had been cleared for publication by the Westinghouse Hanford Company and the U.S. Department of Energy (DOE), Richland Field Office (RL) and had been sent to the DOEHeadquarter's (DOE-HQ) for review. In July 1992, the DOE-HQ, Office of Environmental Restoration and Waste Management (EM), provided several review comments and requested an explanation of their dispositions before final issuance of the document. The added review step was prompted by the general programmatic interest of DOE-HQ EM in the Hanford Site Tank Waste Remediation System (TWRS) Program rebaselining effort, plus a specific interest in the TWRS waste immobilization function and its particular linkage to the topic of waste form qualification. Overall, the changes needed to disposition the DOE-HQ EM comments were not extensive.

During the period involved in obtaining and dispositioning the DOE-HQ EM review comments, several fundamental changes occurred in (1) the DOE waste acceptance process definition of the documentation needed for waste form qualification," and (2) the planning documents hierarchy to be used, starting in fiscal year 1993, by the immobilization function of the TWRS Program. The revisions that would be needed to make the document current with respect to the changes referred to in items (1) and (2) would be substantial. This raised the question as to whether the document should be delayed further and rewritten to reflect the results of the TWRS Program rebaselining effort that was under way and the changes in the waste acceptance process documentation that had occurred. The DOE-RL decision (November 1992) was to direct WHC to publish the version of the report that included only those revisions made to address the DOE-HQ EM review comments. The DOE-RL conclusion was that ... "Although, the subject document reflects an earlier Tank Waste Remediation System baseline plan for vitrification of double-shelled tank waste, we believe that (1) the hierarchy of strategies described in the document should be used as a. reference in future communications, and (2) the document will provide an excellent starting point for future waste form qual ification planning by the HWVP Project personnel. Issuing the document as a referenceable "benchmark" is deemed appropriate."

*See the preface paragraphs for Appendixes A and B for a more detailed descriptinn of the changes that occurred during this time period in the DOE waste acceptance process documentation hierarchy concerning waste form qualification. 


\section{PREFACE (cont)}

The plan is to prepare and issue a revision of this report, as soon as practical, after the Tri-Party Agreement group (i.e., the DOE, Washington State Department of Ecology, and the U.S. Environmental Protection Agency) agree to a new baseline program for the Hanford Site TWRS Program. The proposed revision will also include the appropriate updates pertaining to the recent $D O E$ changes in the waste form qual ification documentation hierarchy. 


\section{HANFORD WASTE VITRIFICATION PLANT PROJECT WASTE FORM QUALIFICATION PROGRAM PLAN}

E. H. Randklev

\section{ABSTRACT}

The U.S. Department of Energy has created a waste acceptance process to help guide the overall program for the disposal of high-level nuclear waste in a federal repository. This Waste Form Qualification Program Plan describes the hierarchy of strategies used by the Hanford Waste Vitrification Plant Project to satisfy the waste form qualification obligations of that waste acceptance process. A description of the functional relationship of the participants contributing to completing this objective is provided. The major activities, products, providers, and associated scheduling for implementing the strategies also are presented. 
WHC-EP-0522

This page intentionally left blank. 


\section{EXECUTIVE SUMMARY}

The Hanford Waste Vitrification Plant (HWVP) Project has chosen to prepare a Waste Form Qualification (WFQ) Program Plan (Plan) to provide a structure for fulfilling the obligations of WFQ and to interface these WFQ activities with the rest of the project planning. This Plan describes the strategies, activities, activity products, product providers, scheduies, and programmatic relationships the HWVP Project judges necessary to satisfactorily complete the tasks comprising the WFQ portion of the U.S. Department of Energy (DOE) waste acceptance process. The emphasis is on the activities needed to ensure that the HWVP waste form product will meet the acceptance specifications established by the geologic repository program. A hierarchy of WFQrelated strategies is presented that addresses (1) the general strategy for - the HWVP Project, (2) the program strategy for satisfying WFQ and supporting the HWVP Project hot start, and (3) the technology strategy for each acceptance specification. The Plan was prepared in accordance with the HWVP Project baseline schedule and program às of March 1992 (i.e., the HWVP would start processing actual waste in December 1999, the high-level waste [HLW] from the double-shell tanks would be processed f.jrst, etc.).

The intent is to use this Plan in conjunction with WHC-EP-0417, Hanford Waste Vitrification Plant Applied Technology Plan," as a mutually complementing and closely interfaced set of primary planning documents for the HWVP Project technology development and WFQ compliance activities. The topical interface between the two documents is that they identify, in some manner,

\footnotetext{
"0. L. Kruger, 1992, Hanford Waste Vitrification Plant Applied Technology Plan, WHC-EP-0417, Westinghouse Hanford Company, Richland, Washington. (Note: According to the March 1993 rebaseline proposal for the Han ord Site Tank Waste Remediation System Program, this technology planning documentation will be covered by Tank Waste Remediation System Frogram Plans.)
} 
those WFQ compliance supporting technology topics and associated activities that are formally assigned responsibilities of the HWVP Project.

The general approach of the HWVP Project to WFQ consists of the following major tasks.

- Work with the DOE geologic repository program and the other DOE HLW vitrification projects to establish the acceptance specifications for the HWVP waste form product.

- Focus the design of the HWVP and waste form product to ensure compliance with the repository acceptance specifications.

- Test the proposed process and equipment designs to provide sufficient evidence that the product will meet the acceptance specifications.

- Maintain the operation within the required operational limits once the facility is in production to make only an acceptable waste form product.

- Prepare the vitrification project documents required by the waste acceptance process.

Where practical, compliance with the repository waste acceptance requirements will be achieved by an appropriate combination of data from direct measurements of process or product attribites. When such an approach is not practical, correlations will be used to relate an attribute, which is suitably 
measurable and controllable, to the one specified in a given acceptance specification. In a few cases, administrative controls also will be a significant contributor to the compliance approach. This Pian presents summarized listings of the particular combinations of work activities, products, and schedules that satisfy the compliance basis for each acceptance specification.

For certain specifications, the respective compliance basis will be primarily obtained from the combined results of scaled system testing of feed processing and melter operations, including cold testing performed in the HWVP. Such scaled system testing will primarily involve the testing of nonradioactive simulations of proposed waste feeds. Some test systems also will be run using feed made from samples of the actual HLW. At least a portion of the compliance bases for a few of the specifirations will have to come from HWVP operating experience with actual waste processing (i.e., after "hot startup"). Another source for some of the compliance basis information will be the testing and operations experiences of the West Valley Demonstration Projert at West Valley, New York; and especially the Defense Waste Processing Facility at Aiken, South Carolina. These DOE HLW vitrification projects are considerably nearer completion than the HWVP Project.

This Plan will be updated regularly so it can be coordinated with the key planning documents for the immobilization technology development associated with the Hanford Site Tank Waste Remediation System Program. Schedule information in this document is for general information purposes only, but is consistel.t with the current (i.e., March 1992) HWVP Project schedule baseline, which is documented el sewhere. 
WHC-EP-0522

This page intentionally left blank. 


\section{CONTENTS}

1.0 INTRODUCTION ..................... . . . . . . .

1.1 OBJECTIVE .................... . . . . . .

1.2 SCOPE . . . . . . . . . . . . . 1-1

1.2.1 Topics Covered ............. . . . 1-1

1.2.2 Established Current Baseline Schedule and Program . . . 1-i

1.2.3 Program Redefinition ............. 1-2

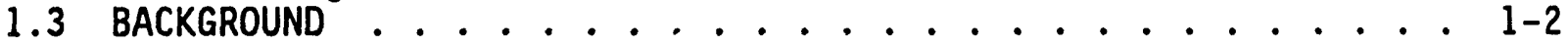

2.0 WFQ DEFINITION, REPORTING, AND PROJECT FUNCTIONAL RELATIONSHIPS . . 2-1

2.1 DEFINITION ................... 2-1

2.2 REPORTING ................... 2- . . . . .

2.2 .1 Introduction .............. 2-1

2.2.2 Repository WAS ............... 2-1

2.2 .3 WFCD ..................... 2-2

2.2 .4 WCP ...................... 2-2

2.2 .5 HQR ..................... 2-4

2.2 .6 PRs and SSRs .............. 2-. 24

2.2.7 Reporting and Information Requested ....... 2-4

2.3 FUNCTIONAL RELATIONSHIPS OF ORGANIZATIONS SUPPORTING

THE HWVP PROJECT $\ldots \ldots \ldots \ldots$

2.3.2 HWVP Project: Supporting Organizations/Programs ... 2-8

3.0 STRATEGIES FOR WFQ ...................

3.1 INTRODUCTION .................... 3-1

3.2 STRATEGY HIERARCHY . . . . . . . . . . . . 3-1

3.3 GENERAL STRATEGY FOR THE HWVP PROJECT . . . . . . . . . . 3-2

3.3.1 Background ................ 3-2

3.3.2 General Strategy . . . . . 3-2

3.4 PROGRAM STRATEGY FOR SATISFYING WFQ AND SUPPORTING

TANK WASTE DISPOSAL PLANNING . . . . . . . . . . . . . . $3-3$

3.4.2 Program Strategy . . . . . . . . . . . . . 3-3

3.4.3 Program Redefinition ........... 3-8

3.5 TECHNOLOGY STRATEGIES FOR ACCEPTANCE SPECIFICATION
CSMPLIANCE AND WFQ REPORTING FOR EACH WASTE TYPE ....... $3-8$

3.5.1 Introduction . . . . . . . . . . . . 3-8

3.5.2 Technology Strategies: General Summary Characterization ......... . 3-10

3.5.3 Technology Strategies: Detailed Summary
Characterizations ............... 3-16

3.6 MAJOR ISSUES TO BE RESOLVED . . . . . . . . . . . . 3-18

4.0 QUALITY ASSURANCE . . . . . . . . . . . . . 4-1

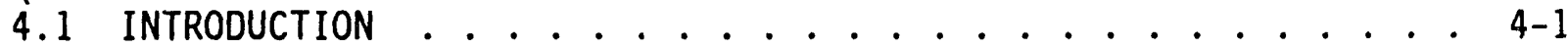

4.2 HWVP PROJECT ACTIONS IN ACCORDANCE WITH DOE/RW-0214

REQUIREMENTS .................... 4-1

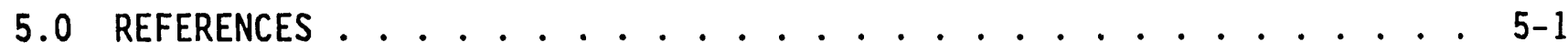

6.0 GLOSSARY . . . . . . . . . . . . . . . . GL-1 
WHC-EP-0522

CONTENTS (cont)

APPENDIXES

A DESCRIPTION AND IMPLEMENTATION OF THE WASTE ACCEPTANCE PROCESS . . . . . . . . . . . . . . . . . . A-1

B WASTE ACCEPTANCE PRELIMINARY SPECIFICATIONS . . . . . . . . . . B-1

C TABLE FOF SECOND LEVEL OF GENERAL SUMMARY CHARACTERIZATION OF TECHNOLOGY (ACTIVITY) STRATEGIES . . . . . . . . . . . C C-1

D DETAILED SUMMARIES OF TECHNOLOGY STRATEGIES AND ASSOCIATED
SCHEDULES FOR COMPLYING WITH THE ACCEPTANCE SPECIFICATIONS • • D-1

\section{LIST OF FIGURES}

2-1 Summary Schedule for Waste Form Qualification Documents . . . . . 2-3

2-2 Hanford Waste Vitrification Plant Project Functional Organization and Interrelationships . . . . . . . . . . . . . . . 2-9

3-1 Major Hanford Waste Vitrification Plant Project Activities Important to Waste Form Qual ification as of March $1992 . . . . .3-7$

\section{LIST OF TABLES}

2-1 Waste Form Qualification Reporting in Relation to Information Requested by the Waste Acceptance Preliminary Specifications . . . . 2-5

3-1 First Level of General Summary: Technology Strategies for Complying with the Acceptance Specifications . . . . . . . . . 3-11 


\section{ACKNOWLEDGMENTS}

Issuance of this document was made possible by the combined support of numerous Hanford Site employees and special recognition is given to the following people. Westinghouse Hanford Company employees R. L. Gibby, J. F. Erben, J. R. Baker, G. E. Stegen, E. T. Weber, R. L. Hand, and H. Spanheimer reviewed and commented on the document; and R. G. Seymour, T. H. May, and R. N. Wagner assisted with the summary schedule figure.

P. E. LaMont of the U.S. Department of Energy, Richland Field Office, provided review and editing comments. Review comments were also provided by J. C. Tseng and J. M. Allison of U.S. Department of Energy-Headquarters, Office of Environmental Restoration and Waste Management. Pacific Northwest Laboratory employee G. Schiefelbein provided valuable assistance in formulating the early versions of the summary strategy tables, and $W$. L. Kuhn provided review comments on the tables. The initial word processing support for the tables was provided by $L$. C. Inman of Westinghouse Hanford Company. The Boeing Computer Services Richland, Inc. Publications Services staff provided the formal editing and word processing assistance. The Boeing Computer Services Richland, Inc. Graphics group provided the extensive graphics support required to complete the schedules in Appendix $D$. 
WHC-EP-0522

This page intentionally left blank. 


\section{HANFORD WASTE VITRIFICATION PLANT WASTE FORM QUALIFICATION PROGRAM PLAN}

\subsection{INTRODUCTION}

\subsection{OBJECTIVE}

The objective of this document is to describe the Hanford Waste Vitrification Plant (HWVP) Project's overall strategy, program structure, and schedules for ensuring that the waste form product is acceptable for disposal in a U.S. geologic repository for high-level nuclear waste (HLW).

\subsection{SCOPE}

\subsubsection{Topics Covered}

To accomplish the objective previously addressed, the scope of this document includes the following: (1) a hierarchy of strategies that collectively defines the basic approach paths the HWVP Prnject will follow; (2) a description of activities, organizational interactions, and sequence of documentation; and (3) details concerning important activity and schedule : Tinkages to baseline planning.

\subsubsection{Established Current Baseline Schedule and Program}

This document focuses on a particular portion of the HWVP Project and the support it provides for waste tank remediation work on the Hanford Site according to the baseline as of March 1992. The basel ine schedule calls for HWVP construction to begir. in April 1992 and end in June 1998. The processing of radioactive waste would begin in December 1999. The waste remediation program (DOE 1987) identifies the Hanford Site double-shell tanks (DST) as being the first tanks scheduled for retrieval, pretreatment, and HWVP processing. The HLW in the DSis is classified into four types:

- Neutralized current acid waste (NCAW)

- Neutralized cladding removal waste (NCRW)

- Plutonium Finishing Plant (PFP) waste

- Complexant concentrate (CC) waste.

According to prior program planning associated with the baseline schedule, NCAW is scheduled to be the first of these waste types to be fed to the HWVP following pretreatment. The NCAW pretreatment will consist primarily of a water-washing process. The other three DST HLW types were listed as candidates for pretreatment using a transuranic (TRU) separations process. Planiling for the HWWP feed sequence regarding the other three waste types is still preliminary, but has been assumed to follow the order just listed. 


\subsubsection{Program Redefinition}

During fiscal year (FY) 1991, a risk assessment study (Miller et al. 1991) was performed to better determine the risks associated with the Hanford Site DST vitrification baseline plans (DOE 1988a). The resilts of the risk assessment study resulted in another study that examined the overall tank waste disposal alternatives for the Hanford Site and proposed a reference course of action (Grygiel et al. 1991). The recommendation from the latter study was that the DST and single-shell tank (SST) programs should be integrated and that a new pretreatment facility should be constructed ( $i . e$. , instead of using B Plant) to house the TRU separations process. In this new integrated program, the sequential order for waste retrieval and pretreatment would be guided by a... "near-term strategy with the goal of enhancing tank safety."

The Westinghouse Hanford Company (Westinghouse Hanford) Tank Waste Remediation System (TWR) Division is required by a U.S. Department of Energy (DOE) directive to implement the program redefinition (Grygiel et a1. 1991) by replanning a new baseline program case by the end of March 1993. The next revision of this PI an and WHC-EP-0417, Hanford Waste Vitrification Plant Applied Technology Plan (Kruger 1992), will address the rebaselined program according to the implementation of the redefinition proposals.

The basic elements of the strategy hierarchy described in this Plan are believed to be applicable to the current program and to the newly integrated program proposed by the redefinition study. However, including the HLW types from the SSTs would significantly increase the work scope to implement the strategies described in this Plan.

\subsection{BACKGROUND}

This section contains information on the major events and decisions that have shaped the course of the HWVP Project up to the current baseline program. Some of this information was adapted or directly excerpted from either WHC-EP-0250, Hanford Waste Vitrification Plant Preliminary Safety Analysis Report (Herborn et al. 1991) or from the preceding version of a waste form qualification (WFQ) program planning document for the HWVP Project (Nelson 1988).

A major mission of the DOE/Hanford Site Tank Waste Remediation System (TWRS) Program is to provide a waste form product for the permanent disposal of Hanford Site defense waste using safe, environmentally acceptable, and cost-effective disposal methods that meet applicable regulations. This program is part of a broader-based national program as required by $D O E$ Order 5820.2A, Radioactive Waste Management (DOE 1988b). Several decisions that were made in the early 1980's regarding the cleanup of high-level defense waste at the Savannah River Site (SRS) in South Carolina were important precedents relative to subsequent decisions regarding $H L W$ cleanup at the Hanford Site. The SRS was chosen by the U.S. Congress and the DOE as the lead DOE site for such waste cleanup. In December 1982, the decision process for the SRS culminated in a Record of Decision (ROD) that formalized the selection of borosilicate glass as the waste form for immobilizing the high-level portion of the SRS nuclear waste. This decision was subsequently endorsed by the 
U.S. Environmental Protection Agency, the U.S. Nuclear Regulatory Commission (NRC), and several independent review groups.

Relative to the Hanford Site, immobilization of the HLW in DSTs in a glass matrix waste form was 1 isted as the preferred HLW disposal alternative in DOE/EIS-0113, Final Environmental Impact Statement (EIS), Disposal of Hanford Defense High-Level, Transuranic, and Tank Wastes (DOE 1987). On April 8, 1988, the DOE issued the ROD for the Hanford Site (DOE 1988a), based on the final EIS. The ROD for the Hanford Site stipulated that the preferred alternative, as discussed in the Hanford Site EIS (DOE 1987a), be implemented. However, a decision on SST waste was deferred pending further study. The HWVP Project was established to provide the vitrification plant for producing such a waste form. The HWVP will be a key facility in the cleanup of HLW at the Hanford Site.

The HWVP will immobilize the high-level portion of pretreated defense waste in a borosilicate glass and cast the glass into stainless steel canisters. The filled canisters are to be temporarily stored onsite and later shipped to a federal geologic repository, which will be specifically designed and licensed for the disposal of HLW. The low-activity fraction from the pretreated Hanford Site HLW will be solidified as a cement-based grout in the Hanford Site Grout Treatment Facility. The grout will be disposed of on the Hanford Site in near-surface multilayered vault systems constructed specifically for this purpose.

In terms of the waste feed into the HWVP, the DOE initially decided to focus on the Hanford Site defense waste stored in DSTs. According?y, the first waste to be processed would be the NCAW. The three other types of DST waste, i.e., NCRW, and PFP and CC wastes, would then be processed in some optimized scheduling order. This previous planning made no commitment regarding the extent to which the HLW stored in the Hanford Site SSTs would be processed through the HWVP. As noted in Section 1.2, the Westinghouse Hanford TWRS Program has begun a process to redefine the baseline program, which will include decisions on what is to be done with the SST waste. Because the HWVP design has already been under way for several years, the HWVP Project staff has proceeded with what is judged to be sufficient flexibility to accommodate the HLW portion of the SST waste with possibly some process modifications.

The decision to send the defense HLW to a federal geologic repository for the commercial HLW (i.e., spent nuclear fuel) was made in 1985, in accordance with provisions of the Nuclear Waste Policy Act of 1982. It was recognized that the vitrification plants planned for the SRS in South Carolina, the West Valley Site in New York, and probably the one at the Hanford Site in Washington would be ready for startup before the federal geologic repository was licensed. To help ensure that the product (i.e., canistered waste form) from these three facilities would be acceptable for disposal at the future repository, the DOE created and instituted a plan called the waste acceptance process (WAP). A more detailed description of the WAP is provided in Appendix A, which was excerpted from WHC-EP-0045, Hanford Waste Vitrification Plant Preliminary Waste Form Qualification Plan - FY 1988 Update (Nelson 1988).

Among the major topics covered by the WAP was the creation of acceptance specifications for the canistered waste form produced by each of the vitrification plants. Because these specifications are the responsibility of the 
repository program, the DOE-Office of Civilian Radioactive Waste Management (OCRWM) created a Waste Acceptance Committee (WAC) and assigned it the responsibility of preparing waste acceptance preliminary specifications (WAPS).

The WAC comprises representatives from the three repository (site) projects that were being evaluated during the early 1980's. For technical and programmatic integration purposes, the WAC was augmented by appointing supporting representatives from each of the DOE HLW producer sites. The first assignment was to produce the preliminary acceptance specification documents for the West Valley Demonstration Project (WVDP) and the SRS Defense Waste Processing Facility (DWPF). Versions of these documents were generated and underwent several refinement cycles. Following the action by the U.S. Congress in early 1987 to delete two of the three candidate repository sites from the DOE-OCRWM program, the WAPS for WVDP and DWPF (DOE-OCRWM 1986) were further revised to meet the specifications specific to the needs of the remaining repository candidate, the Yucca Mountain tuff site in Nevada.

During the past several years, whenever a perspective was needed on what the preliminary acceptance specifications might be for the HWVP product, management chose (Ne1son 1988) to use the WAPS for the DWPF, either as a surrogate or (at least) for primary guidance. Choosing the DWPF was logical, given the close similarity of the respective facilities, the process layouts, proposed waste form products, and even the initial waste to be processed. In late 1990, the DOE-OCRWM program began a major revision of the WAPS. The document was changed into one that is generic for all currently planned vitrified HLW producers (i.e., WVDP, DWPF, and HWVP). A process of verification reviews and suggested revisions by affected parties continued up to completion of a draft document in June 1991 (see Appendix B) for review within the DOEOCRWM. Recent1y, the DOE, Richland Field Office directed the HWVP Project (DOE-RL 1991) to use the June 1991 draft of the WAPS document as a basis for planning testing and design work. 
WHC-EP-0522

\subsection{WFQ DEFINITION, REPORTING, AND PROJECT \\ FUNCTIONAL RELATIONSHIPS}

\subsection{DEFINITION}

As part of the WAP description, the DOE created a flow diagram to identify the type and sequence of documentation needed to complete this process for a given waste form. Appendix A (from Nelson 1988) provides the DOE description of the WAP. A particularly important subset of the documentation outlined in the WAP constituted a task generally referred to as WFQ, which consists of the following.

\section{Responsibility of the repository project}

- Waste acceptance specifications (WAS), including their predecessor, the WAPS

\section{Responsibility of each waste form producer project}

- Waste form and canister description (WFCD) document

- Waste compliance plan (WCP)

- Waste qualification report (WQR)

- Production records (PR)

- Storage and shipping records (SSR).

The SSRs were not explicitly identified in the DOE WAP flow diagram. They were subsequently identified by the repository program in the WAPS (borosilicate waste form) as a type of record distinct from the PR and necessary for complying with certain specifications of the WAPS.

\subsection{RËPORTING}

\subsubsection{Introduction}

Each of the three DOE HLW vitrification projects in the DOE program is responsible for preparing site-specific versions of the five documents required as part of satisfying the WFQ portion of the WAP.

Relative to the decision to start the HWVP processing on a given waste type, the first three WFQ document types are products of the preparation stage for such a decision; whereas, the final two are produced as part of the HWVP production and follow-on interim (onsite) storage operations. All five document types are prepared primarily for the benefit of the repository project.

\subsubsection{Repository WAS}

As noted at the end of Section 1.3, Westinghouse Hanford recently received written notification from the DOE, Richland Field Office (DOE-RL 1991), to begin using the July 1991 draft of the revised VAPS. See Appendix B for a copy of the WAPS and the DOE instructions. 
The WAPS contain a set of acceptance specifications derived by the repository program from design and licensing needs for the federal repository project. The specifications in the WAPS are divided into the following topical categories:

- Waste form

- Canister

- Canistered waste form

- Quality assurance (QA).

Because the WAPS is the responsibility of the DOE repository program for HLW disposal, the HWVP Project does not prepare schedules tracking the intermediate progress of this document. The document has been in a high-level review process within the U.S. Department of Energy-Office of Radioactive Waste Management (DOE-RW) organization since July 1991.

\subsubsection{WFCD}

The WFCD document provides the repository project with some early data and predictions regarding the specifications in the WAPS, particularly those involving waste form characteristics. According to the WAPS, such information assists the repository project to define and plan waste form-related testing, design studies, preliminary performance analyses, etc. It is expected that more than one revision of this document will be needed to adequately capture the projected characteristics of the waste types that will be processed by the HWVP. The latest version of this document was issued in 1990 (Colburn 1990). The current HWVP Project technology program schedule calls for the next WFCD revision to be done in FY 1994 (Kruger 1992). The FY 1992 Hanford Site TWR Division redefinition task will provide the planning basis for deciding the scope and scheduling of the next WFCD document revision.

Figure 2-1 provides the latest HWVP Project scheduling (i.e., a modification of that provided in the Kruger 1992 reference) for future revisions of the WFCD document in accordance with the current baseline program. The content and scheduling of future revisions of the WFCD document will no doubt be considerably affected by the program redefinition and rebaselining. The addition of new waste types from the SSTs will create the need for several updates of the WFCD document during the coming years.

\section{2 .4 WCP}

The WCP describes the technical approach that the particular DOE vitrification project proposes to use to achieve compliance with the acceptance specifications established by the repository project. Besides being a document that each vitrification project must complete for the WFQ portion of the DOE WAP, the WCP also provides a focal point for getting the project to select a reference method, and in many cases an alternate choice of the favored compliance approach, for each specification. The HWVP Project is interfacing closely with the DWPF and the WVDP regarding their respective WCP preparations. Project representatives attend the respective sets of DOE Technical Review Group (TRG) meetings that are held to discuss TRG review comments and DWPF and WVDP dispositions of those comments concerning their respective WCP 
Figure 2-1. Summary Schedule for Waste Form Qualification Documents.

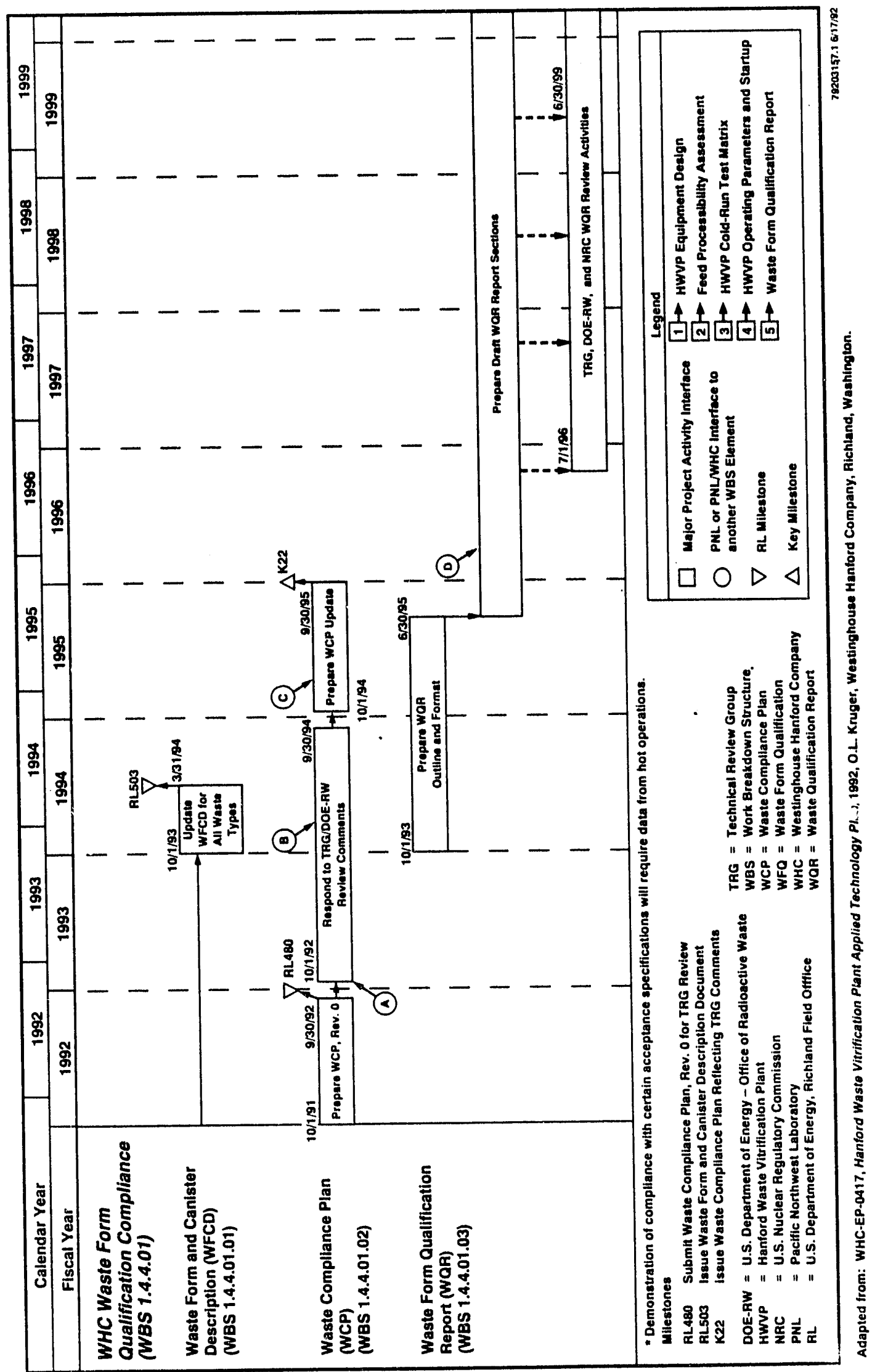


documents. The HWVP Project maintains a file of all such TRG review material for use in completing the HWVP version of such WFQ documents.

See Figure 2-1 for the proposed schedule regarding preparation, reviews, and completion of the HWVP WCP.

\subsubsection{WQR}

The other key WFQ document type that focuses on compliance with the acceptance specifications is the WQR. The WAPS states that the vitrification project must provide sufficient evidence to substantiate the claims made in the WCP regarding how compliance with the acceptance specifications can be achieved. The WQR is one of the last major steps to satisfying WFQ and an important input and precursor to the decision to start hot (i.e., actual HLW form) production in the HWVP. In planning for preparing the WQR, the HWVP Project is interfacing closely with the DWPF and the WVDP regarding their respective WQR preparations. In addition, the HWVP Project is reviewing such material as it becomes available for use in helping guide the HWVP Project efforts to prepare a review draft of the WCP. As with the DWPF and WVDP WCP documents, the HWVP Project staff has regularly attended the DOE TRG meetings concerning the dispositioning of review comments on the respective DWPF and WVDP WQR sections. The similarities between the HWVP and the DWPF designs, and the precedents estabiished by the DWPF and WVDP WFQ documentation to date, should facilitate preparation of the HWVP WQR.

In FY 1992, the focus will remain on monitoring the respective WQR document development for the DWPF and the WVDP. Figure 2-1 provides the latest HWVP Project scheduling (Kruger 1992) in accordance with the current basel ine program for the next versions of this Plan. The encircled alphabetical characters used in Figure 2-1 refer to the information dependency between tasks as portrayed in the Kruger (1992) reference.

\subsubsection{PRs and SSRs}

The PRs and SSRs are specifically required by the WAPS for completing the compliance requirements of several of the acceptance specifications. Refer to Sections 2.2.7 and 3.0 for more details on the information, timing, and responsible parties concerning the preparation of these two types of WFQ documents.

\subsubsection{Reporting and Information Requested}

Table 2-1 provides a summary of the WFQ reporting that the HWVP Project must provide to the repository project as part of complying with the WFQ obligations of the WAP and, more specifically, with the individual acceptance specifications of the WAPS (WAS). The WFCD document is 1 isted in Table 2-1 even though it is no longer called out specifically in the WAPS. It is still a part of the WFQ documentation required by the WAP and the information is still needed by the repository project. Note that Tabie 2-1 also provides a brief notation identifying the general types of information (i.e., estimates, methuds, data, design, etc.) that the WAPS specifically require the project to provide in specific WFQ documents. The WAPS in Appendix B provide additional details on the technical requirements. 


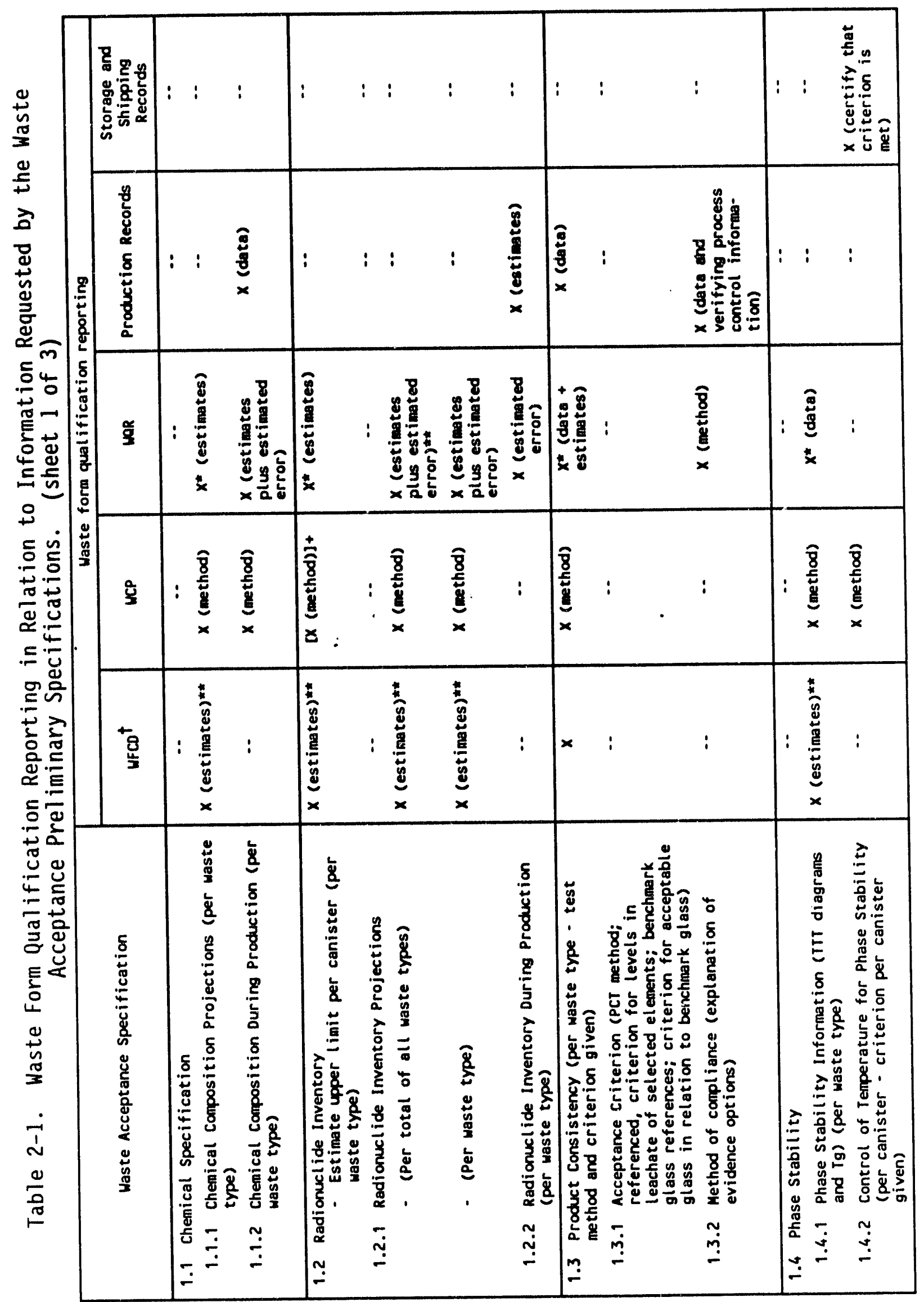




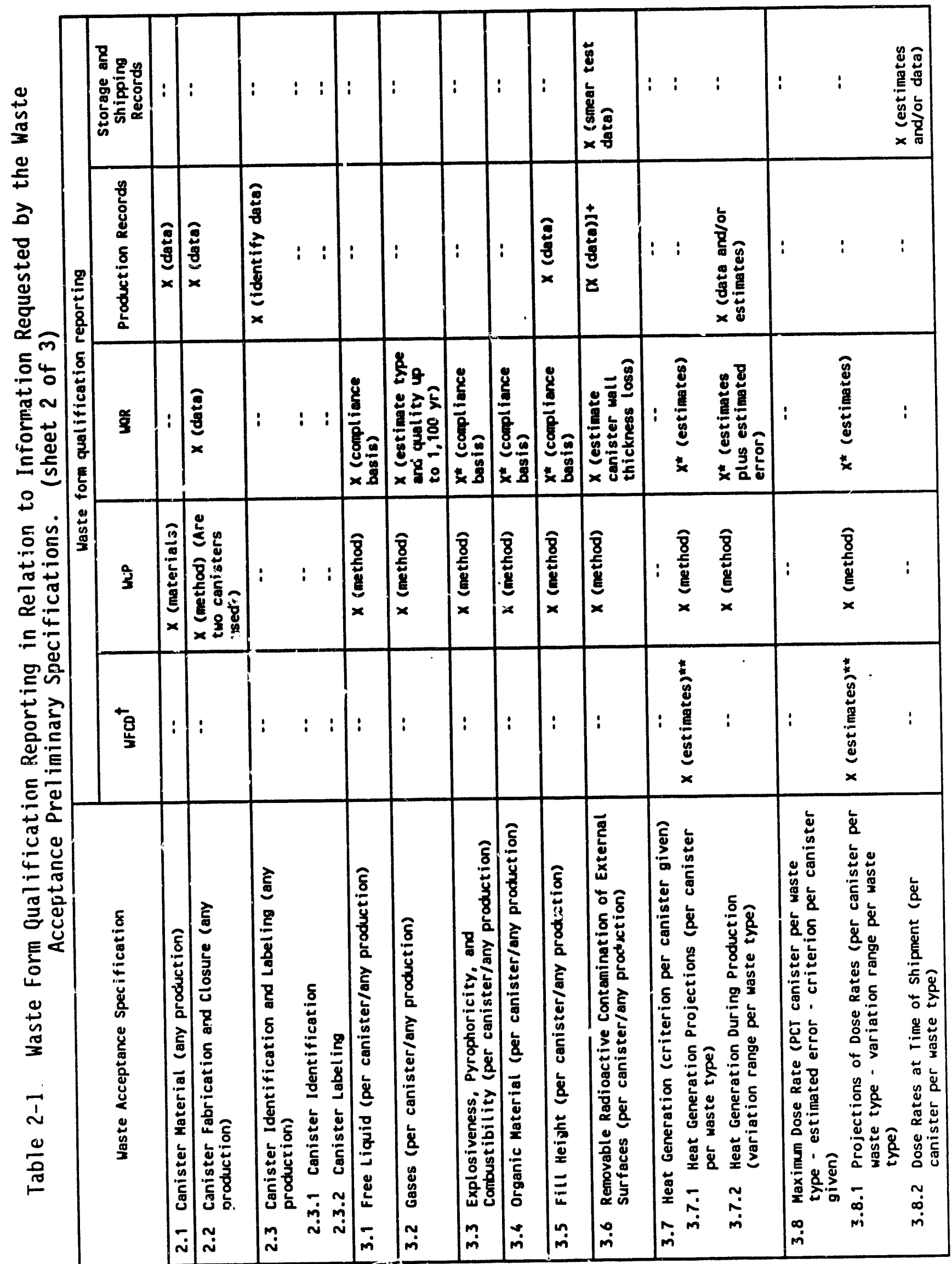




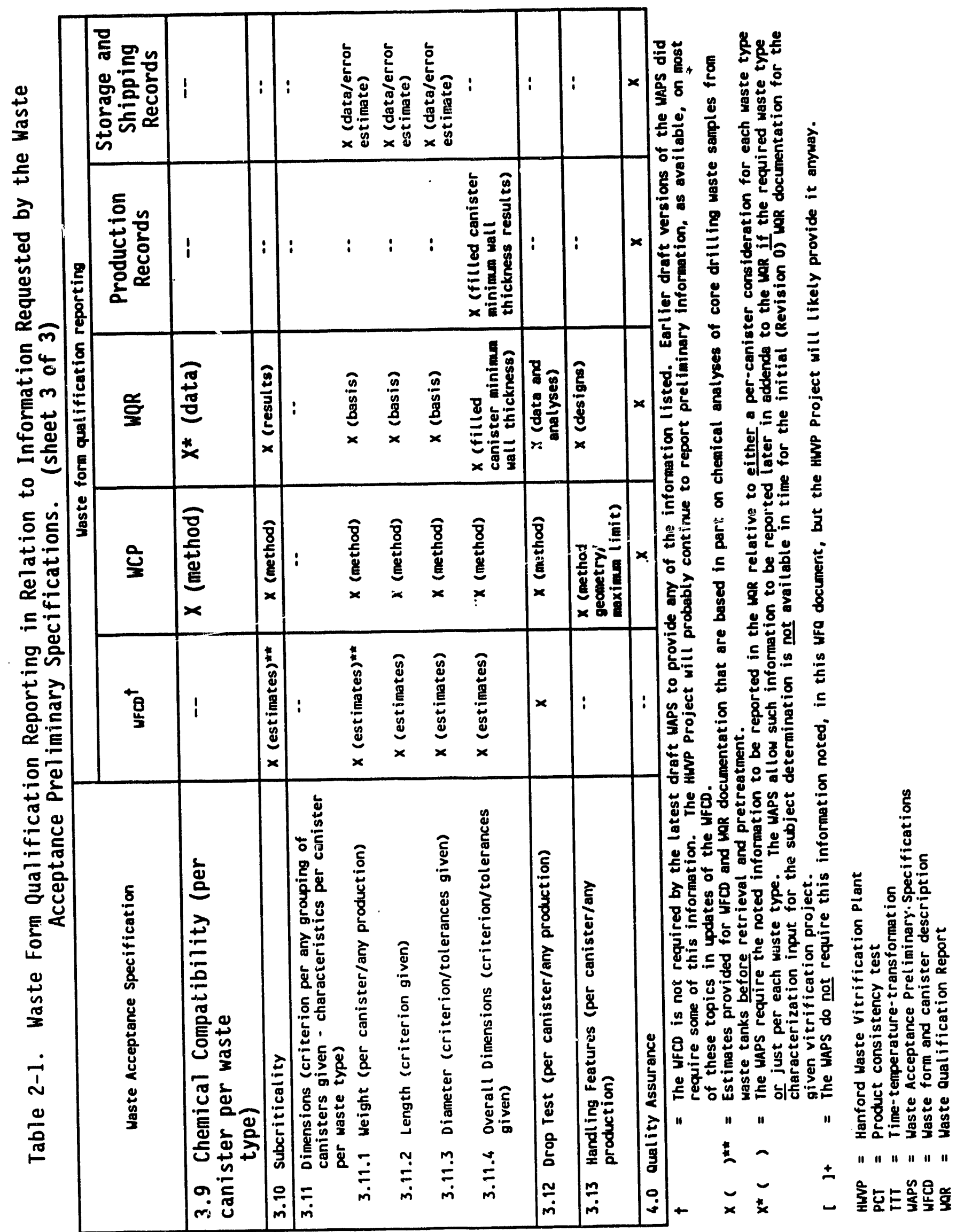


WHC-EP-0522

\subsection{FUNCTIONAL RELATIONSHIPS OF ORGANIZATIONS SUPPORTING THE HWVP PROJECT}

\subsubsection{Introduction}

To accomplish the tasks identified by the DOE WAP, important contributions must be made by several organizations. Figure 2-2 (DOE 1990a) illustrates the relationships and roles of these organizations, and notes which of these organizations are inside and which are outside the formal HWVP Project structure.

As Integrating Contractor for the HWVP Project, Westinghouse Hanford has the lead responsibility in preparing the documents that form the primary basis for complying with the requirements of the DOE WAP. Relative to the organizations directly supporting the HWVP Project, Pacific Northwest Laboratory (PNL), Fluor Daniel, Inc. (Fluor), and the Westinghouse Hanford HWVP Operations group will be the primary contributors of information needed to satisfy the WFQ obligations.

\subsubsection{HWVP Project: Supporting Organizations/Programs}

This section provides a discussion on the expected role of the HWVP Project participants, including a more detailed breakdown of Westinghouse Hanford organizations that are supporting the HWVP Project regarding various aspects of WFQ. In addition to the following discussion, further details about the supporting role of the other two DOE high-level vitrification projects are presented in Section 3.0.

2.3.2.1 PNL. Pacific Northwest Laboratory is the DOE-designated technology support contractor for the HWVP Project. The PNL has estabi ished the PNL HWVP Technology Development project organization to perform this function. Relative to WFQ, PNL has major assignments regarding such topics as glass composition versus glass properties testing, correlation development, slurry feed process testing, much of the scaled feed/melter system testing, process/product model development, etc.

2.3.2.2 Offsite Testing Contractors. The following participants will be providing support to the HWVP Project.

2.3.2.2.1 Westinghouse Savannah River Company (WSRC). The HWVP Project is relying heavily on the DWPF Project for data, analyses results, design information, lesson learned-type information, etc., applicable to WFQ and non-WFQ needs of the project. Detailed information on the expected WFQ contributions to be provided by the DWPF Project will be presented in Section 3.5.

The HWVP Project has funded WSRC to perform feed process testing and then melter processing of these feeds with HWVP feed compositions. The focus is on the investigation of hydrogen offgassing from the formate addition processing of feeds that contain significant concentrations of noble metals and melter retention of noble metals. The work is being done with the integrated DWPF melter system (IDMS) cold-testing system at the SRS TNX facilities. The contract involves testing that will be performed through at least early 
Figure 2-2. Hanford Waste Vitrification Plant Project Functional Organization and Interrelationships.

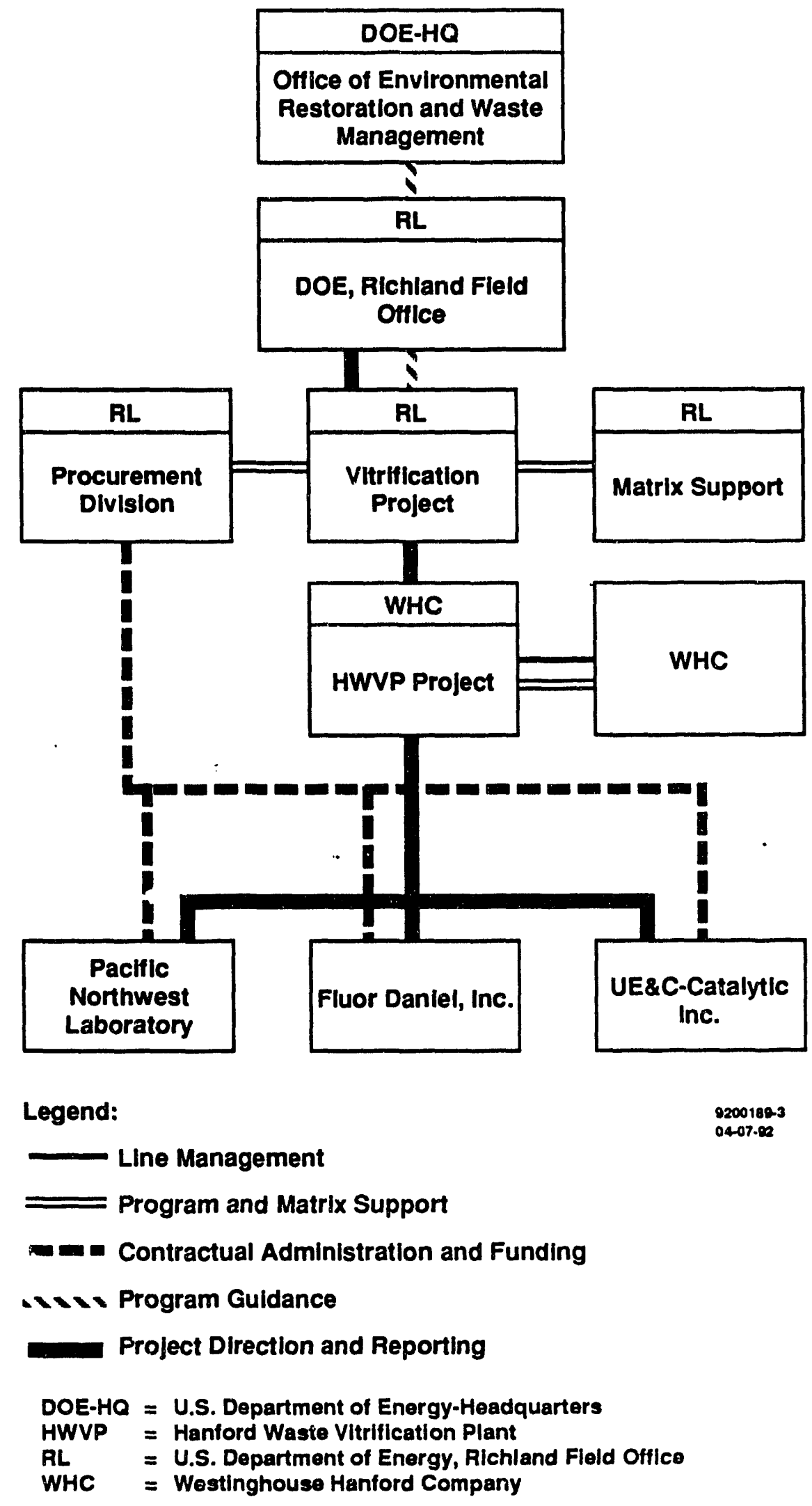


FY 1993. See WHC-EP-0417, Hanford Waste Vitrification Plant Applied Technology Plan (Kruger 1992), for more details on this work. This current IDMS testing work is considered to be basically process development work. As such, it is not expected to contribute primary-type information to the compliance bases for any of the acceptance specifications.

2.3.2.2.2 Testing at Kernforschungszentrum Karlsruhe GmbH (KfK) in the Federal Republic of Germany. The HWVP Project has a contract with KfK in the Federal Republic of Germany to perform a series of feed/melter system tests irvolving cold-simulated waste feeds containing noble metals. See WHC-EP-0417, Hanford Waste Vitrification Plant Applied Technology Plan (Kruger 1992), for more details.

As with the testing work at WSRC/IDMS, the work at KfK is considered to be developmental work and will not be directly providing data for satisfying WFQ requirements.

2.3.2.3 Fluor. As the A-E for the HWVP Project, Fluor is responsible for creating a design that will meet the design requirements established by Westinghouse Hanford for the HWVP. The project is addressing the designrelated needs of WFQ by taking all the specifications in the WAPS and interpreting them into design requirements for the HWVP design.

2.3.2.4 UE\&C-Catalytic Inc. (UCAT). The UCAT is the General Construction Contractor for the HWVP Project. The UCAT will not be supplying data or information for use in WFQ compliance documentation, except for the selected $Q A$ records associated with completion of the procurement activities because UCAT is responsible for all procurements that support construction.

2.3.2.5 Westinghouse Hanford - HWVP Project Integrating Contractor. The Westinghouse Hanford role in supporting the HWVP Project is divided among several contributors.

2.3.2.5.1 Westinghouse Hanford: Operations Program. The HWVP Operations group, within the TWR Division, is responsible for taking over the HWVP once construction and Westinghouse Hanford startup operations work are completed, and then operating the plant from there on. The Operations group already has staff working with HWVP Project staff in preparation for this role. Relative to WAPS (WAS) compliance, the Westinghouse Hanford Operations group will be operating the HWVP when the WFQ data supporting the compliance basis are being obtained. As noted in Section 3.0, this will occur during the combination of the operational testing period and the qualification runs for supporting most of the initial WQR submittal and then continue into hot production for completing the initial WQR submittal for certain specifications and fulfilling any WFQ requirements, in accordance with the WAPS, when the HWVP is in production.

2.3.2.5.2 Westinghouse Hanford: HWVP Startup Program. The HWVP Startup group will be responsible for the preoperational testing shown in Figure $3-1$. Currently there is no intention of trying to collect (WFQ) data for use in the WQR during the preoperational testing phase. The primary rationale for this position is that construction work will still be in process throughout this testing phase. Because the HWV will not be fully operational during this period, it seems unlikely that significant data suitable for the WQR could be collected. 


\subsection{Westinghouse Hanford: Waste Tank Characterization Program.}

The Waste Tank Characterization program supports the HWVP Project by supplying data characterizing the waste in the Tank Farm tanks. Relative to needs for WFQ, this information will initially consist of such things as chemical analyses from core (small volume) sampling of a given waste type. The resultant waste feed characterization data will be used by the project to support important early testing and analyses activities. Such work will consist of preparing the composition variability study (CVS), updating the feed processibility assessment, recipe decisions for cold simulation of waste feed for use in testing, supporting design and permitting, and preparing projections in early versions of the WFCD, etc. The characterization work also supports the pretreatment processing development, which ultimately determines the final character of the feed for a given waste type that will be input into the HWVP process.

The testing strategy to support WFQ reporting needs and the preparations for hot start heavily depend on the information provided by the waste characterization efforts.

\subsection{Westinghouse Hanford: Waste Retrieval, Pretreatment, and} Characterization Programs. The waste retrieval, pretreatment, and characterization $\operatorname{program}(s)$ help prepare each proposed waste feed for the HWVP Project testing and eventually the actual HWVP feed processing. Pretreatment and characterization also work in conjunction with the initial analyses work done on core (small volume) samples from waste tank characterization (Section 2.3.2.5.3). All three contributions to this effort will be needed to support the later feed preparation work on the large volume of waste samples taken to support the bench-scale testing.

An important final step in this support work will be the characterization of the post-pretreated waste feed located in the waste feed tank(s) that supply feed to the HWVP processing. The quality of this waste feed (e.g., homogeneity, etc.), and the quality of the characterization data on this material will be important when satisfying each of the chemical compositiondependent WFQ (WAPS) specifications (see Appendixes C and D for details). 
WHIC-EP-0522

This page intentionally left blank. 
WHC-EP-0522

\subsection{STRATEGIES FOR WFQ}

\subsection{INTRODUCTION}

To effectively contribute to the TWRS Program (i.e., the overall program contributed to by Westinghouse Hanford and the DOE), the HWVP Project needs to define and document the overall strategy for satisfying the requirements of WFQ. Such strategy formulation is needed because the topic is relatively complex, and there is more than one option available for attaining the goal. Defining strategy options and selecting a reference is a process that is typicaliy focused on reducing the level of risk in relation to the cost and other types of benefits associated with attaining a goal. A well-constructed strategy provides an orderly and reasoned means for handling change and uncertainty in the program.

Waste form qualification, as driven by the requirements of the WAPS (WAS), affects many significant aspects of the HWVP Project. The following subsections describe the project's overall strategy for complying with the requirements of WFQ and for obtaining DOE approval for hot start. Both topics are addressed according to the estabilished FY 1992 baseline schedule and program (i.e., the HWVP design basis mission to process the DST HLW first). In addition, some limited speculation will be provided on strategy modifications that may be needed to handle the TWRS Program redefinition case (i.e., integrating the DST and SST waste disposal efforts to provide an optimized waste remediation sequence).

\subsection{STRATEGY HIERARCHY}

The topical scope of the effort required to comply with the WFQ portion of the DOE WAP is broad, multilayered, and in some cases, technically complex. No one statement of strategy can adequately characterize all the important topical needs and objectives associated with completing this job. A hierarchy of strategies is required that is appropriately interfaced to form an integrated and comprehensive overall strategy package for the project. The WFQ strategy hierarchy for the HWWP Project consists of the following major components:

- A general strategy for conducting the HWVP Project

- A program strategy for satisfying WFQ, and in particular the WAPS, and supporting the TWRS Program optimization for waste disposal planning

- A technology strategy for each specification of the WAPS, which summarizes the types of work activities and products needed and relates them to the baseline schedule. 


\subsection{GENERAL STRATEGY FOR THE HWVP PROJECT}

\subsubsection{Background}

Early DOE instructions to the HWVP Project have served informally as the general strategy for guiding design, WFQ work, etc., relative to basic HWVP Project plaining. As reflected in the HWVP functional design criteria documentation for the project (Kalia 1990), the HWVP Project will use vitrification technology from existing DOE-funded programs to the maximum extent practical based on technical and economic considerations.

Both the DWPF and WVDP programs were anticipated to be significant providers of technology and hardware developments that could be used by the HWVP Project. It was recognized early in the planning and conceptual design of the HWVP Project that the DWPF Project would be serving as the primary source of such information.

\subsubsection{General Strategy}

The general strategy for design and WFQ activities of the HWVP Project is as follows.

- The HWVP Project will use vitrification technology from existing DOE-funded programs (especially the DWPF Project) to the maximum extent practical based on technical and economic considerations. The HWVP Project will supplement such information as needed with results. from HWVP Project-specific testing and analysis tasks. The purpose is to save time and money while still achieving the technical goals of the HWVP Project.

The HWVP Project closely follows the status of the DWPF Project and the WVDP. Of particular interest are any concerns revealed in DWPF Project testing that appear to relate to the DWPF design features that are in common with, or similar to, those in the proposed HWVP design. To minimize the risk to the HWVP Project of such a dependency, the following steps have been taken:

- A formal technical exchange program has been under way for several years with DWPF and WVDP to facilitate the level of awareness concerning progress and problems and to speed the flow of such information to the HWVP Project.

- The HWVP Project has had a resident manager onsite at the DWPF for several years to assist in the gathering and transmittal of information to the HWVP Project and the Architect-Engineer. Such a representative of the HWVP Project eventually will be assigned to the WVDP also.

- Representatives of the Westinghouse Hanford HWVP Operations group have recently started serving temporary assignments at the DWPF to assist in startup work on that plant. 
3.3.2.1 Program Redefinition. This general strategy is not expected to be significantly changed by the future decisions that will come from implementing the TWRS Program redefinition decision plan.

\subsection{PROGRAM STRATEGY FOR SATISFYING WFQ AND SUPPORTING TANK WASTE DISPOSAL PLANNING}

\subsubsection{Introduction}

This level of the HWVP Project strategy hierarchy identifies the key programs and associated activities used by the HWVP Project to assess the ability to comply with relevant WFQ requirements as a function of proposals on different HWVP waste feeds and to then provide conclusions back to the TWRS Program to complete disposal planning for the given waste type. Such a strategy is needed to ensure that the HWVP Project will be able to cost effectively process each proposed feed. The basis for determining whether a proposed waste feed can be processed by the HWVP into an acceptable product is developed in stages. These stages are phased in relation to critical decision points in the project schedule, as based primarily on the best available characterization of proposed HWVP feeds and subsequent HWVP feed processibility assessment results.

The program strategy primarily focuses on the level of the WFQ program that is concerned with how the project proposes to address WFQ in relation to the multiple waste feed compositions that would result from the basei ine remediation program for the DST wastes. An important point to note in this regard is that not all of the specifications in the WAPS will have a compliance basis that is dependent on waste form composition. Hence, the challenge upon the WFQ program to accommodate different waste (feed) types during the life of the HWVP only concerns a selected number of the 21 specification topics in the WAPS, i.e., principally the 4 in the waste form section and to generally lesser and varying extents, about 8 of those in the canistered waste form section.

\subsubsection{Program Strategy}

The program strategy addressing WFQ and the general dependence of processibility on waste feed composition consists of the following five general components.

- Obtain characterization of each proposed HWVP feed (waste) to be prepared from a given HLW type.

- Establish and confirm correlations between waste form composition and required ranges of certain waste form properties.

- Conduct a feed (waste) processibility (HWVP) assessment for the candidate feed.

- Conduct feed/melter system testing to help refine and confirm the feed processibility assessment and to contribute other processing 
and/ar product performance information needed for developing the WFQ compliance bases.

- Update the feed processibility assessment and provide return input to the TWRS Program waste disposal planning cycle.

The first component of this program strategy is contributed by portions of the TWRS Program that are outside the formal HWVP Project. It is accomplished by applying retrieval, pretreatment, and waste material characterization technologies to the task of characterizing the proposed waste feed (type) that will be supplied to the HWVP. The HWVP Project will also obtain information from this task effort concerning the uncertainty associated with such feed characterization. See the discussion concerning the third component of the strategy for further comments about how such uncertainty, and the associated risk to the project, will be handled.

The second component of the strategy is the responsibility of the HWVP Project, and provides the major computational tools and input needed for conducting the third component of the strategy. This second component is addressed by a laboratory investigation called the CVS, which provides the primary basis for defining the acceptable glass composition envelope. The objective is to correlate glass composition to acceptable ranges of certain glass properties that were selected by the project to be HWVP design requirements. The properties in question include those needed to meet production rate goals and those in support of complying with certain WFQ requirements (e.g., Specification 1.3) in the WAPS. The study establishing these largely empirical correlations is primarily based on testing results obtained by using laboratory-prepared (crucible melted) nonradioactive glass compositions within and around the composition range predicted for a set of waste feed types. The initial approach for the CVS work on the DST HLW types has been to develop correlations covering a composition space that includes the expected feed composition range for the four major DST HLW types. However, if 1 imitations in the CVS test data or the timely availability of waste feed characterization data require it, the correlations can be focused on either subset groupings of these waste types or even on the individual waste types.

The third component of the program strategy is also the responsibility of the HWVP Project. This component is addressed by a waste feed processibility assessment, which depends heavily on input provided by the first two components of this program strategy that consists of several task steps. One of the primary steps involves applying the glass composition to glass properties results, i.e., models, from the second component of this program strategy. Another important step in this assessment simulates the HWVP process flowsheet and projects a general material balance for the proposed feed case. These two calculational tasks are used in a sequential manner to collectively perform a set of determinations characterizing the general ability of the HWVP to process the proposed waste feed. Depending on the results of each revision of the feed processibility assessment, the assessment process may involve going back to the characterization/retrieval/pretreatment program and obtaining additional information and/or evaluating other options for a proposed waste feed composition. 
The uncertainty in the inputs to the feed processibility assessment (e.g., waste feed composition, as influenced by uncertainties in tank waste sampling/analysis, waste retrieval, and waste pretreatment development work) is a topic that the project must continue to consider and assess. Likewise, the project must continue to assess the uncertainties associated with the proposed limitations of the HWVP design concerning waste feed processibility (i.e., preparation, vitrification, etc.). An integrated consideration of the various technical uncertainties forms the basis for evaluating the technical risks that the HWVP (design) could not actually meet the design requirement goals. In that regard, the objective of such evaluation work is to reduce, during the development phase of the project, these risks to acceptable levels. Likewise, the strategy for dealing with this topic must be one that is compatible with the strategy for dealing with the later waste feed types that will not be fully defined until after the HWVP begins processing the first waste feed types. Later text in this subsection (3.4.2) comments on the process development testing strategy, as well as the general stages of refinement envisioned for the waste feed characterization database. Relative to HWVP operation with any given waste feed type that is finally supplied to the plant, the processing strategy available for dealing with residual uncertainties concerning waste feed processibility will always have as one of the options the choice of reducing the waste oxide loading fraction. Although this option would result in an economic penalty for the TWRS Program (i.e., more canisters of waste form to send to the federal repository for disposai), it would enable the plant to process just about any given batch of waste feed into glass waste form acceptable according to WFQ requirements.

The fourth component of the strategy consists of several types of testing activities. To confirm the CVS correlations, the work starts with a limited number of companion laboratory tests that are also conducted using feed made from actual (small volume) waste samples taken from the resident waste tank(s) for a given waste type. Another major type of confirmation test data will be provided by later glass preparations (nonradioactive and radioactive) such as the bench-scale (feed/melter system) testing program. Relative to the program strategy, the feed/melter systems testing provides data from systems of increased sophistication and levels of system integration. To support the program strategy, the data will be used to check the conclusions obtained from the preceding cycle of the feed processibility assessment work. During the life of the project, this testing work will have involved several different test systems, which have been scaled to efficiently focus on certain types of data needs/objectives. Listed in order of melter system size, from the smallest to the largest, the test systems are as follows:

- Laboratory scale--typically focuses on batch forming a glass in a small crucible

- Bench scale--approximately a one-fiftieth scale liquid-fed ceramic melter integrated with slurry feed preparation and offgas treatment capability

- Pilot scale--approximately a one-tenth scale liquid-fed ceramic melter integrated with slurry feed preparation and offgas treatment capability 
- Demonstration scale--approximately a one-fourth to one-third scale liquid-fed ceramic melter integrated with slurry feed preparation and offgas treatment capability

- Full scale--this system will be the one in the HWVP (and/or data will be provided by the DWPF testing).

Based on the combined results from the first three components of the program strategy, all the test systems used in the fourth component of the strategy will be run using nonradioactive feed simulations for at ieast selected waste types. In addition, the laboratory- and bench-scale systems will run at least some WFQ tests using actual radioactive waste feed. The number of composition points (i.e., with respect to the proposed waste feeds derived from the DST HLW types) that will be tested in these systems decreases rapidly whenever the test system size is increased. The primary reason for this is the large cost increase that results as the system size is increased. The full-scale (i.e., the HWVP in-plant) testing to support WFQ focuses on testing the integrated subsystems and of the overall integrated processing system. Section 3.5 explains that for certain acceptance specifications, it is anticipated that at least some (confirmation) compliance evidence will have to come from the initial HWVP processing of a given waste type or, in some cases, just the first one that is processed.

The fifth component is self-explanatory and no further comment is needed at this time.

See Figure 3-1 for a summary schedule layout of important activities within the pretreatment/characterization, CVS correlation, and modeling and testing programs relative to WFQ activities such as WQR preparation. More detailed schedules are presented for each acceptance specification in the WAPS as part of the discussion in Section 3.5.4.

The extent to which this strategy is successful strongly depends on the technical risk reduction achieved by a scheduled series of stepwise improvements in the characterization of the proposed waste feed(s) derived from each of the DST HLW types. The first major stage of this characterization is based on the (small volume) samples taken from the waste in the resident (waste storage) tank(s) for each DST HLW. Some additional refinements in this level of the characterization are made by the supplementary (tank waste) samples of this type that will be taken, as needed, to complete this level of the effort. Likewise, refinements in the proposed waste treatment processing also contribute to refinements in this level of the feed characterization.

The second major stage of the (waste) feed characterization occurs when such data become available from characterizing the proposed bench-scale testing waste feed, which is made from large-volume waste samples also taken from the resident (waste storage) tanks. At this point in the development of the proposed reference feed, the various supporting technologies (e.g., sampling, pretreatment, characterization, etc.) will have matured substantially. Hence, the feed characterization results at this stage should be a considerable improvement over the first stage of the database (i.e., in relation to the final version of this feed for HWVP processing). 
Figure 3-1. Major Hanford Waste Vitrification Plant Project Activities Important to Waste Form Qualification as of March 1992.

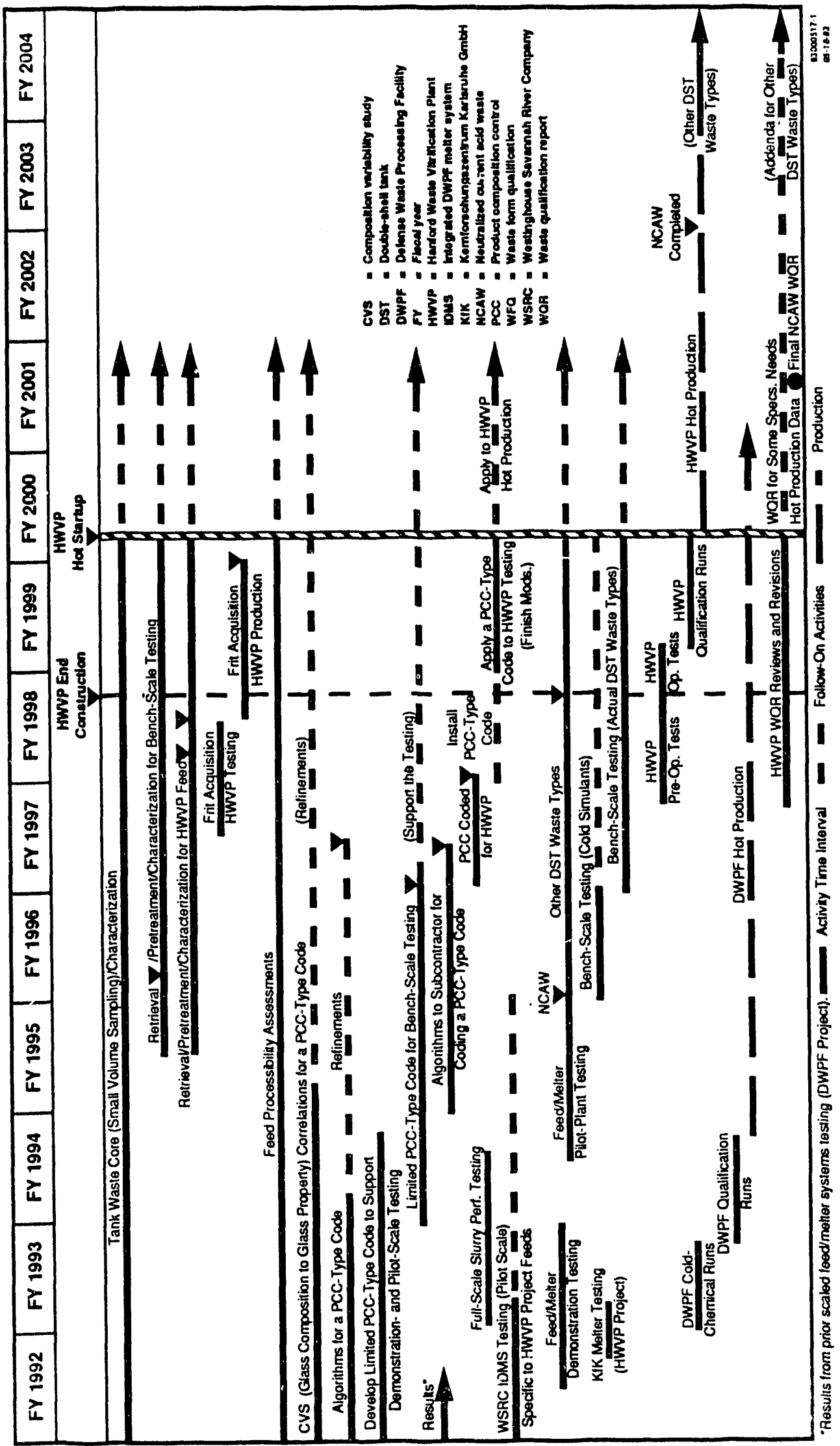


The $t$ ird and final stage in the evolution of the (waste) foed characterization occurs when the final pretreated waste feed destined for HWVP processing is (extensively) characterized. This stage of the (waste) feed characterization must, according to current prsject estimates of the frit procurement scheduling, be completed early during the 18-month lead period necessary to obtain frit for HWVP production needs. For ths first waste type to be processed, it would be desirable to have it available in time to support frit procurement for the HWVP WFQ cold testing activity.

\subsubsection{Program Redefinition}

The five general components of the program strategy are also expected to be able to accommodate the changes that will result from implementing the decision plan on redefinition of the TWRS Program. The current program is already addressing a set of waste types (i.e., the DST HLW types) for HWVP processing. The program redefinition includes consideration of more waste types, and likely will change the proposed sequential order for HWVP waste feed processing. The next lower-level strategies that currently guide the work on the individual components of the program strategy probably will have to change. Because the TWRS Program is to be rebaselined to the redefinition case by March 1993, completing the assessment of resultant impacts on the WFQ strategy hierarchy will be controlled by this same schedule.

\subsection{TECHNOLOGY STRATEGIES FOR ACCEPTANCE SPECIFICATION COMPLIANCE AND WFQ REPORTING FOR EACH WASTE TYPE}

\subsubsection{Introduction}

The technclogy (activities) strategies are the most detailed level of the WFQ strategy hierarchy. The objective is to represent, in a summary format, the current reference strategy for constructing the respective compliance basis to satisfy each acceptance specification. The strategy characterization focuses on what will be needed for each waste type to complete the final WQR reporting reyuired for complying with the WAPS. Two types of tabular format were used to portray, respectively, a general and a detailed summary characterization of the compliance strategy for each acceptance specification and the asSOciated WQR completion for a given waste type.

Each of the two tabular formats summarizes the strategy for each acceptance specification and does this by identifying the combination of technology activity-types that can be lised to create the respective compliance basis. These strategy portrayals were the product of several iterations and collectively involved severa? roviewers.

The following text provides a brief characterization of the major activity categories that were used.

HWVP Feed Tank (Waste Sample) Alalyses--For the final WQR reporting, on a given waste type, this activity category refers to the "multi-functional waste tank facility" tank(s) that are planned for providing waste feed directly into the HWVP processing system. To reach this point, the waste will have been retrieved from the current resident (Tank Fariil) storage, pretreated, and 
transferred to the feed $\operatorname{tank}(s)$ for the HLVP. At this point, the waste feed will be as well mixed as it will get before entering the HWVP process. Sampies of this waste feed will be taken and characterized to support the final feed processibility assessment for this feed, frit procurement, and the final WQR compliance bases for the specifications (WAPS) that request projections on chemical or radionuclide inventory composition, or properties related to them.

A matter still open for project consideration is the extent to which waste (feed) types proposed for later HWVP processing will be addressed in the WQR submitted for the first waste type to be processed. Reporting for such (WAPS) projections pertaining to these later waste types would be limited to preliminary results because such (final) feed tank data would nor likely be available yet. Instead, the projections, if included in the WQR submitted, probably would be based on earlier waste retrieval sampling from the resident waste storage tanks, pretreatment development, and characterization of the proposed waste feed. The tables used for the detailed portrayal of the technology strategy (discussed in Subsection 3.5.2) will provide further definition of the supporting activities needed for such preliminary projection work.

Codes, Models, Analyses and Projections--This activity category includes all the modeling (algorithm) and code development, the calculational-type analyses and projections, estimates, and the technical assessments based on input from these types of work.

This category, under the subheading of "Analyses" (and Assessments), is also used to include any design performance analyses and related technical assessments done to help determine the extent to which the DWPF WQR (compliance bases) can be applied to HWVP Project WחR needs. The scope of such analyses activity will depend strongly on the extent to which the HWVP desig; differs from the DWPF design regarding features that are judged as importani to achieving compliance with a certain (WAPS) specification.

Process Data--This activity category is primarily meant to include all data and information obtained from process parameter " "nitoring and sampling/ analyses or measurements made on the feed slurr; as it is undergoing processing in the HWVP.

Qualify the Process--This activity category refers to the intention of the HWVP Project to comply with certain acceptance specifications by assembling enough compliance basis evidence, before the hot start decision, such that little or no further monitoring activity will be needed during production.

Froduct Testing--This activity category refers to any direct sampling/analyses and/or measurements done on either the glass waste form or the canistered waste form unit. Primary examples are the occasional glass samples that will be taken from the pour stream as it enters the canister. An example of the latter type will be the smear testing that will be done on the exterior of the canistered waste form product before it is shipped to the geologic repository.

Administrative--This activity category refers to procedures and administrative documentation (e.g., operator and supervisor signoffs, etc.) that will be a part of the operating system for the HWVP. Both types of strategy summary tables contain some "DWPF" entries under this category. These entries are 
meant only as an indication that the HWVP Project may be able to apply some of these DWPF procedures with appropriate modifications.

Although some text description is provided to clarify the role of certain activities in the technology strategy, it is beyond the scope of this PIan to provide a comprehensive text description of the reference compliance strategy for each specification. The WCP will be the document that fulfills that assignment.

\subsubsection{Technology Strategies: General Summary Characterization}

This subsection provides the general summary of the specific combinations of major activity categories needed to portray the compliance bas is for each specification of the WAPS and completion of the WQR for a given waste type. The general summary characterization of these technology strategies is presented in two levels of characterization, with the second level containing significantly more information than the first level. A common tabular format is used in portraying each of the two levels.

3.5.2.1 First Level of General Summary. Table 3-1 provides the first level of the general summary and focuses on identifying only the particular combinations of activity categories that make up the strategy for a particular (WAPS) specification.

One of the objectives, which led to creating Table 3-1, was the need for an overall assessment of the work scope to be done to comply with the WAPS acceptance specifications. The following subjects were of particular interest:

- Some sense of the relative importance of the major activity categories chosen for this characterization, i.e., taking note of the number of times a given activity category was identified as needed for contributing to the overall job of complying with the WAPS

- An estimate of the activities most important for complying with the four divisions of specifications in the WAPS, i.e., Specifications 1.0, "Waste Form Specifications;" 2.0, "Canister Specifications;" 3.0, "Canistered Waste Form Specifications;" and 4.0, "Quality Assurance."

Observations: Table 3-1

The review of the overall results portrayed in Table 3-1 led to the following observations.

1. The final WQR for a given waste type will depend heavily on the sampling/analysis of the (large) HWVP waste feed tank(s) to comply with the specifications involving projections. As noted in Section 3.5.1, preliminary projections for later scheduled waste types, if included, will depend on sampling of the unpretreated waste currently stored at the Tank Farm. 


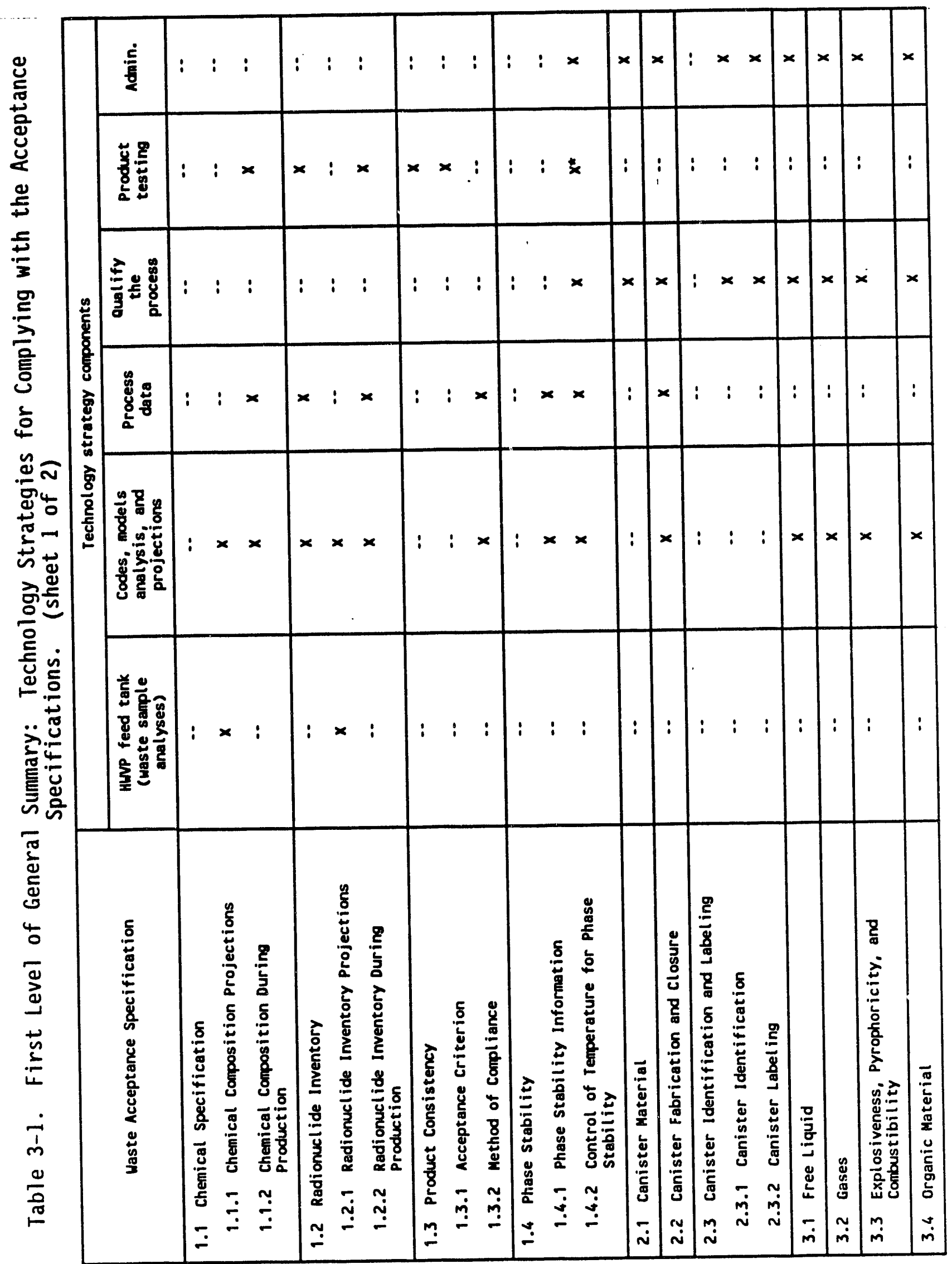




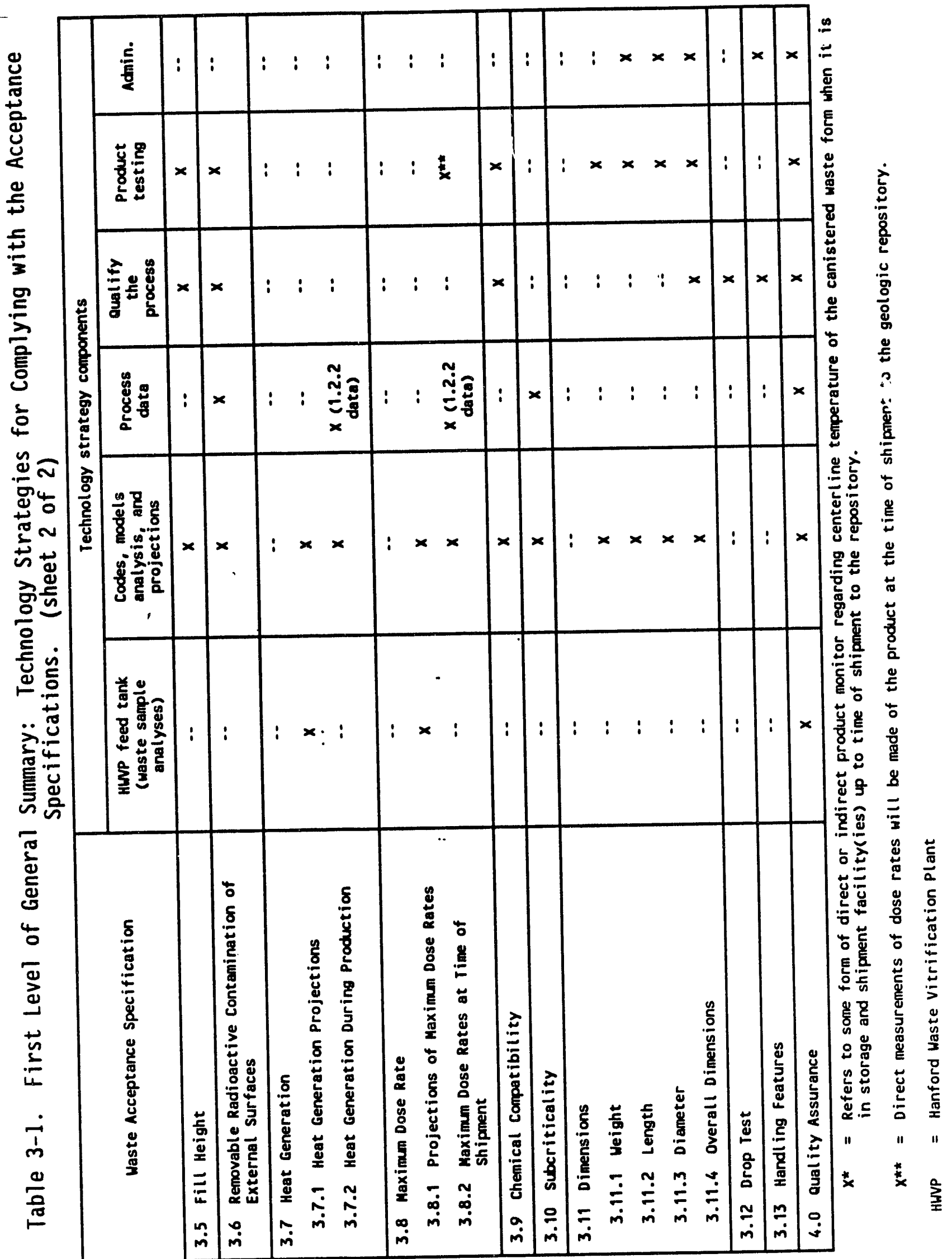


Other specifications, such as 1.3 , may need such feed tank sampling information depending on the particular way in which the process/ product control modeling is used as part of the compliance approach.

The scheduling of when these (projection-type) specifications can be addressed primarily depends on the schedule for the feed tank sampling as needed for input into the frit procurement task. As noted in Section 3.4.2, current plans call for the (production) frit procurement to start 18 months before delivery to the HWVP.

2. Activities in the correlations, modeling, etc., category will be needed for more than half of the specifications and in particular, for all the specifications dependent on the characterization and/or control of product composition.

3. Nearly half of the specifications will be met, at least in part, by the results of the category titled "Qualifying the Process." This means that testing, analysis, etc., will need to be done before the HWVP hot start decision to demonstrate that the proposed process, including operating limits, etc., will inherently comply with the specification.

4. Administrative control will be a part of the compliance position for more than half of the specifications.

3.5.2.2 Second Level of General Summary. Appendix C, Table C-1, provides the second level of the general summary characterization for the WFQ technology strategies. The purpose of Table $\mathrm{C}-1$ is to extend the summarization of the technology strategies for WAPS compliance down to the next logical and more detailed level of description. The goal is to gain more insight into the character of the overall job, and for each specification. Table C-1 identifies the following types of supplemental information:

- Primary work products that must be obtained from each general activity category

- Primary organization(s) expected to provide the respective work products

- Particular testing program expected to provide data for selected activity categories.

The work products (or sources of testing data, etc.) identified in Table $c-1$ are presented in descriptive terms (i.e., names, acronyms--see footnotes) which, for the most part, are also used in the next more detailed description schedules (discussed in Section 3.5.5 and located in Appendix D).

\section{Caveats}

Several caveats need to be mentioned in relation to some of the testing and modeling/code development activities category listed in Appendix $C$, Table C-1. The principal caveat is that for certain types of testing (e.g., feed/melter system testing), there is still considerable uncertainty associated with the specific test type and facility identification and the associated scheduling. The HWVP Project is in the process of eliminating or 
significantly reducing such uncertainties. Respective task teams are working out proposed revisions to the reference testing strategy that the HWVP Project needs to use to fulfill the remaining expected needs for design, WFQ, permitting, etc. These review and redefinition efforts were a result of issues and questions raised within the HWVP Project during the work on this document and on the FY 1992 version of the Hanford Waste Vitrification Plant Applied Technology Plan (Kruger 1992). The FY 1991 Westinghouse Hanford risk assessment work on tank waste disposal and the follow-on proposal for tank waste program redefinition (Grygiel et al. 1991), which combined SSTs and DSTs into a single planning base, also reinforced the need for addressing these concerns. The results of these HWVP technology program rederinition/ modification efforts will be reflected primarily in revisions of this report and in the next revision of the Hanford Waste Vitrification Plant Applied Technology Plan, or whatever replaces it as the immobilization technology development plan for the Hanford Site TWRS Program. The following topics are or will be addressed.

1. Process/product model development

Program review, strategy revisions, and selected replanning began in late FY 1991, and the first stage of the effort will conclude in late FY 1992.

2. Role of a product composition control-type code in WAPS compliance

Program review and replanning began in late FY 1991, and the first stage (i.e., strategy definition) will conclude in late FY 1992 (relates closely to item 1 ).

3. Feed/melter system testing

Program review and replanning began in early FY 1992 and will conclude in late FY 1992. Studies are currently (as of March 1992) undergoing HWVP Project review.

4. Nonradioactive versus radioactive feed testing

Although work has not been started on this topic, it is covered in part by the redefinition and replanning work for item 3 .

5. Correlation of glass properties to composition

Program review and replanning began in mid-FY 1992 with review of the test plan for the next phase of the effort and will continue through FY 1992.

6. HWVP cold testing for input to the WQR

An HWVP WFQ cold-testing plan (i.e., covering any WFQ testing during the operational testing and during the qualification runs) will be developed in conjunction with future updates of this Plan. 


\section{Observations: Table $C-1$}

The summary format makes it easier to identify prominent features of the overall job of complying with the acceptance specifications (WAPS). The following statements are general observations regarding the information provided in Table $\mathrm{C}-1$.

- The large scope of the dependence on data and information from DWPF is readily apparent. This dependence will include contributions from possibly the scaled laboratory testing, the DWPF cold-chemical runs and/or qualification testing, and the DWPF hot-production experience.

- For those specifications where the proposed compliance strategy summary involves the activity titled "Qualifying the Process," the key observation is that most of these cases will depend heavily on DWPF WQR evidence, etc. and DWPF production experience. The DWPF also is seeking to comply with most of these specifications by "Qualifying the Process." It also is expected that some HWVP equipment and process qualification work will be done for most of these topics during HWVP cold-testing activities (i.e., operational testing and qualitication runs). Refer to Section 3.3.2 for a summary discussion of how the HWVP Project is attempting to minimize the risk of such a dependency strategy regarding usage of WFQ compliance bases results from the other two DOE-HQ EM HLW vitrification projects.

- For the category titled "Analyses," one key ubservation is that the HWVP Project will need the results of several DWPF:HWVP design comparisons. The A-E has been tentatively identified to provide the design comparisons but the assignment has not been formally agreed to yet. The purpose will be to identify the differences, if any relative to components, etc., judged necessary for WFQ compliance. Subsequently, an evaluation by Westinghouse Hanford and/or PNL will need to be made to the extent to which it will be appropriate to still use DWPF WQR results for HWVP Project WFQ needs.

- Products from the CVS work are vital to completing the compliance bases for all of Specification 1.0, "Chemical Specifications," and for several in Specification 3.0, "Canistered Waste Form Specifications."

- Most of the acceptance specifications complied with, at least in part, by testing either the feed slurry or the glass waste form product results (i.e., under the "Process Data," "Product Testing," etc., activity categories) will necessitate some in-plant (HWVP) testing. Principally, it will be the HWVP Qualification Runs that will have to provide these results. As noted in Section 3.4.1.1, some of this information may be obtainable from the cold-chemical testing phase of the operational testing phase, which precedes the Qualification Runs (see Figure 3-1). 


\subsubsection{Technology Strategies: Detailed Summary Characterizations}

This section provides the detailed summary characterization regarding the proposed reference strategy for providing the WAPS (WAS) compliance basis in the final WQR for a given waste type. Relative to the general summary characterization presented in Table C-1, the scope and format of the detailed summary characterization was structured to address the following objectives.

1. Create a more detailed summary (characterization) format that included an estimated schedule for the respective activities.

2. Include a more obvious cross-linkage between these WFQ technology strategy summaries, which characterize compliance with the WAPS, and the primary planning document (Kruger 1992) that summarizes the overall scope of technology activities being conducted in support of the HWVP Project.

3. Include supporting descriptive detail, with each activity heading, regarding what the major inputs are, what specific subparts of the activity are used, and what the major outputs are that feed into follow-on activities of the strategy for a given specification.

The package of detailed (activity) strategies created to meet these objectives is located in Appendix $D$. The general format uses an annotated bar chart schedule for each significant activity needed to summarize the WFQ contributions from each activity category. The activity categories are the same as those used in the preceding tables for the general summary characterization (i.e., Tables 3-1 and $C-1$ ). Appendix $D$ represents an initial definition of the WFQ strategies at this level of the hierarchy. As work continues on developing a WCP for the HWVP Project, refinements to these WFQ strategies will be made.

The following format options were chosen to help meet the objectives for these tables:

- The first objective was addressed by estimating the time interval during which data, etc., that could be used in preparing the first WQR would be gathered. This interval was represented by a cross-bar marked box.

- Several things were done to address the second objective. Where an applicable activity was already identified and scheduled in WHC-EP-0417, Hanford Waste Vitrification Plant Applied Technology Plan (Kruger 1992) for the current baseline schedule and program, the schedule interval from that reference was used. Also, the activity titles and work breakdown structure (WBS) numbers are consistent with those used in the planning description tables in WHC-EP-0417.

- The third and last of these major objectives was addressed by annotating each of the activity intervals (i.e., box portion, dashedline portion, etc.) to provide considerable detail on identifying 
what input was used, what products were produced, etc. The annotation al so was used to help complete the cross-linkage to the abbreviated activity product identifiers used in Table $\mathrm{C}-1$.

- If that schedule interval is already known to be outdated (e.g., according to recent test plans), the box was adjusted using a dashed-line border.

- To address the continuation of potential refinements in the activity, or particularly to address the work on the remaining waste types not completely addressed in the first WQR that will be submitted, a dashed line was used and annotation provided.

- In some cases, past project planning has not directly included some of the activities that are needed to complete the respective detailed summary characterization of the compliance basis for a given acceptance specification. The newly defined activity entries are easily identified because they lack a WBS number at the end of the activity title.

- In some instances, such as for canister procurement, an estimate was made using recent (verbal) information from DWPF and from the HWVP Project, with a footnote reminder that this is a preliminary estimate.

- In other cases, such as describing the WFQ tests to be run in the HWVP, the annotation was typically brief and specific because detailed project planning for this activity has not been done yet and is beyond the scope of this revision of the WFQ program plan.

- All activities needed for each summary characterization for each specification were included with one exception. The WAPS 1.2 abbreviated listings were not used in order to avoid losing an accurate sense for the whole job.

The purpose of the second objective is to prepare for future efforts to enhance the integration between this Plan and the Hanford Waste Vitrification Plant Applied Technology Plan (Kruger 1992), or whatever replaces it as the immobilization technology development plan for the Hanford Site TWRS Program. The technology planning document contains the full scope of the technology support to the program (i.e., those supporting the WFQ objectives and those supporting other objectives, such as non-WFQ-related design development objectives, permitting needs, etc.).

\section{Observations: Table D-1}

The following statements are general observations regarding the information provided in Table D-1.

- The relatively short time interval available for HWVP WFQ (in-plant) testing adds emphasis to the need for starting to develop the testing strategy options for this HWVP work. 
- Several significant WFQ support activities do not have WBS numbers and thus are not yet formally planned and tracked by the HWVP Project.

\subsection{MAJOR ISSUES TO BE RESOLVED}

Relative to the compliance strategy summary, the following major issues have been identified as needing resolution.

\section{Issues Outside the Control of the HWVP Project}

1. The techrical complexity and cost of attempting to define and demonstrate a compliance approach for the WAPS 1.3 topic is a large burden on the HWVP Project. With respect to the CVS approach being used by the HWVP Project, the property regarding this specification is by far the most difficult one to correlate to glass composition and has not been completed for any of the waste types.

The HWVP Project is aware that this topic is being discussed between the affected parties (i.e., DOE-EM, DOE-RW, and the NRC) and is looking forward to a resolution of the issue.

2. A decision is required concerning the proposed sequence of waste types to be processed by the HWVP according to the resulting baselining effort for the proposed redefinition program. The identification of these waste types is vital to the planning for the technology testing support needed between now and hot start of the HWVP. It is assumed that this issue likely will be resolved in. several s.tages during the Westinghouse Hanford TWRS Program rebaselining efforts. 


\subsection{QUALITY ASSURANCE}

\subsection{INTRODUCTION}

The HWVP Project is being conducted as part of a QA program that meets the requirements of ASME NQA-1-1989, Quality Assurance Requirements for Nuclear Facilities (ASME 1989). In 1990, the DOE-RW published an additional set of $Q A$ requirements (DOE 1990b) that amplified some of the requirements of NQA-1-1989 when applied to . . " "waste acceptance process activities of highlevel waste form production." Since the release of the DOE document, which goes by the designator, DOE/RW-0214, the HWVP Project has made the necessary changes in the affected QA programs, and has been involved in various followon aspects of the application of these new requirements.

\subsection{HWVP PROJECT ACTIONS IN ACCORDANCE WITH DOE/RW-0214 REQUIREMENTS}

The DOE/RW-0214 document requires that.. "A methodology shall be developed to identify those items and activities to which the quality assurance program applies." Westinghouse Hanford, as Integrating Contractor for the HWVP Project, has prepared this required information for use by the various project participants.

Activities conducted to support the WFQ process will be accomplished under the controls of the project $Q A$ program. This includes design, testing, data collection and analysis, and resulting documentation. All applicable acceptance documentation (e.g., the WAPS, the WCP, etc.) must be available for support in preparing the WQR and to verify compliance (e.g., WQR, PR, and SSR) of the waste product for shipment to the waste repository.

The project participants are in turn responsible for determining the specific requirements to be applied to specific elements of the work. Westinghouse Hanford has been actively working with Fluor on such aspects of the job. Westinghouse Hanford has prepared a general and a specific description, Caplinger (1990) and Hand (1990), respectively, of the QA program needed for the HWVP Project.

Fluor is in the final review/modification stage of preparing a WAP activity rationale and implementation matrix. This document addresses which parts of the design are considered to be part of the WAP activity category and thus subject to the amplified QA requirements of DOE/RW-0214. 
WHC-EP-0522

This page intentionally left blank. 


\subsection{REFERENCES}

ASME, 1989, Quality Assurance Requirements for Nuclear Facilities, ASME NQA-1-1989, American Society of Mechanical Engineers, New York, New York.

Caplinger, W. H., 1990, Hanford Waste Vitrification Plant Quality Assurance Program Description -- Overview and Applications, WHC-EP-0393, Part 1, Westinghouse Hanford Company, Richland, Washington.

Colburn, R. P., 1990, Hanford Waste Vitrification Plant Preliminary Waste Form and Canister Description - Fiscal Year 1990 Update, WHC-EP-0376, Westinghouse Hanford Company, Richland, Washington.

DOE, 1987, Final Environmental Impact Statement, Disposal of Hanford Defense High-Leve 7, Transuranic and Tank Wastes, DOE/EIS-0113, U.S. Department of Energy, Washington, D.C.

DOE, 1988a, Disposal of Hanford Defense High-Level, Transuranic, and Tank Wastes, Hanford Site, Richland, Washington; Record of Decision, Federal Register V.53, No. 72, pp. 12449-12453, U.S. Department of Energy, Washington, D.C.

DOE, 1988b, Radioactive Waste Management, DOE Order 5820.2A, U.S. Department of Energy, Washington, D.C.

DOE, 1990a, Hanford Waste Vitrification Plant Project Management Plan, HWVP-89-002, Revision 1, U.S. Department of Energy, Rich1 and Operations Office, Richland, Washing.ton.

DOE, 1990b, Quality Assurance Requirements Document for the Civilian Radioactive Waste Management Program, DOE/RW-0214, U.S. Department of Energy, Washington, D.C.

DOE-OCRWM, 1986, Waste Acceptance Preliminary Specifications for the Defense Waste Processing Facility High-Level Waste Form, OGR/B-8, U.S. Department of Energy-Office of Civilian Radioactive Waste Management, Washington, D.C.

DOE-RL, 1991, "Incorporation of Draft Waste Acceptance Preliminary Specifications into the Hanford Waste Vitrification Plant Baseline Requirements," Letter from R. W. Brown/Project Manager/U.S. Department of Energy, Richland Field Office, Vitrification Project Office, to President (T. M. Anderson), Westinghouse Hanford Company, November 12, Correspondence No. 91-VTB-12B, PRMC 9105959B, U.S. Department of Energy, Richland Field Office, Richland, Washington.

Grygiel, M. L., C. A. Augustine, M. A. Cahi11, J. S. Garfield, M. E. Johnson, M. J. Kupfer, G. A. Meyer, J. H. Roecker, Westinghouse Hanford Company; L. K. Holton, V. L. Hunter, M. B. Triplett, Pacific Northwest Laboratory, 1991, Tank Waste Disposal Program Redefinition, WHC-EP-0475, Westinghouse Hanford Company, Richland, Washington. 
Hand, R. L., 1990, Hanford Waste Vitrification Plant Quality Assurance Program Description for Defense High-Level Waste Form Development and Qual ification, WHC-EP-0393, Part 2, Westinghouse Hanford Company, Richland, Washington.

Herborn, D. I., and D. A. Smith, 1991, Hanford Waste Vitrification Plant Preliminary Safety Inalysis Report, WHC-EP-0250, Revision 0, Westinghouse Hanford Company, Richland, Washington.

Xalia, J., 1990, Hanford Waste Vitrification Plant Functional Design Criteria, WHC-SD-HWV-FDC-001, Revision 4, Westinghouse Hanford Company, Richland, Washington.

Kruger, n. L., 1992, Hanford Waste Vitrification P7ant Applied Technology Plan, WHC-EP-0417, Westinghouse Hanford Company, Richland, Washington.

Miller, W. C., D. W. Hamilton, L. K. Holton, and J. W. Bailey, 1991, Hanford Waste Vitrification Systems Risk Assessment - Final Report, WHC-EP-0421, Westinghouse Hanford Company, Richland, Washington.

Nelson, J. L., 1988, Hanford Waste Vitrification Plant Preliminary Waste Form Qualification Plan - FY 1988 Update, WHC-EP-0045, Revision 1, Westinghouse Hanford Company, Richland, Washington.

Nuclear Waste Policy Act of 1982, 42 USC 10101 et seq. 


\subsection{GLOSSARY}

\section{ABBREVIATIONS AND ACRONYMS}

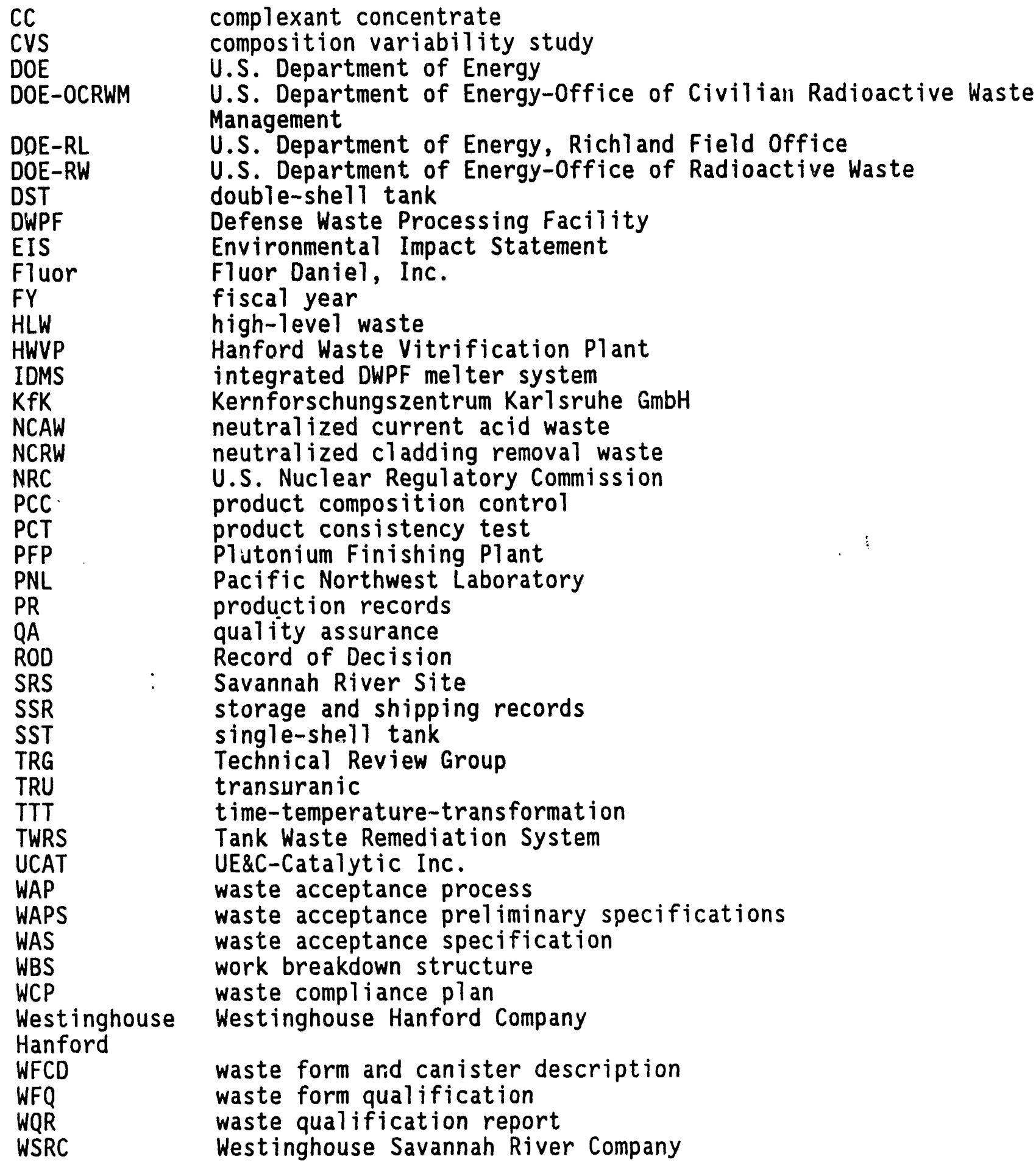


WHC-EP-0522

This page intentionally left blank.

GL-2 
WHC-EP-0522

APPENDIX A

DESCRIPTION AND IMPLEMENTATION OF THE

WASTE ACCEPTANCE PROCESS

A-1 
WHC-EP-0522

\section{APPENDIX A}

\section{DESCRIPTION AND IMPLEMENTATION OF THE WASTE ACCEPTANCE PROCESS}

\section{PREFACE}

Between the preparation date of April 1992 and the final publication date of June 1993, the Appendix A reference information on the U.S. Department of Energy-Office of Civitian Radioactive Waste Management (DOE-RW) "waste acceptance process description" has become outdated by certain DOE decisions. The DOE is planning to create an updated revision. The following paragraph summarizes the major DOE decisions and follow-on actions pertaining to the changes that have occurred.

In July of 1992, the DOE-RW decided not to baseline the proposed draft (July 1991) of the "Waste Acceptance Preliminary Specifications" (WAPS). The WAPS presented the proposed DOE-RW acceptance specifications for the reference vitrified high-level waste (HLW) form to be made by each of the three HLW vitrification projects for disposal in a geologic repository. Instead, DOE-RW departed from the documentation path outlined in the waste acceptance process description that is provided in this appendix. As a replacement, DOE-RW created the Waste Acceptance Systems Requirements Document (WASRD), which is a broader scoped document than the July 1991 WAPS, and addresses the DOE-RW repository program waste (form) acceptance requirements for several types of waste forms (i.e., commercial power reactor spent fuel, transuranic wastes, as well as the vitrified HLW). The WASRD was structured to provide a traceable path between each acceptance specification and higher levels of the technical document hierarchy for the Civilian Radioactive Waste Management System. The U.S. Department of Energy-Office of Environmental Restoration and Waste Management (DOE-EM) organization, per discussions with DOE-RW, then decided to prepare a waste acceptance product specifications document that deals only with the standard form of vitrified HLW. The product specifications, Waste Acceptance Product Specifications for Vitrified High-Level Waste Forms, ${ }^{2}$ are in most cases the same as the requirements found in the DOE-RW WASRD.

However, under the agreement with DOE-RW, DOE-EM has the prerogative of adding specification topics or changing the specification limits. What DOE-EM is not allowed to do is to make any of the specifications less restrictive than the requirements stated in the DOE-RW WASRD. The U.S. Department of Energy, Rich1 and Operations office formally transmitted guidance, ${ }^{3}$ dated March 29 ,

'DOE/RW-0351P, Waste Acceptance System Requirements Document (WASRD), Revision 0, 1993, U.S. Department of Energy, Washington, D.C.

${ }^{2}$ DOE/EM-WAPS, Waste Acceptance Product Specifications for Vitrified HighLevel Waste Forms (WAPS), Revision 0, 1993, U.S. Department of Energy, Washington, D.C.

${ }^{3}$ Letter, L. Erickson/U.S. Department of Energy, Richland Operations Office, to President/Westinghouse Hanford Company, "Waste Acceptance Product Specifications for Incorporation Into the Hanford Waste Vitrification Plant. Basel ine Requirements," dated March 29, 1993, Richland, Washington. 
WHC-EP-0522

1993, to the Westinghouse Hanford Company to implement these new documents within the Hanford Waste Vitrification Plant Project. 
WHC-EP-0045

\section{A.1 DESCRIPTION AND IMPLEMENTATION OF THE WASTE ACCEPTANCE PROCESS}

The WFQ process was described in a WAP flow diagram (Fig. A-1) proposed by the OCRW.II on January $15,1985$.

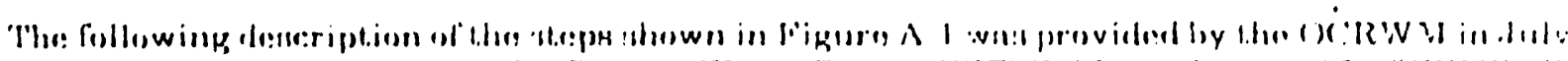
$1985^{*}$. Step 1 refers to a site-specitic, Generic Waste Form (GWF) WAR** (site-specitic GW L' WAR) document. In this document, each repository project would identify requirements for an unspecinicd waste form for its candidate site. Topics considered in developing the site-specific GWF WAR would include regulatory constraints and limitations created by the host geologic environment and repository design. Examples of such limitations might be rock thermal limits or waste form solubility. The dashed lines in Figure A-1, Step $l$ indicate the actual issuance of site-specific GWF WAR are not necessary, but that identification of WAR by each project must be completed for use in Step 2 .

The multiple site-specific GWF WAR will be combined into a single generic site (GS). GWF WAR (Step 2). The contents of this document would include the requirements of the site-specilic GWF WARs, with some parallel site-specific requirements. The purpose of this GS GWF WAR would be to provide uniform early guidance (before development of WAS ${ }^{\dagger}$ ) to future HLW producers on the minimum requirements for a waste form for acceptance at any of the candidate repository sites. This - doidument. would be the vehicle for compliance with the 10 CFR 6ח. Appendix E. Suhpart D. require. ment for identification of the minimum requirements for a commercial $\mathrm{kl}$ Li $W$ form. It will also provide guidance for selection of waste forms to such potential generators as Idaho . Vational Engineering Laboratory and for the determination of processing activities required for miscellanenus waste inrms such as high-temperature gas reactor fuel and Three Mile.lsland rubble. It is highly desirable to develop the GS GWF WAR to a quality sufficient for inclusion in the license application is the basis for accepting future waste forms for repository disposal without further regulatory review. This may not be practicable, and it may be necessary to present some lower level, more specific document (such as the site-specific GWF WAR) to serve this function.

-The Nuclear Waste Policy Amendments Act of 1987 reduced the number of candiciate repository sites from 3 to $\mathrm{l}$. The official WAP description has not yet been updated to reflect this change. The discussion provided here remains as promulgated in 1985.

* 'Waste Acceptance Requirements- $\Lambda$ compilation of generally applicable criteria that specify the minimum conditions for acceptability of a waste form at one (site-specific) or all (GS) repository sites. The requirements will include identification of repository environmental conditions, constraints imposed by the geologic media, packaging and handling limitations, regulatory requirements, and minimum levels of acceptable performance for candidate waste forms.

+Waste Acceptance Specification--A compilation of quantitative, detailed criteria that deīne specific waste form materials and acceptable ranges for various properties of the waste form and its container (if applicable), which ensure that each individual waste form produced will perform satisfactorily in a repository environment and will be within limits of operation of the repository facility. Requirements for documentation, which must be provided by the waste producer on a one-time basis for each production lot and for each individual wsate form, wil also be specified. The WAPS will be developed based on the best available information and will be revised as necessary from time to time. As the repository program proceeds through the site selection ad licensing steps, the preliminary specification (Step 3) will evolve into the updated llicense application) WAS (Step 14) and ultimately into the final WAS (Step 16). 


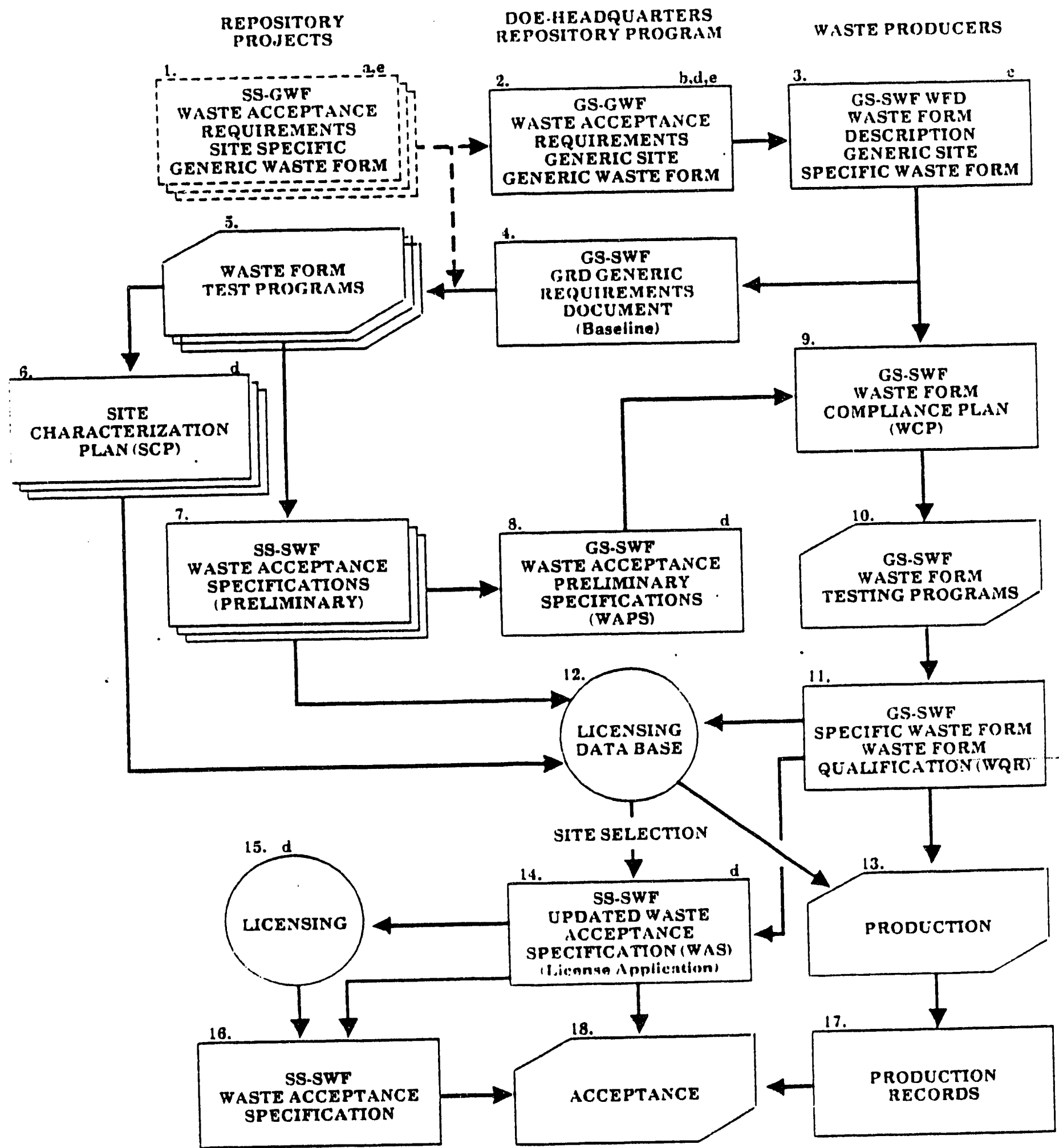

2. "Siton" refors to rupneitory sito.

"Fenorie Waste Fnrm" rafers to vacto froen any producer

"Specifle Wecte Forra" refors to wasto from a specifle producor.

d. "VRC" indleates currerely plasand intorsetlon point wich NRC.

d. "NRC" indlentas Currorely plarad as prerequisiten to Steps 7 \& $B$

PS831260.A.1

Figure A-1. Waste Acceptance Process Proposed by the U.S. Department of Energy Headquarters. 
Using the GS GWF WAR, the waste form producers would prepare a waste iorm description (WFD) (GS, specific waste form (SWF) Step 3). The WFD for HWVP, NCAW glass was issued in .July 1988.

The OCRWM has determined that portions of the WFD will appear in the Generic Requirements Document (GRD) as baseline GS SWF GRD (step 4) information. (The WFD will also be the source of information for developing waste management system interface information in the "Office of Civilian Radioactive Waste Mlanagement Systems Requirements Document"). The repository projects use the GRD as the generic basis for site-specific design requirements. Information on spent fuel, West Valley HLW, and defense HLW appears in Appendix B of the GRD, "Waste Source System Interface." As more waste producers reach the point where a WFD can be written, there will be information on additional waste forms added to the GRD.

Information in the GRD and the waste package performance requirements of 10 CFR 60 are used to generate the repositury projectg' site-specific, SWF testing programs (step 5). 'T'ests deycribed in these programs will provide data relevant to waste form performance in the repository environment for use in waste package performanc assessments and licensing. These test programs, as they become developed, are fully described in the repository projects' site characterization plans (step 6).

Each of the sites' test programs, along with the information in the WFD, GRD, and GS GWF WAR, will be used by the repository projects to produce site-specific. SWF preliminary WAS (step 7). These site-specific specifications will leature a more extensive level of detail than the site-specinic GWF WAR because they are targeted to a particular waste form (e.g., borosilicate glass) from a specilied producer (e.g., DWPF). Included in the specifications are constraints and data requirements. which will ensure that performance expectations derived from repository test program results are applicable to the actual product. The constraints and data requirements shall be supplied by the producer. Design features and details tor handling storage, packaging, and piacement will also be specified to ensure compatibility with repository design. Examples of these documents are the in-

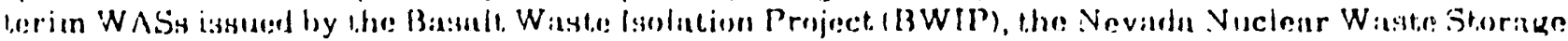
Investigation, and the Salt Repository Project Office for borosilicate glass from the DWPF. The sitespecific SWF WAS will include a discussion of the bases for each specification and the rationaie used in developing them.

The site-specific SWF WAS from each of the repository sites will be compiled to produce a GS SWF WAPS (step 8 ) for the repository program. This document is produced to provide a single unified source for use by the SWF producers and respository designers. Where appropriate, the GS SWF WAPS will incorporate envelope or "worst case" specifications. Repository approach is not effective. The GS SWF WAPS will identify the minimum specifications and data requirements to ensure that the waste is acceptable at any of the repository sites. This document will include a discussion of the rationale used in developing the individual specifications from the project-specific specifications. In developing the preliminary GS SWF WAPS, reconcilation of conflicting or inconsistent requirements from the site-specific WASs will be undertaken.

Based on the (AS SWF WAPS, the specific waste producer will develop a WCP (3tep 9). This plan will uitimately identify the specific tests and procedures, including specific tests (as out.lined by the repository projects) to be used to demonstrate compliance with the WAPS. The waste producers will undertake waste form testing programs (step 10 ) to produce the data necessary to show compliance with the WAPS. The results from these tests and related analyses will be compiled in the GS SWF WQR (step 11). The WQR will contain information on the waste form itesif and on the processes used to produce it, such as process controls, limits on ranges of variability, quality assurance, and demonstrations that the actual waste product meets (i) the product specifications, (2) is represented by waste forms tested in repository test programs, and (3) will be consistently and verifiabiy produced by the reference process. 
The supporting information in the WQR, along with the respository licensing data from the waste form test program and site-specific SWF WAS, will all become a part of the licensing data base (step 12). At some time, prior to repository site selection in the cases of the DWPF and WVDP, the available data base may be used as the basis to support the start of production (step 13). For the DWPF and WVDP, startup before repository licensing involves a degree of risk that the waste will indeed be acceptable for disposal. The startup decision will be an important milestone decision within the DOE. The OCRWM will provide input on the acceptability of the produce program as part of the DOE startup decision. This emphasizes the need to carefully plan the content of the licensing data base and the execution of the requisite testing to ensure the timely availability of data of sufficient quantity and quality to enable this decision to be made within minimum residual risk.

After the repository site selection, the site-specific SWF updated WAS (step 14) for the license application can be prepared. This license application WAS will probably be very similar to the earlier GS SWF WAPS; however, the selection of one site should cause elimination of site-specific requirement(s) associated with the two unchosen sites.

Following completion of licensing (step 15), the site-specific SWF WAS will be upgraded to incorporate any additional specifications or modifications generated during licensing into its final form (:strep If). Thn finnl WAS and productionn records (step 17) from the waslin producers will provide the

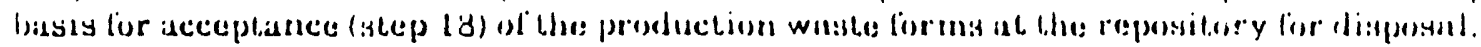

\section{A.2 IMPLEMENTATION OF THE WASTE ACCEPTANCE PROCESS}

Figure A-2 illustrates how the proposed WAP will be administered. The Materials Steering Committee (MSC) will be responsible for implementation and coordination of the WAP. A WAC, composed of a chairman from DOE-OCRWM and contractor personnel directly involved in waste acceptance, will be responsible for a detailed definition of the WAP and preparation of certain WAP documentation. The WAC will report to a Materials Steering Executive Committee (MSEC), composed of three members, one each from DOE-OCRW.M, DOE Defense Programs (DP), and DOE-Nuclear Energy $(N E)$, and will receive guidance from them.

A WAC chairman is selected by the OCRW.Y member of the MSEC, with VE and DP inember (1)n. currence. Contractor personnel will be drawn from the OCRWM technical support contractor (who will serve as executive secretary), the Materials Characterization Center, contractors from the repository project, and each waste-producing project (DWPF, WVDP, HWVP, Idaho National Engineering Laboratory, and the Nuclear Waste Treatment Program). The VRC will not be directly involved or participate in the activities of the WAC.

The current WAPS address only the disposal requirements for the repository program. Other requirements will be addressed at a later time. A complete listing of the DWPF $W A P S$ is provided in Section 3.0. A discussion of the regulatory bases for the WAPS is provided in Appendix $B$. 
WHC-EP-0522

WHC-EP-0045

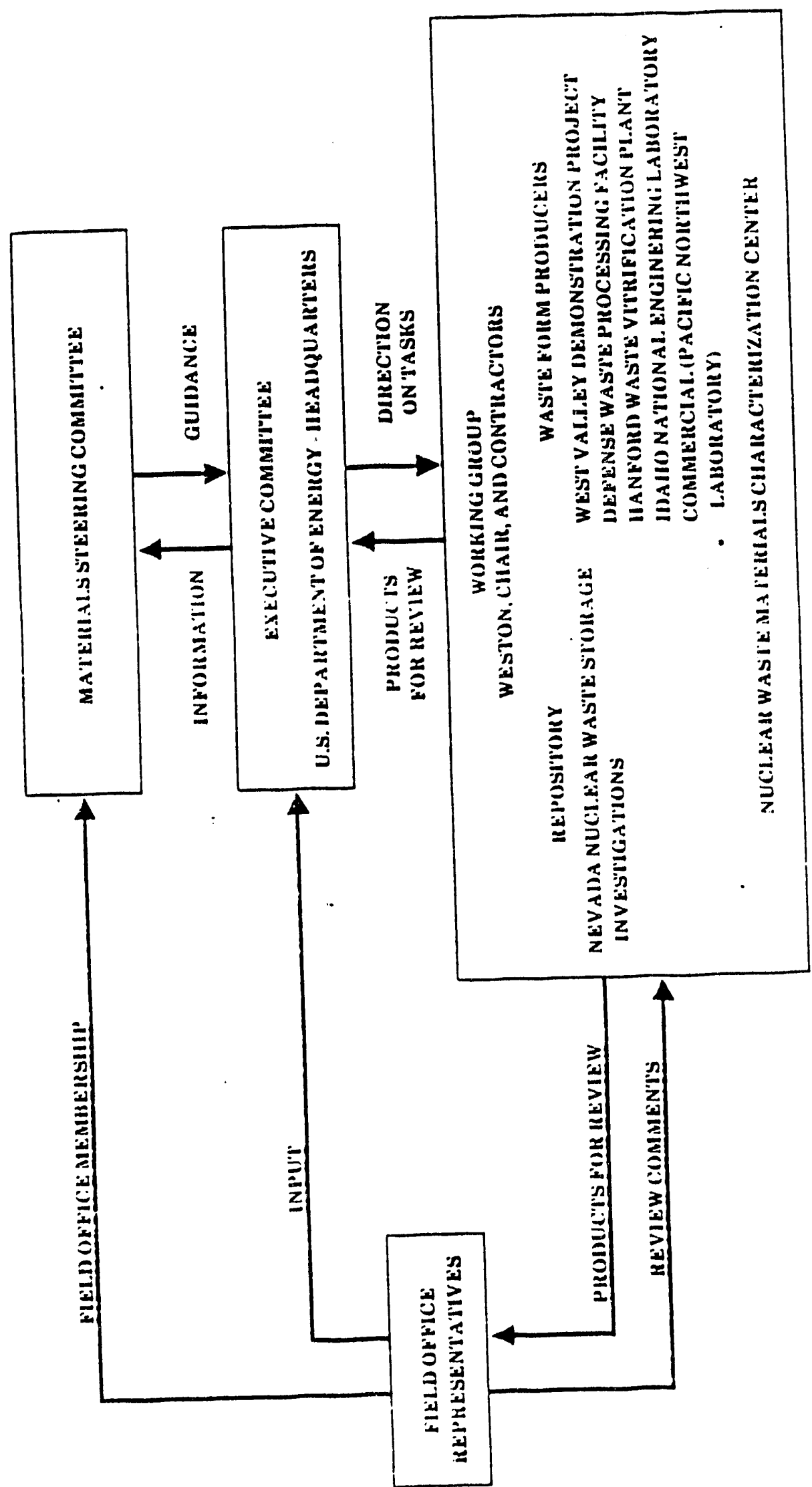

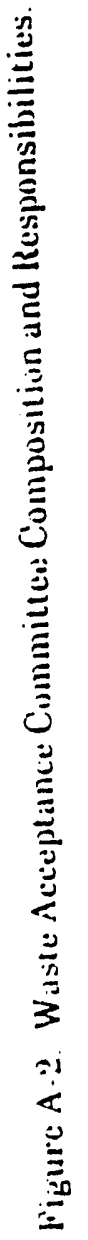


WHC-EP-0522

APPENDIX B

WASTE ACCEPTANCE PRELIMINARY SPECIFICATIONS

B-1 
WHC-EP-0522

\section{APPENDIX B}

\section{WASTE ACCEPTANCE PRELIMINARY SPECIFICATIONS}

\section{PREFACE}

Between the preparation date of April 1992 and the final publication date of June 1993, the Appendix B reference information concerning the July 1991 draft of the U.S. Department of Energy-Office of Civilian Radioactive Waste Management (DOE-RW) Waste Acceptance Preliminary Specification for Vitrified High-Level Waste Forms ${ }^{1}$ has become outdated by certain DOE decisions. The DOE has since created a replacement document. The following paragraph summarizes the major DOE decisions and follow-on actions pertaining to the changes that have occurred.

In July of 1992, the DOE-RW decided not to baseline the proposed draft (July 1991) of the "Waste Acceptance Preliminary Specifications" (WAPS). The WAPS presented the proposed DOE-RW acceptance specifications for the reference vitrified high-level waste (HLW) form to be made by each of the three HLW vitrification projects for disposal in a geologic repository. Instead, DOE-RW departed from the documentation path outlined in the waste acceptance process description that is provided in this appendix. As a replacement, DOE-RW created the Waste Acceptance Systems Requirements Document (WASRD), ${ }^{2}$ which is a broader scoped document than the July 1991 WAPS, and addresses the DOE-RW repository program waste (form) acceptance requirements for several types of waste forms (i.e., commercial power reactor spent fuel, transuranic wastes, as well as the vitrified HLW). The WASRD was structured to provide a traceable path between each acceptance specification and higher levels of the technical document hierarchy for the Civilian Radioactive Waste Management System. The U.S. Department of Energy-Office of Environmental Restoration and Waste Management (DOE-EM) organization, per discussions with DOE-RW, then decided to prepare a waste acceptance specifications document that deals only with the standard form of vitrified HLW. The product specifications, Waste Acceptance Product Specifications for Vitrified High-Level Waste Forms, 3 are in most cases the same as the requirements found in the DOE-RW WASRD. However, under the agreement with DOE-RW, DOE-EM has the prerogative of adding specification topics or changing the specification limits. What DOE-EM is not allowed to do is to make any of the specifications less restrictive than the requirements stated in the DOE-RW WASRD. The U.S. Department of Energy, Richland

${ }^{1}$ Letter, R. W. Brown/U.S. Department of Energy, Richland Operations office, to President/Westinghouse Hanford Company, "Incorporation of Draft Waste Acceptance Preliminary Specifications into the Hanford Waste Vitrification Plant Baseline Requirements," dated November 27, 1991, Richland, Washington.

${ }^{2} \mathrm{DOE} / \mathrm{RW}-0351 \mathrm{P}$, Waste Acceptance System Requirements Document (WASRD), Revision 0, 1993, U.S. Department of Energy, Washington, D.C.

${ }^{3} \mathrm{DOE} / \mathrm{EM}$-WAPS, Waste Acceptance Product Specifications for Vitrified HighLevel Waste Forms (WAPS), Revision 0, 1993, U.S. Department of Energy, Washington, D.C. 
Operations Office formally transmitted guidance, ${ }^{1}$ dated March 29, 1993 , to the Westinghouse Hanford Company to implement these new documents within the Hanford Waste Vitrification Plant Project.

${ }^{1}$ Letter, L. Erickson/U.S. Department of Energy, Richland Operations Office, to President/Westinghouse Hanford Company, "Waste Acceptance Product Specifications for Incorporation into the Hanford Waste Vitrification Plant Basel ine Requirements, " 93-TRB-020, Correspondence No. 9302651B, dated March 29, 1993, Richland, Washington. 


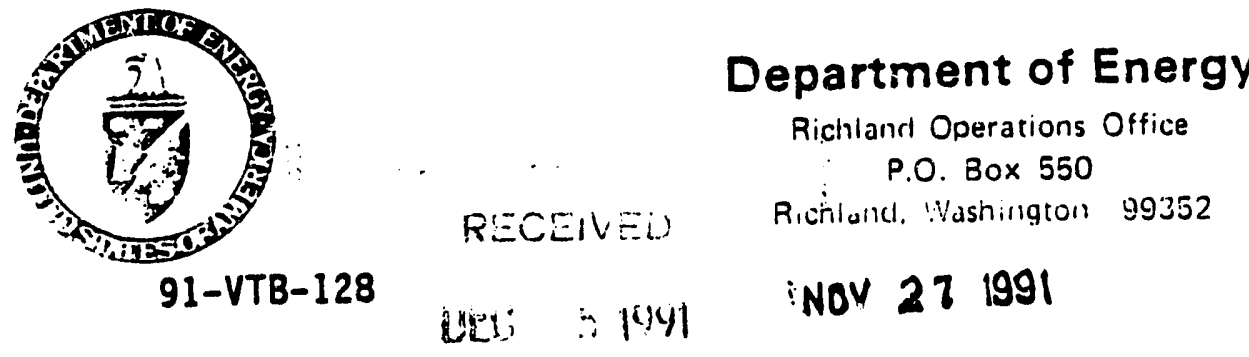

E. T. WEEER

President

Westinghouse Hanford Company

Richland, Washington

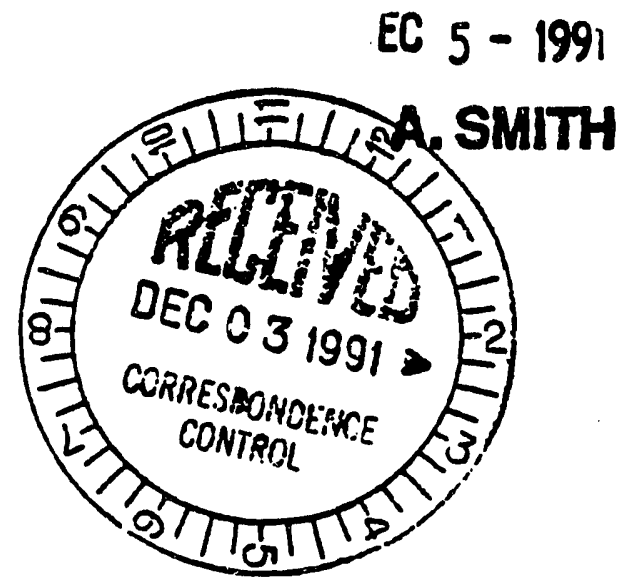

Dear Sir:

INCORPORATION OF ORAFT WASTE ACCEPTANCE PRELIMINARY SPECIFICATIONS INTO THE HANFORD WASTE VITRIFICATION PLANT BASELINE REQUIREMENTS

For some time cice WHC Hanford Waste Vitrification Plant (HWVP) project staff have pursued the development of guidance for the project Architect-Engineer on the subject of waste form qualification. These efforts resulted in the HWVP Project Change Request. (CR-0482), which included a. revision to the HWVP Technical Data Package (TDP) based on the Waste: Acceptance Prel iminary Specifications for Defense Waste Processing Facility (DWPF) High-Level Waste Form, OGR/B-8, as issued in 1986. This Change Request was approved by the HWVP Project Ch age Control Board on November 21, 1991.

However, new Waste Acceptance Preliminary Specifications (WAPS) have been drafted in order to specifically accommodate 1) the canistered waste forms to be produced by all three of the DOE high-level waste vitrification projects and 2) the difficulties experienced by DWPF in its waste form qualification activities based on OGR/B-8. The new draft WAPS have been reviewed by the waste producer projects, and comments have been addressed. Although certain technical concerns remain, further changes to the draft WAPS before issuance by the Office of Civilian Radioactive Waste Management (RW) are considered to be problematic. Therefore, we have conciuded that the HWVP project should adopt the latest draft WAPS (enclosed) into the HWVP technical requirements baseline without further delay.

Consequently, WHC is requested to prepare a revision to the Hanford Waste Vitrification Plant Functional Design Criteria (FDC) to incorporate appropriate functional requirements for a capability to produce a vitrified product which meets the latest draft WAPS. A Change Request for the proposed revision should be submitted by January 17, 1992. Concurrently, it is expected that WHC will further revise the TDP in order to be technically consistent with the latest draft WAPS. In implementing this direction, it is 
WHC

recognized that certain hoids or "TBD's" may be appropriate pending the development of additional technical information from various sources.

Please contact P. E. LaMont, of my staff, on (509) 376-6117 if there are any questions.

VPO:PEL

Sincerely,

Robert $\omega . B$

Robert W. Brown, Project Manager

Vitrification Project Office

Enclosure

cc w/encl :

R. A. Smitin, WHC 
Author

RW Brown/RL
Addressee

President/WHC
INCOMING

Correspondence No.

$9105959 B$

Subject Incorporation of Draft Waste Acceptance Preliminary Specifications Into The Hanford Waste Vitrification Plant Baseline Requirements

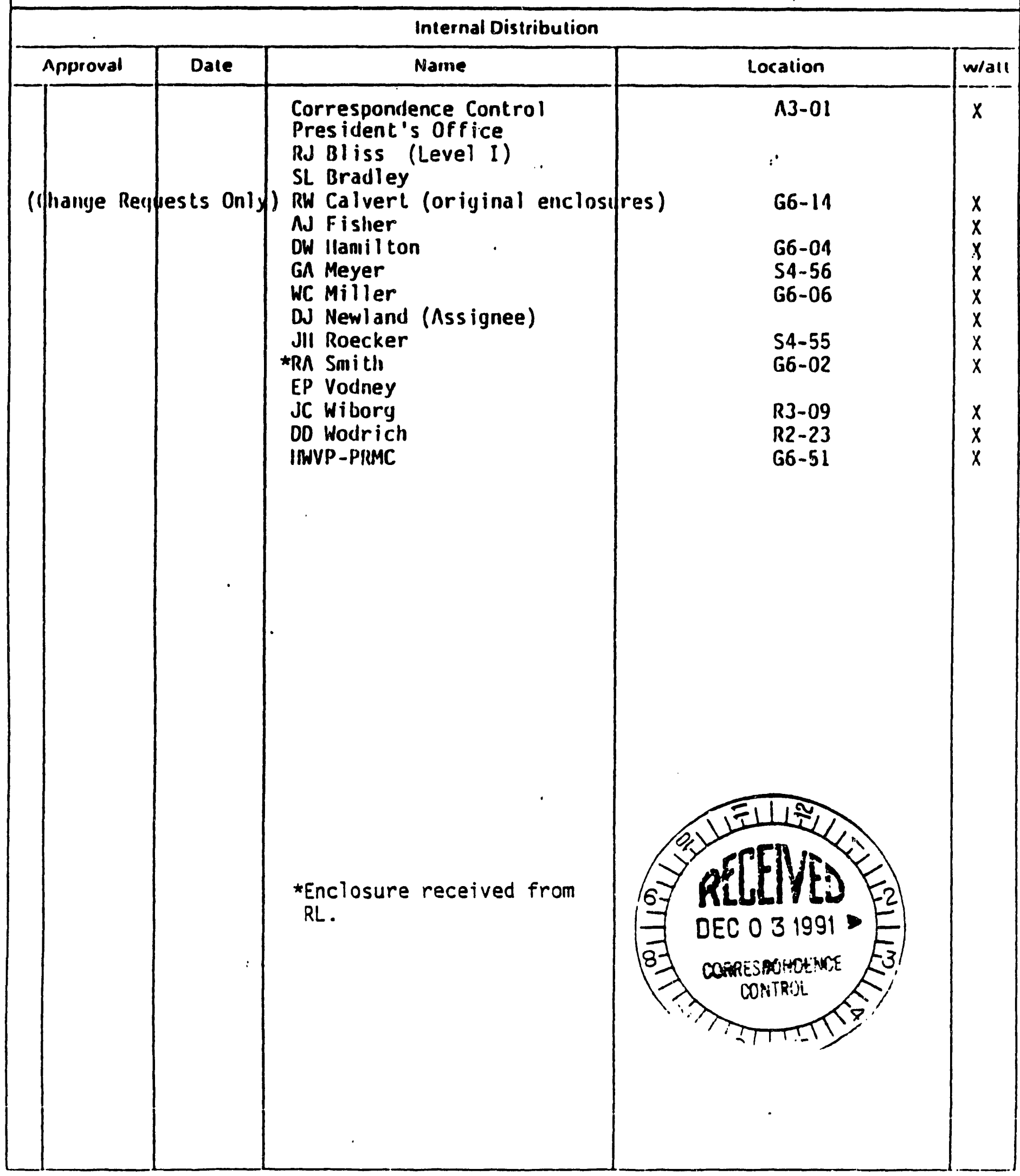


DOE/ S̄NT-

ofsice of Civilian Racisacsive Naste Management

WASTE ACSEZTANCE

PEEIIMINARY SPECIEICATEONS

FOR VITRIEIED RIG:-IEVEL WASTE FORMS

July 1991

Office of Civilian Radioactive Fagte Management

O.S. Deparemene of Dnezgy 


\section{WASTE ACCEPTANCE \\ PRELIMINARY SPECIFICATIONS \\ FOR VITRIEIED HIGH-LEVEL RASTE EORMS \\ DOE/RIT-XXXX, REVISION 0}

\section{APPROVED:}

John w. Bartlett, Director

Date

Office of Civilian Radioactive

Waste Management

U.S. Department of Energy

Leo E. Duffy, Director

Date

office of Enviromental Restoration

and Waste Management

U.S. Department of Energy 


\section{MSTE ACCERTHACE \\ PREMTHINARY SPECIFICANIONS \\ FOR \\ VITRIEIED BIGZ-LEVET RASTE FOFUS}

Office of Civilian Radioactive Maste Management United States Department of Energy

TABLE OF Coviteris

INTRODUCTION

1. WASTE FORM SRECIFICATIONS. . . . . . . . . . . . . . 4

1.1 Chemical specification ................ 4

1.2 Radionuclide Inventory Specification . . . . . . . . . 4

1.3 Specification for Product Consistency . . . . . . . . . 5

1.4 Specification for Phase stability . . . . . . . . . 6

2. CANISTER SPECIFICATIONS ............ 7

2.1 Material Specification . . . . . . . . . . . . 7

2.2 Fabrication and Closure Specification . . . . . . . . T

2.3 Identification and Labeling Specifications . . . . . . 7

3. CANISTERED WASTE FORM SPECIFICATIONS . . . . . . . . . . . 8

3.1 Free Liquid Specification . . . . . . . . . . . . 3

3.2 Gas Specification.............. 8

3.3 Specification for Explosiveness, Pyrophoricity, and Combustibility . . . . . . . . . . . .

3.4 Organic Materials Specification . . . . . . . . . 8

3.5 Eill Height Specification . . . . . . . . . . . 9

3.6 Specification for Removable Radioactive Contamination on External Surfaces ...........9 
WHC-EP-0522

3.7 Heat Generation Specification .............9

3.8 Specification for Maximum Dose Rates . . . . . . . 10

3.9 Chemical Compatibility Specification .......... 10

3.10 Subcriticality specification ............. 10

3.11 Specifications for Weight, Length, Diameter, and overall Dimensions ............. 11

3.12 Drop Test Specification . . . . . . . . . . . . 12

3.13 Handling Features Specification . . . . . . . . . . 12

4. QuALITY ASSURANCE SPECIFICATIONS . . . . . . . . . . . 13 GLOSSARY FOR THE RRSTE ACCERTANCE PRELIMINARY SPECIFICATIONS . . . . . 14 Appendix A - Rationale for Waste Acceptance Preliminary Specifications for Vitrified High-Level Waste Forms . . . 16

Appendix B - References for Waste Acceptance Preliminary Specifications for Vitrified High-Level Waste Forms . . . 25 
WHC-EP-0522

\author{
WASTE ACCEPTANCE PRELIMINARY SPECIFICATIONS \\ FOR VITRIFIED HIGH-LEVEL WASTE FORMS
}

INTRODUCTION

The Waste Management System Requirements Document (WMSR) (Reference 1] defines the functions performed by each element of the waste management system (WMS). Four upper-tier functions are defined: Accept waste; Transport waste; Store Waste; and Dispose of Waste. Volume I: General System Requirements of the WMSR states that "The waste management system shall accept spent nuclear fuel (SNE) and commercial high-level radioactive waste (HIFW) in accordance with the provisions of the contracts executed pursuant to 10 CFR Part 961, subpart B." It also states that the WMS shall accept West Valley ERRW "in accordance with an agreement to be made between the Department of Energy and the State of New York" and that the WMS shall accept defense HIFW "in accordance with the memorandum of agreement between $O C F N M$ (Office of Civilian Radioactive Waste Management) and the DOE Office of Defense Programs." Section D of Appendix $E$ of 10 CFR Rart 961. Subpart B states that "The DOE shall accept high-level radioactive waste. Detailed acceptance criteria and general specifications for such waste will be issued by the DOE..."

The Waste Acceptance Preliminary Specifications (WAPS) are the first steps in this process. These WAPS specify technical requirements that the waste form must meet and the documentation that the producers must provide in order that the OCFMM, U.S. Department of Energy (DOE), may take possession of such products from the producers for the purposes of transportation, storage, and final disposal. Compliance with the WAPS assures the OCrWM that the product is a consistent glass with a bounded composition and geometry, that complies with the U.S. Nuclear Regulatory Commission (NRC) requirements in 10 CFR Part 60 [Reference 2], particularly 10 CFR 60.135. In addition, the NAPS must be consistent with these other WMSR functions, transportation and storage. These interfaces are also noted in the WMSR, Volume I, Section 2.3.2.

Volume IV: Mined Geologic Disposal System (MGDS) of the MMSR defines the functions that have been allocated to the MGDS. These include: Transport Waste (limited to receipt from the rransportation system); Store Naste (as required for operational efficiency); and Dispose of waste (which includes two subfunctions- Process Waste and Isolate Waste). The subfunction Process Waste includes the "packaging and emplacement of waste....necessary to facilitate meeting the postclosure repository objectives specified in 10 CFR Part 60.112 and 10 CFR Part 60.113." Thus, the design of the waste package and engineered barrier system and the qualification of the products for disposal at a specific repository site are a part of the functions allocated to the moss. However, part of the basis for developing design specifications for the repository and the waste package will be contained in the final version of the acceptance specification. 
It is recognized that some individual canistered waste forms may not comply in every respect with these specifications. For these cases, each producer will identify the non-conformances and propose a remedy for evaluation by the repository project on a case-by-case basis. The repository project will evaluate the proposed remedy, and a final disposition of the non-conforming waste forms will be determined in accordance with the repository license.

The underlying rationale for many of the requirements of these WaPS are those found in 10 CFR 60.135, which deals with the criteria for the waste packages and their components. Another important section is 10 CFR 60.131 dealing with general design criteria, particularly criticality control. The rationales for all of the specifications is given in Appendix A.

The waste acceptance process requires demonstration of compliance in the WAPS via four different documents, each prepared by the procucers and concurred with by the repository project: (1) the Waste Form Compliance Plan (WCP) the Waste Form Qualification Report (WQR), (3) Production Records and Storage and Shipping Records. The Savannah River Plant, South Carolina; the West valley Demonstration Project (WVDR) at West Valley, New York; and the Hanford waste Vitrification Plant (HWVP) at the Hanford Reservation, Richland, Washington.

The WCP is the producer's plan for demonstrating compliance with each specification in the WAPS. The WCP is to include detailed descriptions of the testing, analyses, and process controls to be performed by the producers, testing, analyses, and process conteduction records to be provided, to
including the identification of producications.

The WQR is a compilation of the results from testing and analysis that presents the detailed evidence that the canistered procuct will comply with each specification during actual waste form production. Sources of uncertainty in specification during actual waste form production.
the testing results and analysis are also provided. Concurrence by the 0 crwM,
based upon the review by the Technical Review Group, will be required for the WQR, which will mean that the results from testing and analysis as described and documented provide a satisfactory demonstration of comoliance with each specification.

Production Records refers to documentation, provided by the producers, that describes the production and characterization of the actual canistered waste forms for review by the repository project before the waste is shipped. The content of the Production Records will be specified in the WCP. Concurrence will mean that individual canisters of glass are deemed to be in compliance with the specifications and are therefore acceptable to OCFWM.

Storage and Shipping Records describe the physical attributes of the canistered waste forms which are stored at the producer's site and later shipped to the repository. 
WHC-EP-0522

The WAPS are based on the best available information current as of the date of issue. The WAPS will be finalized into the Waste Acceptance Specifications (WAS) when the Director, OCFWM, the Director, office of Environmental Restoration and Waste Management, (פM), and the Secretary of Energy (or the Secretary's appointee) have approved the waps and the WQR from the "cold" operation of the first producer site, currently scheduled to be the DWPE. 


\section{WASTE EORM SRECIEICATIONS}

\subsection{CHEMICAL SPECIEICATION}

The waste form is borosilicate waste glass.

\subsubsection{Chemical Comosition Projections}

The producer shall include in the WQR the chemical composition and crystalline phase projections for each waste type. The method to be used to demonstrate compliance shall be described by the producer in the WCP. Waste form compositions not available for reporting in the initial woR shall be included in an addendum to the WRR.

\subsubsection{Chemical Comoosition During Production}

The producer shall include in the Production Records the oxide composition of the glass waste form for the oxides of elements present in concentrations greater than 0.5 percent by weight for each waste type. The producer shall describe the method to be used for compliance in the WCP. An estimate of the error of the composition and the basis for the estimate shall be reported in the WRR.

\subsection{RADIONUCLIDE INVENTORY SPECIFICATION}

The producer shall report the estimated inventory of radionuclides (in curies) that have half-lives longer than 10 years and that are or will be present in concentrations greater than 0.05 percent of the total radioactive inventory for each waste type at any time up to 1100 years after production. The proctucer shall also report the upper limit of all radionuclides for any canistered waste form. These estimates shall be indexed to the year 2025 . The inventory at year 3125 shall also be provided.

\subsubsection{Radionuclide Inventory Projections}

The producer shall provide in the WOR estimates of the total quantities of individual radionuclides to be shipped to the repository and the estimated error in the values. The producer shall also provide in the WQR estimates of the inventories for each waste type and the estimated error. The method to be used for demonstrating compliance shall be described by the producer in the wCP.

\subsubsection{Radionuclide Inventory During Production}

The producer shall provide in the Production Records estimates of inventories of individual radionuclides in each waste type. The procucer shall also report the estimated error of these estimates in the WQR. 


\subsection{SPECIFICATION FOR PRODUCT CONSISTENCY}

The producer shall demonstrate control of waste form production by comparing production samples to the Environmental Assessment (EA) benchmark glass to satisfy the criterion of Specification 1.3.1. The producer shall describe the method for demonstrating compliance in the WCP and shall provide verification in the Production Records. The procucer shall demonstrate the ability to comply with the specification in the WQR.

\subsubsection{Acceptance Criterion}

The consistency of the waste form shall be demonstrated using the Product Consistency Test (PCT) [3]. For acceptance, the concentrations of lithium, sodium and boron in the leachate, after normalizing for the concentrations in the glass, shall be less than those of the benchmark glass whose composition and release properties are described in the Environmental Assessment for selection of the DWPF waste form [4]. The reported mean PCT results for lithium, sodium, and boron for the glass produced from each waste type shall be at least two standard deviations below the mean PCT results of the EA glass.

\subsubsection{Method of Compliance}

The capability of the waste form to meet this specification shall be demonstrated by a combination of testing of procuction glass samples of process control information. Glass samples shall be taken from the glass pour stream during canister filling or from a convenient location near the mouth of the waste form canister before the canister is sealed.

Production Records shall include results from testing actual samoles, as well as any process control infomation to be used for verification. When using process control information to project PCT results, the producer shall demonstrate in the WQR that the method used will provide information equivalent to the testing of samples of actual procuction glass. 


\subsection{SPECIEICATION FOR PHASE STABILITY}

\subsubsection{Phase Stability Information}

The producer shall provide the following data for each waste type:

(a) The glass transition temperature; and

(b) Time-temperature-transformation (TIT) diagrams that identify the duration of exposure at any temperature that causes significant changes in borosilicate glass waste type.

The method to be used to demonstrate compliance shall be described in the WCP. The data shall be provided in the WQR.

\subsubsection{Control of Temperature for Phase Stability}

At the time of shipment, the producer shall certify that after the initial cool-down, the maximum waste form temperature has always been at least $100^{\circ} \mathrm{C}$ below the glass transition temperature. The producer shall describe the method of compliance in the WCP. 
WHC-EP-0522

\section{CANISTER SPECIFICATIONS}

\subsection{MATERIAL SPECIFICATION}

The waste form canister and any secondary canister applied by the producers shall be fabricated from austenitic stainless steel. The ASTM alloy specification and the composition of the canister material, the secondary canister material, and any filler material used in welding shall be included in the WCP. Documentation of compliance shall be included in the Proctuction Records.

\subsection{FABRICATION AND CLOSURE SPECIFICATION}

The canister fabrication methods, as well as those for any secondary canister applied by the producer, shall be identified in the WCP and documented in the WQR. The outermost closure shall be leaktight to $1 \times 10^{-4}$ atm-cc/sec helium. The method for demonstrating compliance shall be described by the producer in the WCP and documented in the Production Records.

\subsection{IDENTIFICATION AND LABEIING SPECIFICATION}

\subsubsection{Identification}

The producer shali assign a unique alphanumeric identifier to each outermost canister that is produced. This alphanumeric identifier shall appear on the labels of the canistered waste form and on all documentation pertinent to that particular canistered waste form.

\subsubsection{Labeling}

Each canister shall be labeled with the identification code specified above in two locations: one visible from the top and one from the side of the canister. The identification code shall be printed in a type size of at least 92 points using a sans serif type face (or equivalent). A proposed layout shall be provided in the WCP. Labels meeting the requirements above shall be applied to the exterior of the outermost canister and shall not cause the dimensional limits of specification 3.11 to be exceeded. The label materials and method of attachment shall be selected to be compatible with the canister material. The label shall be designed to be legible after filling and storage at the producer's facility, shipment to the repository, and possible lag storage at the repository in air for up to one year prior to final packaging. The method used for demonstrating compliance shall be described in the NC?. Label materials shall be described in the woR. 


\section{CANISTERED WASTE EORM SPECIEICATIONS}

\subsection{EREE LIQUID SPECIEICATION}

After closure the canistered waste form shall not contain free liquids. The producer shall describe the method of compliance in the WCP and provide documentation of the ability to comply with this specification in the waR.

\subsection{GAS SPECIFICATION}

After closure, the canistered waste form shall not contain free gas other than air, cover and radiogenic gases. Cover gases shall be helium, argon, other inert gases, or air. The internal gas pressure immediately after closure shall not exceed $150 \mathrm{kPa}\left(22\right.$ psia) at $25^{\circ} \mathrm{C}$. The proctucer shall describe the method of compliance in the WCP and shall document compliance in the WQR as well as the quantities and compositions of any gases that might accumulate inside the canister after the canister has been subjected to temperatures up to the glass transition temeerature.

The produc : shall also document in the WQR the quantities and compositions of any gases that might accumulate inside the canisters as a result of radioactive decay prior to delivery to the repository and up to 1100 years thereafter.

\section{3}

SPECIFICATION FOR EXPLOSIVENESS, PYROPHORICITY, AND COMBUSTIBILITY

After closure the canistered waste form shall not contain explosive, pyrophoric, or combustible materials. The producer shall describe the method of compliance in the WCP. The producer shall present in the WQR an evaluation of the canistered waste form to demonstrate by administrative controls and other factors that, for the range of material compositions, it remains nonexplosive, nonpyrophoric, and noncombustible after having been subjected to temperatures up to the glass transition temperature.

\subsection{ORGANIC MATERIALS SPECIFICATION}

After closure the canistered waste form shril I not contain more than detectable amounts (approx. $10 \mathrm{ppm}$ ) of organic mate:ials. The producer shall describe the method for complying with this specification in the WCP and document the basis for compliance in the WQR. 
The producer shall fill the canister to a height equivalent to at least $80 \%$ of the volume of the empty canister. The producer shall report this height in the Production Records and describe the method of compliance in the WCP. Documentation supporting the selected method of compliance shall be provided in the WQR.

\subsection{SPECIFICATION FOR REMOVABLE RADIOACTIVE CONTAMINATION ON EXIERRNAL SURFACES}

The level of removable radioactive contamination on all external surfaces of each canistered waste form shall not exceed the following limits:

$$
\begin{array}{ll}
\text { Alpha radiation: } & 220 \mathrm{dpm} / 100 \mathrm{~cm}^{2} \\
\text { Beta and Gamma radiation: } & 2200 \mathrm{dpm} / 100 \mathrm{~cm}^{2}
\end{array}
$$

In addition, the producer shall visually inspect the canistered waste forms and remove visible waste glass on the exterior of the canistered waste form before shipment. The producer shall also provide in the HQR an estimate of the amount of canister material, particulariy wall thickness, that is removed during the decontamination and the basis for that estimate. The producer shall describe the method of compliance in the WCP and provide contamination level results in the storage and Shipping Records.

\subsection{HEAT GENERATION SPECIFICATION}

The canistered waste form total heat generation rate shall not exceed 1500 watts per canister indexed to the year 2025.

\subsubsection{Heat Generation Tojections}

The prochucer shall document in the WQR the expected themal output of canistered waste formis and the range of expected variation in thermal output for each wast type during the life of the production facility. The method to be used for demonstrating compliance shall be described by the producer in the NCP. Projections for compositions not available for reporting in the initial WQR shall be included in an addendum to the WQR.

\subsubsection{Heat Generation During Production}

The protucer shall report in the Production Records the heat generation rate for each canistered waste form at time of production. The estimated error of the heat generation rates shall be provided in the WQR. The proctucer shall describe the plan for compliance in the wCP. 
wriL-EP-0522

The canistered waste form shall not exceed a maximum surface ganma dose rate of $10^{\text {s }} \mathrm{rem} / \mathrm{hr}$ and a maximum neutron dose rate of $10 \mathrm{rem} / \mathrm{hr}$, indexed to the year 2025.

\subsubsection{Projections of Dose Rates}

The producer shall specify in the KQR the expected values and the range of expected variation for both gamma and neutron dose rates. The procucer shall describe the method for demonstrating compliance in the WCP.

\subsubsection{Dose Rates at Time of Shipment}

The producer shall provide in the Storage and Shipping Records the estimated values for both gamma and neutron dose rates for the canistered waste forms. The producer shall describe the method of compliance in the WCP.

\subsection{CHEMICAL COMPATIBILITY SPECIFICATION}

The contents of the canistered waste form shall not lead to internal corrosion of the canister such that there will be an adverse effect on normal handling during storage, and on an abnormal occurrence such as a canister drop accident. The procuces shall describe the method of demonstrating compliance in the WCP. Corrosion, chemical interactions, and any reaction products generated within the canistered waste forms after exposure to temperatures up to the glass transition temperature shall be discussed in the WQR.

\subsection{SUBCRITICALITY SPECIFICATION}

The producer shall ensure that the canistered waste form will remain subcritical under all credible conditions likely to be encountered at the procucer's site, including the proposed storage array. The calculated effective neutron multiplication factor, $k_{\text {of }}$, must be sufficiently below unity, to show at least a 5 percent margin, after allowance for bias in the method of calculation and the uncertainty in the experiments used to validate the method of calculation. The producer shall describe the method of demonstrating compliance in the WCP and provide supporting documentation in the WQR. The WQR shail also include sufficient information on the nuclear characteristics, such as fissile density, of the canistered waste form to enable the repository project to confirm subcriticality under repository storage and disposal conditions. 
WHC-EP-0522

3.11 SPECIEICATIONS EOR WEIGHT, LENGTH, DIAMETER, AND OVERALL DIMENSIONS

The configuration, dimensions, and weight of the canistered waste form shall not exceed the maximum size and weight which can be received, handled, and emplaced in the repository. These parameters shall be controlled as indicated below and shall be documented at the time of shipment. The producer shall describe the method of compliance in the WCP and the basis for compliance in the WQR.

\subsubsection{Weight Specification}

The weight of the canistered waste form shall not exceed $3,500 \mathrm{~kg}$. The measured weight and estimated error shall be reported in the storage and Shipping Records.

\subsubsection{Length Specification}

The overall length of the final canistered waste form at the time of shipment shall be $3.000 \mathrm{~m}(+0.005 \mathrm{~m},-0.020 \mathrm{~m})$, including the neck and handling flange. The measured length and estimated error shall be reported in the storage and shipping Records.

\subsubsection{Diameter Specification}

The outer diameter of the canistered waste form shall be $61.0 \mathrm{~cm}(+1.5$ $\mathrm{cm},-1.0 \mathrm{~cm})$. The measured diameter and estimated error shall be reported in the Storage and Shipping Records.

\subsection{1 .4 Specification for Overall Dimensions}

The dimensions of the canistered waste form shall be controlled so that, at the time of shipment to a repository, the canistered waste form will stand upright without support on a flat horizontal surface and will fit without forcing when lowered vertically into a right-circular, cylindrical cavity, 64.0 $\mathrm{cm}$ in diameter and $3.01 \mathrm{~m}$ in length.

The proctucer shall stal:e in the WR the minimm canister wall thickness of the filled canister, and the thickness of any secondary canisters, along with their technical basis. The producer shall document the wall thickness in the Production Records. 


\subsection{2}

\section{DROE IEST SPECIEICATION}

The canistered waste form at time of shipment shall be capable of withstanding a drop onto a flat, essentially unyielding surface without breaching. The producer shall describe the method of compliance in the WCP and present the supporting documentation of analysis and test results in the WQR. The test results shall include information on measured canister leak rates and canister deformation after the drop test.

The drop height to meet repository requirements shall be $7 \mathrm{~m}$.

The final Waste Acceptance Specifications will address the transportation requirements.

\subsection{HANDLING FEATURES SPECIFICATION}

The canistered waste form shall have a concentric neck and lifting flange. The lifting flange geometry and maximu loading capacity shall be described in the WCP.

The producer shall design the lifting flange and a suitable grapple, which could be used at the repository. The grapple and the flange shall be designed to satisfy the following requirements:

(a) The grapple shall be capable of being remotely engaged and disengaged from the flange.

(b) The grapple, when attached to a suitable hoist (to be supplied by the repository), and when engaged with the Elange, shall be capable of raising and lowering a canistered waste form in a vertical direction.

(c) The grapple, in the disengaged position, shall be capable of being inserted into and withdrawn in a vertical direction from a right-circular cylindrical cavity with a diameter equal to that of the canistered waste form.

The design of the flange and grapple shall be capable of fulfilling the requirements of specification $3.13(a)$ through $3.13(c)$ without contacting or penetrating the walls of an imaginary right-circular, cylindrical cavity with a diameter equal to that of the canistered waste form, coaxial with the canistered waste form. The design of the grapple shall include features that will prevent an inadvertent release of a suspended canistered waste form when the grapple is engaged with the flange. The producer shall describe the method used for demonstrating compliance in the WCP and provide the designs in the WQR. 


\section{QUALITY ASSURANCE SPECIFICATION}

The producer shall establish, maintain, and execute a quality assurance (QA) program that complies with the current version of the $\delta . S$ Department of Energy, Office of Civilian Radioactive Waste Management, Quality Assurance Reguirements and Description for the Civilian Radioactive Waste Management Program (QARD). The WCPs shall be prepared in aCcordance with the QA program. The quality assurance program shall be applied to all testing and analysis activities that provide information to be included in WQRs. However, existing data generated prior to the inception of the subject QA program may be included in the WCP so long as the data are qualified in accordance with the procedure described in the QARD. The quality assurance program shall also be applied to all activities that affect compliance with waste acceptance specifications during waste form production, handling, storage, and preparation for shipment. The producer shall derelop implementing documents that address the applicable requirements, as prescribed in the QARD.

Notification and disposition of non-conforming canisters of high-level waste glass shall be in accordance with the QARD. 


\section{GLOSSARY FOR THE WASTE ACCEPTANCE PREIIMINARY SPECIFICATIONS}

Borosilicate waste glass - glass typically containing approximately 20 to 40 wt. 8 waste oxides, 40 to 65 wt. 8 silica, 5 to 10 wt. $\%$ boron oxide, and 10 to 20 wt. $z$ alkali oxides, plus other oxide constituents.

Canister - the metal vessel into which borosilicate waste glass is poured during waste form fabrication.

Canister breach - loss of canister leaktightness.

Canistered waste form - the waste form and the surrounding canister as well as any secondary canister applied by the producer.

Combustible material - any material that can be ignited readily, and when ignited, burns rapidly.

Corrosiveness - the tendency of a substance to wear away or alter a material by a chemical or electrochemical (essentially oxidizing) process.

Explosive material - a substance that, in its normal condition, is characterized by a chemical state that remains unchanged with time, but may be made to undergo rapid chemical change without an outside source of oxvgen, whereupon it produces a large quantity of energy generally accompanied by the evolution of hot gases. These substances include those specified in $49 \mathrm{CFR}$ Part 173, subpart $C$, Classes $A$ and $B$.

Free gas - any gas, including radiogenic gases and cover gases like helium, argon, or air, that could contribute to the pressurization of the canister. This includes gases mechanically trapped in the waste form and those generated by chemical reaction and radiolytic decomposition.

Free liquid - liquid that could be drained from the canister either initially or after having been subjected to temperatures up to the transition temperature; free liquid includes liquid that is mechanically trapped in the waste form.

Glass transition temperature - the temperature at which the slope of the thermal expansior versus temperature curve of the glass shows a sharp increase.

Grapple - a device designed to mate with the lifting flange, used to suspend the canistered waste form from an overhead crane for lifting and transporting.

Leaktightness - a leakage rate of $10^{-4} \mathrm{~atm}-\mathrm{cm}^{3} / \mathrm{sec}$ or less based on $\mathrm{d} r \mathrm{y}$ helium Leaktightness - a leakage rate of $10^{-4}$ atm-cm /sainst a vacurm of $10^{-2}$ atm or
at $25^{\circ} \mathrm{C}$ and a pressure differential of 1 atm agains
less (modified from ANSI N14.5-1987, "American National Standard for Leakage Tests on Packages for Shipment of Radioactive Materials" or ASME's "Boiler and Pressure Vessel Code," Section V, Article 10, Appendix IV (1986)).

lifting flange - a protruding rim, edge, rib or collar used to handle the canister.

$$
-14-
$$


Organic material - any material based on methane or methane derivatives, carbon chains or rings, generally containing hydrogen with or without oxygen, nitrogen, or other elements, whether or not derived from living organisms. Free carbon, carbon monoxide, carbon dioxide, and cyanide compounds are excluded.

Production Records - the documentation, provided by the producer, that describes the actual canistered waste forms.

Pyrophoric material - any liquid that will ignite spontaneously in air below $54.4^{\circ} \mathrm{C}$. Any solid material, other than one classed as an explosive, which under normal conditions is liable to cause fires through friction, retained heat from manufacturing or processing, or which can be ignited readily and when ignited burns so vigorously and persistently as to create a serious transportation, handling, or disposal hazard. Included are spontaneously combustible and water-reactive materials, and especially the materials specified in 49 CFR Part 173, Subpart E.

Radiogenic gas - any gas produced by radioactive transformation; that is, the transmutation of an element into a gaseous element by a change in the atomic nucleus through processes such as fission, fusion, neutron capture, or radioactive decay.

Removable radioactive contamination - radioactive material not fixed to a surface. The level of this contamination is determined by wiping an area of 300 $\mathrm{cm}^{2}$ with an absorbent material, using moderate pressure, and measuring the activity on the wiping material (Erom 10 CFR 71.87).

Secondary canister - a sealed metal vessel that is applied by the proctucer and completely surrounds the waste form and its canister.

Storage and Shipping Records - the document that describes the physical attributes of the caristered waste forms which are stored at the producer's site and later shipped to the repository. These records also identify any unexpected events, such as thermal excursions, which have occurred turing storage.

Waste form - the radioactive waste materials and any encapsulating or stabilizing matrix (10 CFR 60.2).

Waste Form Compliance Plan (WCP) - the document that describes the producer's plan for demonstrating compliance with each waste acceptance specification in the WAPS. The WCP includes descriptions of the tests, analyses, and process controls to be perfomed by the producer, including the identification of records to be provided to demonstrate comoliance with the specifications.

Waste Form Qualification Report (WQR) - a compilation of results from waste form testing and analysis which develops in detail the case for compliance with each waste acceptance specification.

Waste type - The waste material fed to each vitrification facility which can be assumed to remain relatively constant in comosition and properties for an extended period of time. 
WHC-EP-0522

\author{
APPENDIX A \\ RATIONALE FOR WASTE ACCEPTANCE RRELIMINARY SPECIFICATIONS \\ EOR VIIRIFIED HIGH-LEVEL WASTE FORMS
}

\title{
1. WASTE FORM SPECIEICATIONS
}

\subsection{RATIONALE FOR THE CHEMICAL SPECIFICATION}

The regulatory requirements outlined in $10 \mathrm{CFR} 60.135(\mathrm{c})$ state that: (1) "All such radioactive wastes shall be in solid form and placed in sealed containers"; (2) Particulate waste focms shall be consolidated (for example, by incorporation into an encapsulating matrix) to limit the availability and generation of particulate"; and (3) All combustible radioactive wastes shall be reduced to a noncombustible form...". Borosilicate glass was selected because it meets these requirements and because of its durability, stability, and ease of manufacture.

The chemical specification addresses two repository information needs. Information on the planned production is required to allow testing of material that is representative of what is to be procuced. Secondly, information on the canistered waste forms is required to confirm that the material actually produced is within the range of materials tested.

The measurement of canistered waste form compositions for each waste type is necessary to allow adequate evaluation of uncertainties in waste form composition for repository perfomance assessment. Analysis of elements present above the 0.5 percent threshold will include those needed to evaluate process conditions and uniformity. These elements represent at least 98 weight percent of the glass.

Oxygen is excluded from the requirements for analysis because it would not provide any data relevant to detemination of the valence state of radionuclides in the glass. A direct measurement of oxygen would have an uncertainty of \pm 1 percent of the measured value. The radionuclides for which release rate control is required are present in concentrations that are collectively less than 0.5 percent; of these, only a small number, such as technetium and plutonium, are redox sensitive. since other, non-radioactive oxides are present in much greater concentrations, a measurement of the oxygen concentration with an uncertainty of more than 1 percent would provide no information on the valence state of the radiomulides of interest.

However, knowledge of the oxides present in the glass, which define the redox state of the glass, is needed for repository performance assessment. 
WHC-EP-0522

\subsection{RATIONALE EOR THE RADIONUCLIDE INVENTORY SPECIFICATION}

The total radionuclide inventory is required for a determination of the producers' contribution to the repository source term for calculations to show compliance with $10 \mathrm{CFR}$ Part 60 release rate and $40 \mathrm{CFR}$ Part 191 total release standards. A reference year was needed for indexing radionuclide inventory values. The year 2025 was chosen to serve this purpose. Inventory estimates for each canistered waste form are required to confirm that each canistered waste form falls within bounds considered in licensing, safety, and isolation assessments, and for estimates of releases under unanticipated processes and events, and accident scenario conditions.

Estimates of expected variations in radionuclide inventories are necessary to help quantify uncertainties in radionuclide release estimates for repository performance assessments. The minimum concentration of 0.05 percent is needed to ensure that: (a) a reasonably accurate Total Release Rate Limit can be calculated; and (b) all radionuclides, whose release rate from the engineered barrier system must be controlled to less than $1 \times 10^{-5} / \mathrm{Yr}$, are specifically identified, in accordance with 10 CFR 60.113 . It also provides a reasonable lower bound for assessment of releases during accidents.

The half-life criterion needs to be as low as 10 years so that "pre-closure" exposure and accident concerns can be addressed. The upper limit values for all radionuclides are needed to address transportation requi rements.

The 1100 years is based on a 1000 year containment period plus 100 years after production for storage, transportation, and operation prior to repository closure, and will be used as the basis for calculating the inventory for the 10 CFR 60.113 release rate criterion.

\subsection{RATIONALE FOR THE SPECIFICATION FOR PRODUCT CONSISTENCY}

The primary justification for this specification is the need to ensure a consistent glass product by the control of the vitrification process.

This specification formally establishes the Environmental Assessment for the selection of the DWPF waste form [4] as a binding comitumt on the waste form producers. The specification requires that the PCT response for the glass waste forms shall be consistently better than the glass described in the Environmental Assessment, which itself is an acceptable glass. The two-sigma limit provides a degree of conservatism.

Specification 1.3.1 uses the Product Consistency Test (PCT) as the basis for this specification. The PCT is considered to be a generally acceptable method of establishing product consistency and can be performed remotely in a hot-cel-enviconment. The three elements to be analyzed (lithium, sodium and boron) for the PCI are sufficient, because they release faster than all other elements for all conceivable types of borosilicate iII glass.

$$
-17-
$$


The specification will provide data useful to the repository project for establishment of repository and waste package design temperature limits. The certifications required will provide assurance that the producer has not handled or stored the waste forms in such a way as to cause changes in the phase structure that could significantly affect glass properties.

The available evidence [5] indicates that the borosilicate glass waste form will retain properties similar to those obtained under specification 1.3 so long as the phase structure and composition of the glass are unchanged from those provided under specification 1.1. The evidence also indicates that neither energy input nor radioactive decay significantly affect release from waste glass, as long as the temperature of the glass does not exceed the glass transition temperature (approximately $500^{\circ} \mathrm{C}$ ). Above this temperature, significant changes in phase composition can occur. 
WHC-EP-0522

\section{CANISTER SPECIFICATIONS}

\subsection{RATIONALE FOR THE MATERIAL SPECIEICATION}

The repository must have a complete materials inventory to evaluate longterm performance under repository conditions. Austenitic stainless steel has been selected as the canister material. This specification acknowledges that fact and establishes the repository's interest in this interface. The current role of the canister as part of the engineered barrier system does not require the canister to act as a post-closure engineered barrier; therefore, the primary requirement of the canister material specification is to ensure that the canister material does not have an adverse impact on waste package performance. By specifying austenitic stainless steel manufactured to ASTM specifications, this requirement is met. Additionally, identification of the materials is necessary to assure that the canister material, and the material of any other component (i.e., secondary canisters and welding fillers), are compatible with other materials in the repository.

\subsection{RATIONALE EOR THE FABRICATION AND CLOSURE SPECIFICATION}

The sealed canister is designed to provide confinement of the waste and protection of the waste form from contact with externally derived liquids and gases until the canister is sealed in a repository container. The canister itself is not intended to meet a post-closure containment requirement. A leak rate of less than $2 \times 10^{-4}$ atm-cc/sec has been established [6] as being sufficient to prevent water from entering the canister. A leak rate of $10^{-4}$ atm-cc/sec (air) has been established as the container failure criterion for repository post-closure service [7]. Thus, a final closure leak-rate specification of $10^{-4}$ atm-cc/sec (helium) for canisters of HIW glass is considered to be both conservative and demonstrable.

\subsection{RATIONALE FOR THE IDENTIFICATION AND LABEIING SPECIFICATIONS}

The regulatory requirements in $10 \mathrm{CFR} 60.135(\mathrm{~b})(4)$ state that "A label or other means of identification shall be provided for each waste package. The identification shall not impais the integrity of the waste package and shall be applied in such a way that the information shall be legible at least to the end of the period of retrievability. Each waste package identification shall be consistent with the waste package's permanent written records."

This specification provides a means of tying the waste package and the canistered waste form together through closure of the repository. The 92 point sans serif type face (or equivalent) results in a letter height and width of approximately $3 \mathrm{~cm}$ by $2 \mathrm{~cm}$ which has been confirmed through observation to be adequate dimensions for visibility. The canister label is needed to identify the canistered waste form through storage at the producer's facility, shipment to the repository, and possible lag storage at the repository prior to final packaging. Once the canistered waste form is received at the repository, the burden of maintaining the identity of the contents shifts to the repository project. 


\section{CANISTERED WASTE FORM SPECIFICATIONS}

\subsection{RATIONALE FOR THE FREE LIQUID SPECIFICATION}

The regulatory requirements outlined in $10 \mathrm{CFR} 60.135(\mathrm{~b})(2)$ state that, "The waste package shall not contain free liquids in an amount that could compromise the ability of the waste package to achieve the performance objectives relating to containment of $\mathrm{kIW}$ (because of chemical interactions or formation of pressurized vapor) or result in spillage and spread of contamination in the event of waste package perforation during the period through permanent closure."

\subsection{RATIONALE FOR THE GAS SPECIFICATION}

The regulatory requirements in 10 CFR 60.135 (a) require that "packages for HIW shall be designed so that in-situ chemical, physical, and nuclear properties of the waste package... do not compromise the function of the waste packages..." and "The design shall include...consideration of...oxidation/reduction reactions, corrosion, hydriding, gas generation, thermal effects....radiolysis, radiation damage..." In order to demonstrate compliance with the regulations, waste package designers require information on gas generation potential of the waste form.

The iritent of this specification is to ensure that gas pressure will not build up inside the container and contribute to loss of containment and dispersion of radionuclides. This specification provides a limit to initial gas pressure and information from which to index the calculation of gas pressure build-up with time due to nuclear decay and temperature changes.

The value for the maximm initial gas pressure, $150 \mathrm{kPa}(22 \mathrm{psia}$ ), was chosen because it has the following attributes: it is low enough to preclude significant stresses in the canister wall arising from internal pressurization, both initially and after the anticipated helium production from alpha decay over the containment period; also, it avoids introducing unnecessary restrictions that will not materially contribute to the overall function of the canistered waste form in the repository.

In general, an internal pressure $P$ in a cylindrical vessel of diameter $D$ and wall thickness $t$ produces tensile hoop stress of $\sigma_{y}=g D / 2 t$ and a tensile longitudinal stress of $\sigma_{L}=\mathrm{PD} / 4 t$ in the wall of the vessel $[8$ ). For a vessel made from Type $304 \mathrm{~L}$ stainless steel, the yield strength at $300^{\circ} \mathrm{C}$ would be at least $96 \mathrm{MPa}(14,000 \mathrm{psi})$ (9). The more rapid cooling of the canister wall than the bulk of the glass after pouring as well as differences in the coefficients of thermal expansion of the two materials are expected to lead to 
tensile thermal stresses approaching or exceeding the yield strength of the stainless steel [9]. In order for the stresses due to internal pressurization to be insignificant in comparison, it wouid be sufficient to limit them to a small percentage of the yield strength. If the hoop stress is limited to 10 percent of the yield strength at $500^{\circ} \mathrm{C}$ or $9.6 \mathrm{MPa}$ ( $\left.1400 \mathrm{psia}\right)$, the maximum internal pressure, based on a $1 \mathrm{~cm}$ ( $3 / 8 \mathrm{in.)}$ thick wall, would be $300 \mathrm{kPa}$ ( $44 \mathrm{psia}$ ) at $500^{\circ} \mathrm{C}$, which is equivalent to $116 \mathrm{kPa}(17 \mathrm{psia})$ at $25^{\circ} \mathrm{C}$.

The maximum pressure increase due to helium release from alpha decay after 1000 years has been calculated to be less than $7 \mathrm{kPa}$ (1 psi) [10]: therefore, an initial pressure less than about $123 \mathrm{kPa}$ (18 psia) would therefore appear to be conservative. With these guidelines, a value of about $1-1 / 2$ atmospheres, or $150 \mathrm{kPa}$ (22 psia), was chosen as conservative and practicable. In actuality, the pressure (evaluated at $25^{\circ} \mathrm{C}$ ) immediately after canister sealing is expected to be much less than $150 \mathrm{kPa}$ (22 psia), due to cooling after sealing.

\subsection{RATIONALE FOR THE SPECIFICATION FOR EXPLOSTVENESS, PYROPHORICITY, AND COMBUSTIBILITY}

This specification is needed to ensure that after closure, the canistered waste form does not explode or burn during normal repository operations and accident conditions.

The regulatory requirements as outlined in $10 \mathrm{CER} 60.135$ (b)(1) state that, "The waste package shall not contain explosive or pyrophoric materials .... in an amount that could compromise the ability of the underground facility to contribute to waste isolation or the ability of the geologic repository to satisfy the performance objectives."

The regulatory requirements on the waste package as outlined in $10 \mathrm{CFR}$ $60.135(a)(2)$ state that, "The design shall include but not be limited to consideration of...fire and explosion hazards." The waste form, as a component of the waste packages must comply with this requi rement.

\subsection{RATIONALE FOR THE ORGANIC MATERIALS SPECIFICATION}

This specification is needed to ensure that organic materials that teno to mobilize radionuclides by formation of complexes or generate gases due to radiolysis are not present in the canistered waste form in significant amounts.

The regulatory requirements on the waste package as outlined in $10 \mathrm{CFR}$ $60.135(a)(2)$ state that, "The design shall include but not be limited to consideration of the following factors: ...gas generation, radiolysis, radionuclide retardation, leaching..." The waste form, as a component of the waste package must be assessed for compliance. 


\subsection{RATIONALE EOR THE CHEMICAL COMPATIBILITY SPECIFICATION}

The specification is required to assure that the canister can be safely hanciled during storage, transportation, and repository operations, and to provide needed data for assessment of long-term performance of the waste package components.

The regulatory rer... rements on the waste package as outlined in 10 CrR $60.135(b)(1)$ state that "The waste package shall not contain.... chemically reactive materials in an amount that could compromise the ability of the underground facility to contribute to waste isolation or the ability of the geologic repository to satisfy the performance objectives."

\subsection{RATIONALE FOR THE SUBCRITICALITY SPECIFICATION}

The regulatory requi rements as outlined in $10 \mathrm{CFR} 60.131$ (b)(7) state that, "The calculated effective multiplication factor ( $k_{0}, g$ ) must be sufficiently below unity, to show at least a 5 percent margin, after allowance for the bias in the method of calculation and the uncertainty in the experiments used to evaluate the method of calculation."

\subsection{RATIONALE FOR THE SPECIFICATIONS EOR WEIGET, LENGTH, DIAMETER, AND} OVERALL DIMENSIONS

The specifications on weight, length, and diameter of the canistered waste form are needed for storage, shipping, and repository design. The overall dimensions of the canistered waste form must be such that (1) no forcing is required to place it in the disposal package container to prevent damage to the inside of the container and (2) there is compatibility with container geometry.

\subsection{RATIONALE FOR THE DROP TEST}

This specification is intended to demonstrate that the canistered waste form can withstand severe physical impact without breaching. By requiring that the canistered waste form pass a performance (drop) test without breaching, this specification obviates the need for establishing detailed specifications on the material properties of the canister and the waste form necessary to describe the radionuclide source term associated with the possible breach of a canister as a result of a drop accident.

The drop height of $7 \mathrm{~m}$ for the repository is based on the maximm lift design height during repository operation. 
WHC-EP-0522

3.13 RATIONALE FOR THE HANDLING FEATURES SPECIFICATION

This specification reflects the lifting and handling requirements necessary for compatibility with current waste package concepts. The specification allows the waste producer maximu flexibility in design of the canister handling arrangements, while ensuring that there are adequate handling features for repository design and operational purposes. This specification essentially limits the number of remotely operated lifting and handling grapples required at the repository.

4. RATIONALE FOR TIE QUALITY ASSURANCE SPECIFICATION

All activities relevant to licensing of a repository must be conducted in accordance with appropriate quality assurance control.s. The office of Civilian Radioactive Waste Management's quality assurance policies and requirements applicable to the high-level waste form production are described in the referenced document. High-level waste form production activities must be conducted in comoliance with the quality assurance policies and requirements established by the Office of Civilian Radioactive Waste Management. 


\title{
APPENDIX B
}

\begin{abstract}
REEERENCES FOR WASTE ACCEPTANCE PRELIMINARY SPECIFICATIONS
\end{abstract} FOR VITRIEIED HIGH-LEVEL WASTE FORMS

[1] U.S. Department of Energy, Office of Civilian Radioactive Waste Management, Waste Management System Requirements Document, Volume I: General Systems Requirements, Volume IV: Mined Geologic Disposal System, Latest Revision.

[2] U.S. Nuclear Regulatory Commission, $10 \mathrm{CFR}$ Part 60, Disposal of Aigh-Level Radioactive Wastes in Geologic Repositories-Technical Criteria.

(3) Jantzen, C.M., "Nuclear Waste Produnt Consistency Test Method Version 3.0," WSRC-TR-90-539, Savannah River Laboratory, November, 1990.

(4) U.S. Department of Energy, Envi ronmental Assessment-Waste Form Selection for SRP High-Level Waste, USDOE Report DOE/EA 0179, Washington, DC (1982).

[5] Bickford, D.F. and Jantzen, C.M., "Devitrification Behavior: of SRL Defense Waste Glass," Scientific Basis for Nuclear Waste Management: VII, G.L. MCVay (ed.), Elsevier, NY, 557-66 (1984).

[6] Light, G.M.., "Investigation of Nondestructive Evaluation Techniques for Inspection of Nuclear Waste Canisters," Southwest Research Institute Report on Project 7588, February, 1984.

(7) U.S. Department of Energy, "Site Characterization Plan, Yucca Mountain Site," DOE/FW-0199, December, 1988.

[8] Popow, E.P., Mechanics of Materials, Prentice-Ball, Englewood Cliffs, NJ, pp. 225-8 (1959).

(9] ASM Metals Handbook, Ninth Edition, Vol. 3, ASM International, Materials Park, OH, p. 192 (1980).

[10] Baxter, R.G., "Description of Defense Waste Processing Facility Reference Waste Form and Canister," DP-1606, Rev. 2, E.I. du Pont de Nemours and Co., Savannah River Plant, Aiken, SC, p. 16 (1983). 
WHC-EP-0522

This page intentionally left blank. 
WHC-EP-0522

APPENDIX C

TABLE FOR SECOND LEVEL OF GENERAL SUMMARY CHARACTERIZATION OF TECHNOLOGY (ACTIVITY) STRATEGIES 
WHC-EP-0522

This page intentionally left blank. 
Table C-1. Second-Level of General Summary: Technology Strategies for Complying with Acceptance Specifications. (sheet 1 of 4)

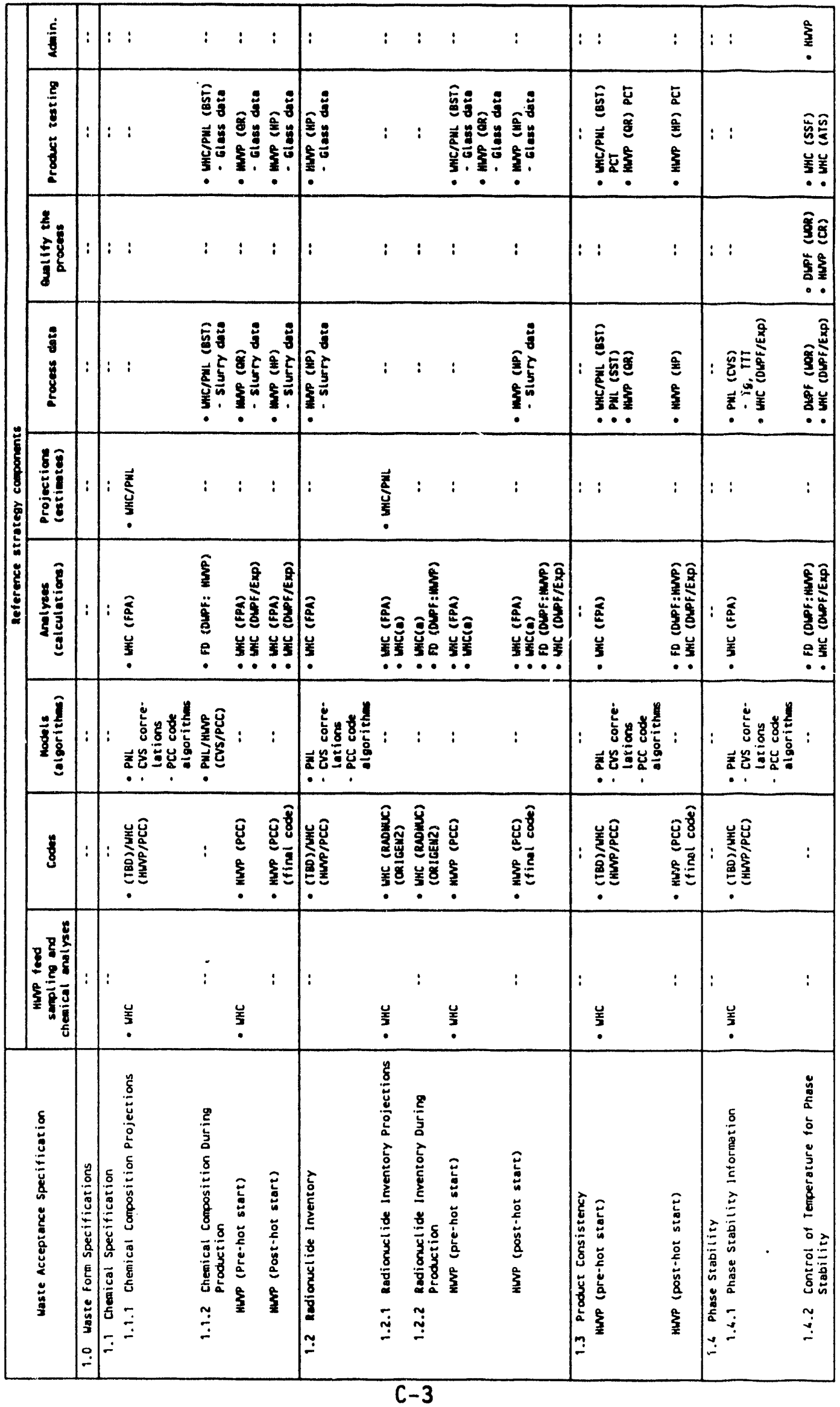


Table C-1. Second-Level of Generai Summary: Technology Strategies for Complying with Acceptance Specifications. (sheet 2 of 4)

\begin{tabular}{|c|c|c|c|c|c|c|c|c|c|c|c|}
\hline$\dot{\varepsilon}$ & 毫毫 & $\mid$ & 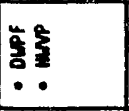 & 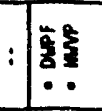 & | & | & | & : & : & |: : & : \\
\hline 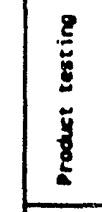 & $::$ & : & $: \quad::$ & : & : & : & : & 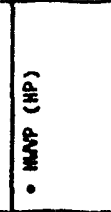 & 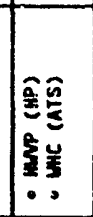 & $:$ : & 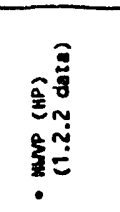 \\
\hline 每 & $:$ : & 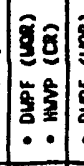 & 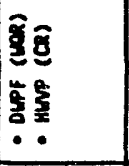 & : & 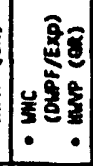 & 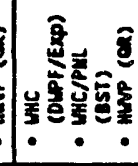 & 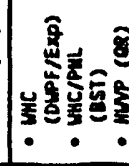 & 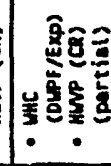 & 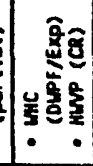 & : : & : \\
\hline 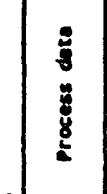 & $:::$ & 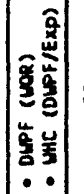 & $: \quad: \quad:$ & :: : & : & : & : & $:$ & $\mid$ & : : & 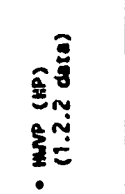 \\
\hline$\frac{1}{8}$ & : & $:$ & $: \quad::$ & $::$ & : & : & : : & : & : & 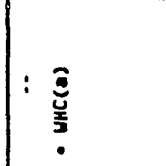 & : \\
\hline$\frac{\bar{z}}{\frac{z}{2}}$ & : & 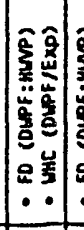 & & 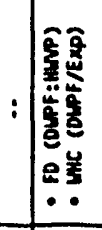 & 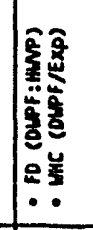 & 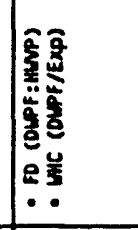 & 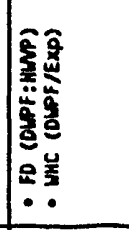 & 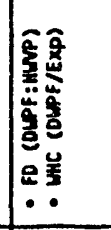 & 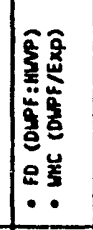 & 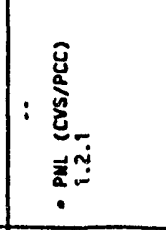 & 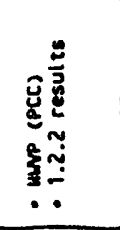 \\
\hline 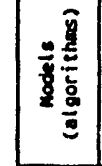 & : & : & $: \quad::$ & : : : & : & : & |: & : & : & : & \\
\hline 8 & $::$ & $:$ & $: \quad::$ & $:$ & : & $:$ & : & : & $:$ & 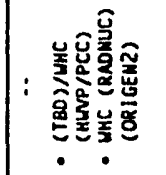 & 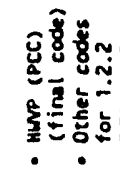 \\
\hline 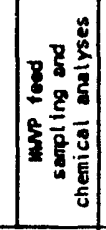 & & : & $: \quad: \quad:$ & |: & |: & : & $:$ & : & : & : & : \\
\hline 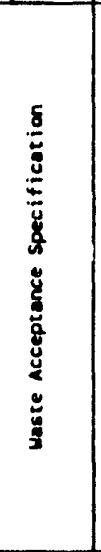 & 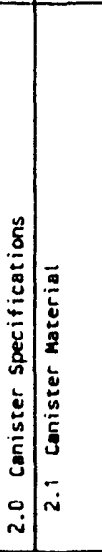 & 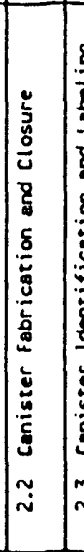 & 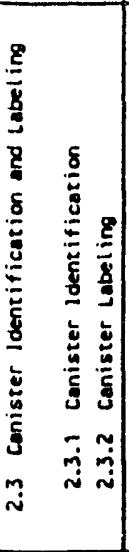 & 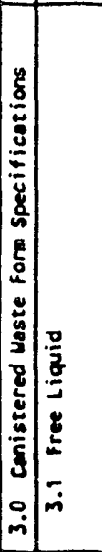 & 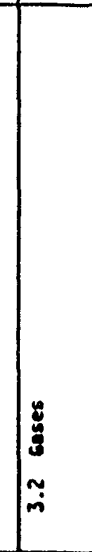 & 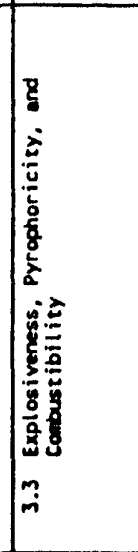 & 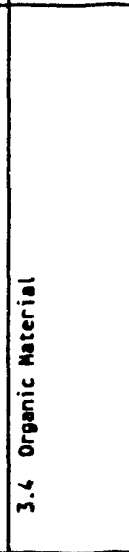 & 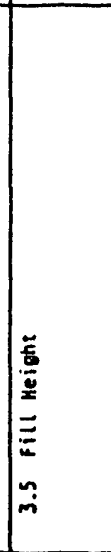 & 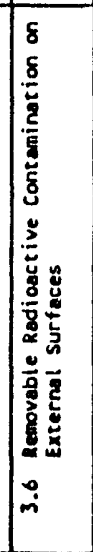 & 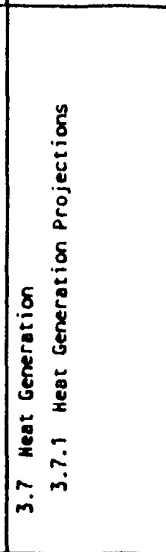 & 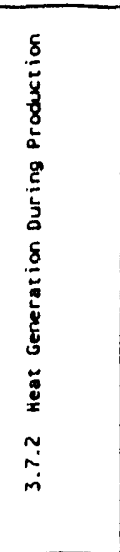 \\
\hline
\end{tabular}


Table C-1. Second-Level of General Summary: Technology Strategies for Complying with Acceptance Specifications. (sheet 3 of 4)

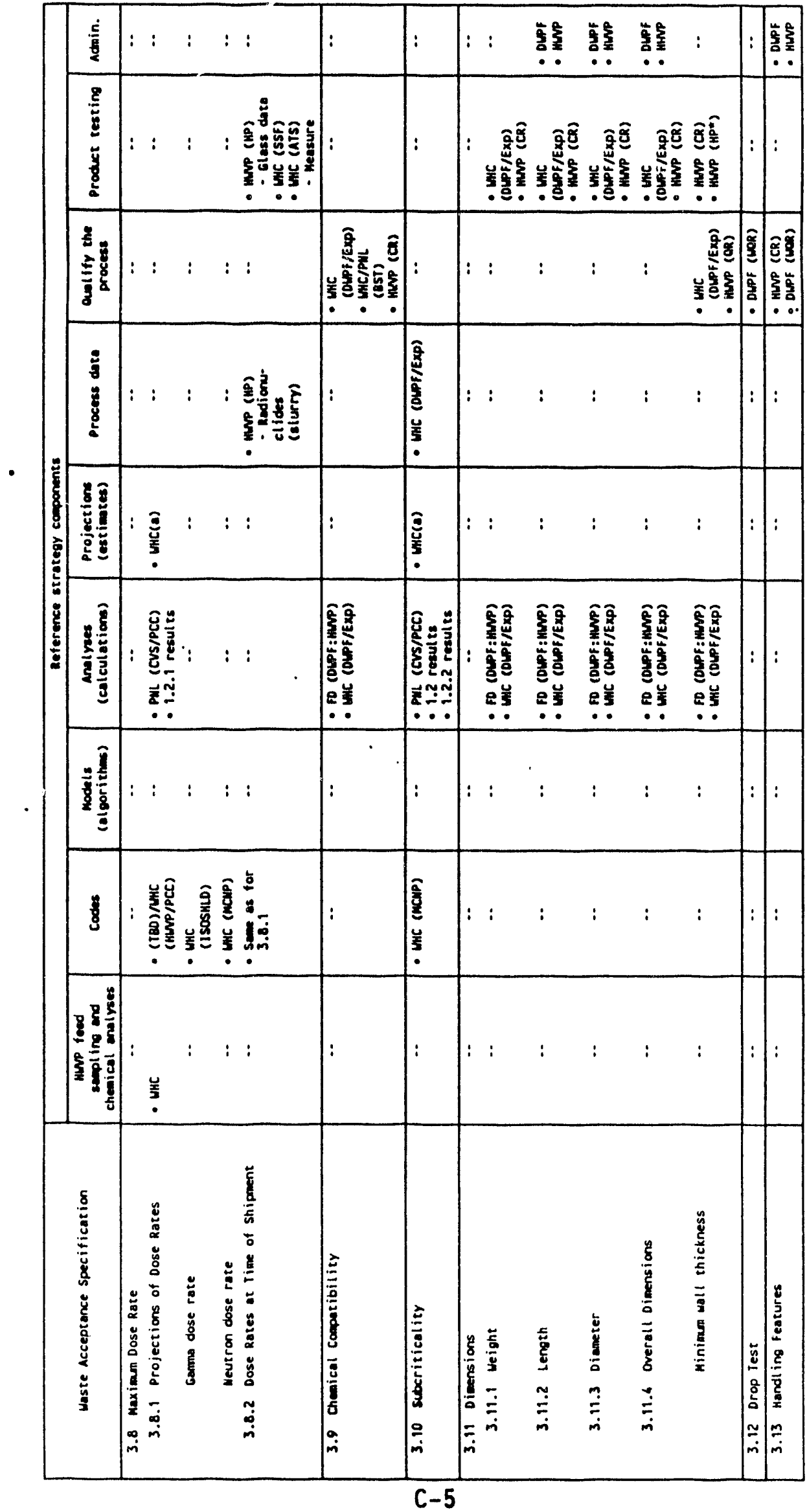


Table C-1. Second-Level of General Summary: Technology Strategies for Complying with Acceptance Specifications. (sheet 4 of 4 )
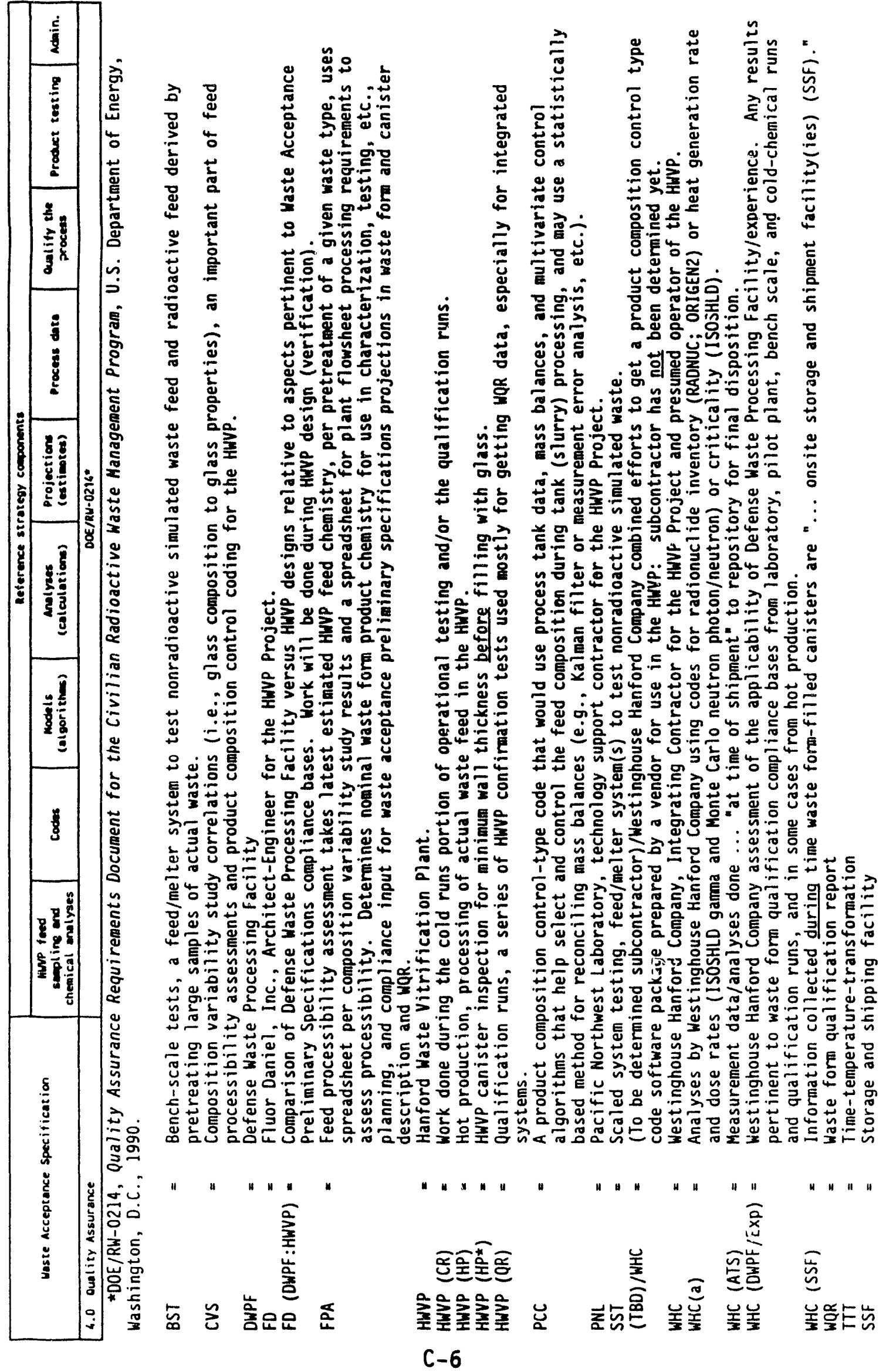
WHC-EP-0522

APPENDIX D

DETAILED SUMMARIES OF TECHNOLOGY STRATEGIES AND ASSOCIATED SCHEDULES

FOR COMPLYING WITH THE ACCEPTANCE SPECIFICATIONS 
Acronym Definitions for Figure D-1

A-E Architect-Engineer

ASTM American Society of Testing Materials

CVS composition variability study

DST double-shell tank

DWPS Defense Waste Processing Facility

Fluor Fluor Daniel, Inc.

HLW high-level waste

HWVP Henford Waste Vitrification Plant

NA not applicable

NCAW neutral:zed current acid waste

PCC

PCT

PNL

QA

QCR

TTT

TWRS

WAPA

WAPS

WBS

WCP

WFCD

WFQ

product consistency code

product consistency test

Pacific Northwest Laboratory

quality assurance

qualified composition region

time-temperature-transformation

Tank Waste Remediation System

waste acceptance process activity

waste acceptance preliminary specifications

work breakdown structure

waste compliance plan

waste form and canister description

waste form qualification

WHC

WQR

Westinghouse Hanford Company

WSRC

waste qualification report

Westinghouse Savannah River Company 
WHC-EP-0522

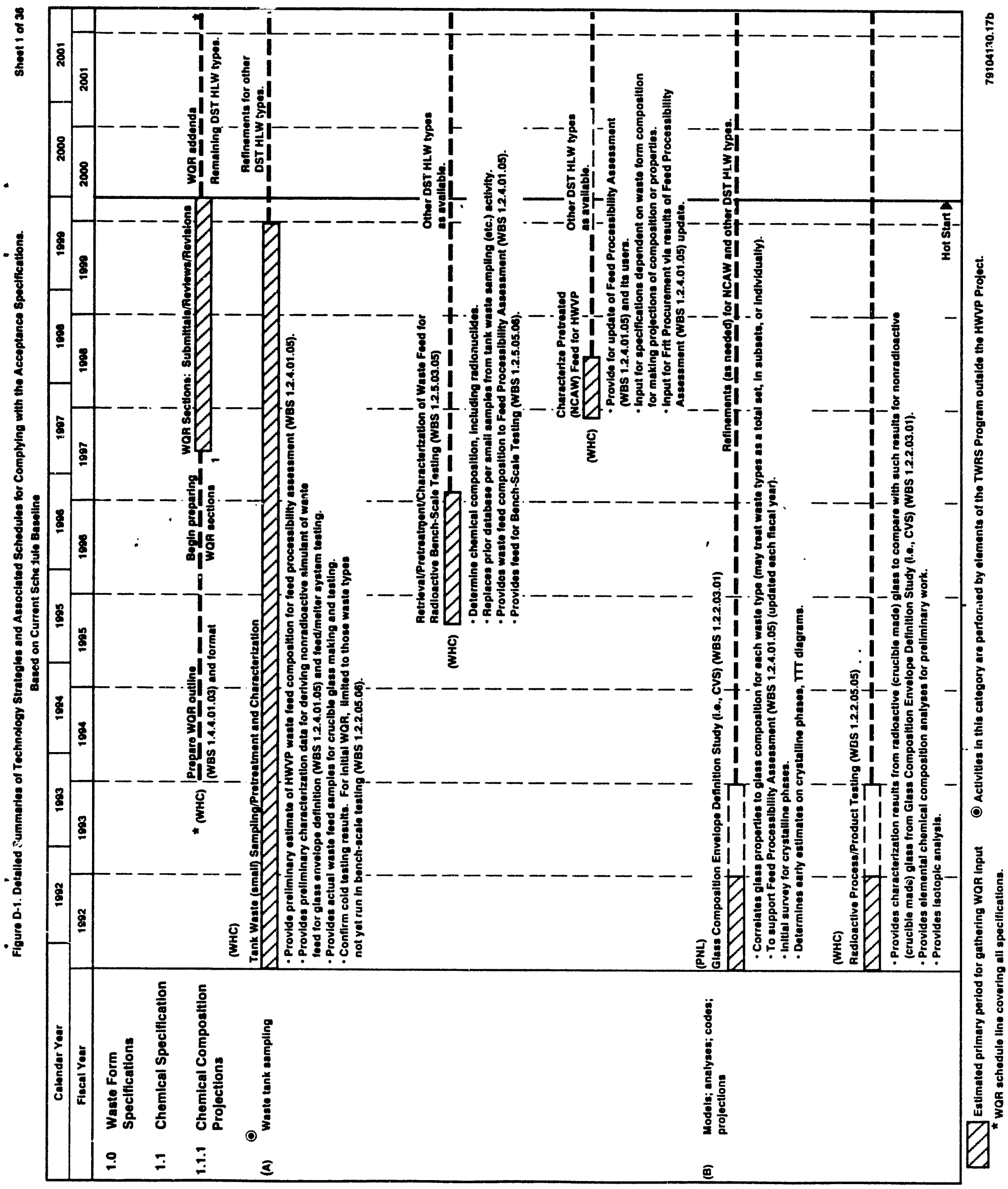


WHC-EP-0522

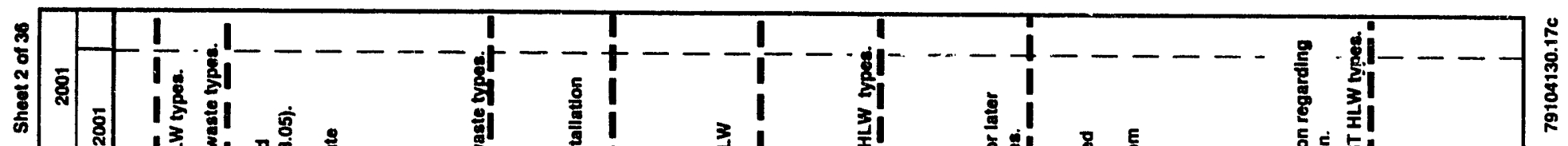

尊

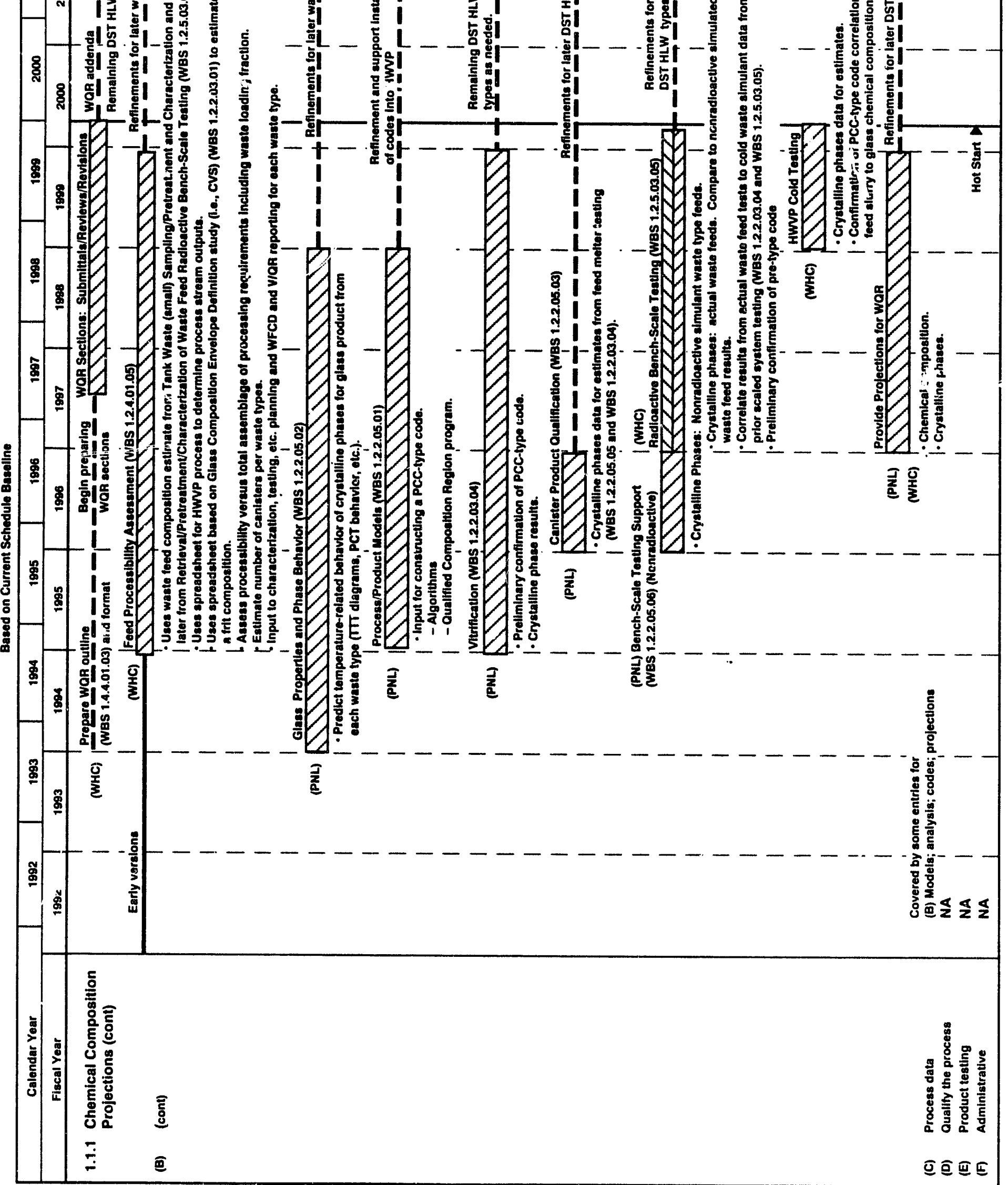


WHC-EP-0522

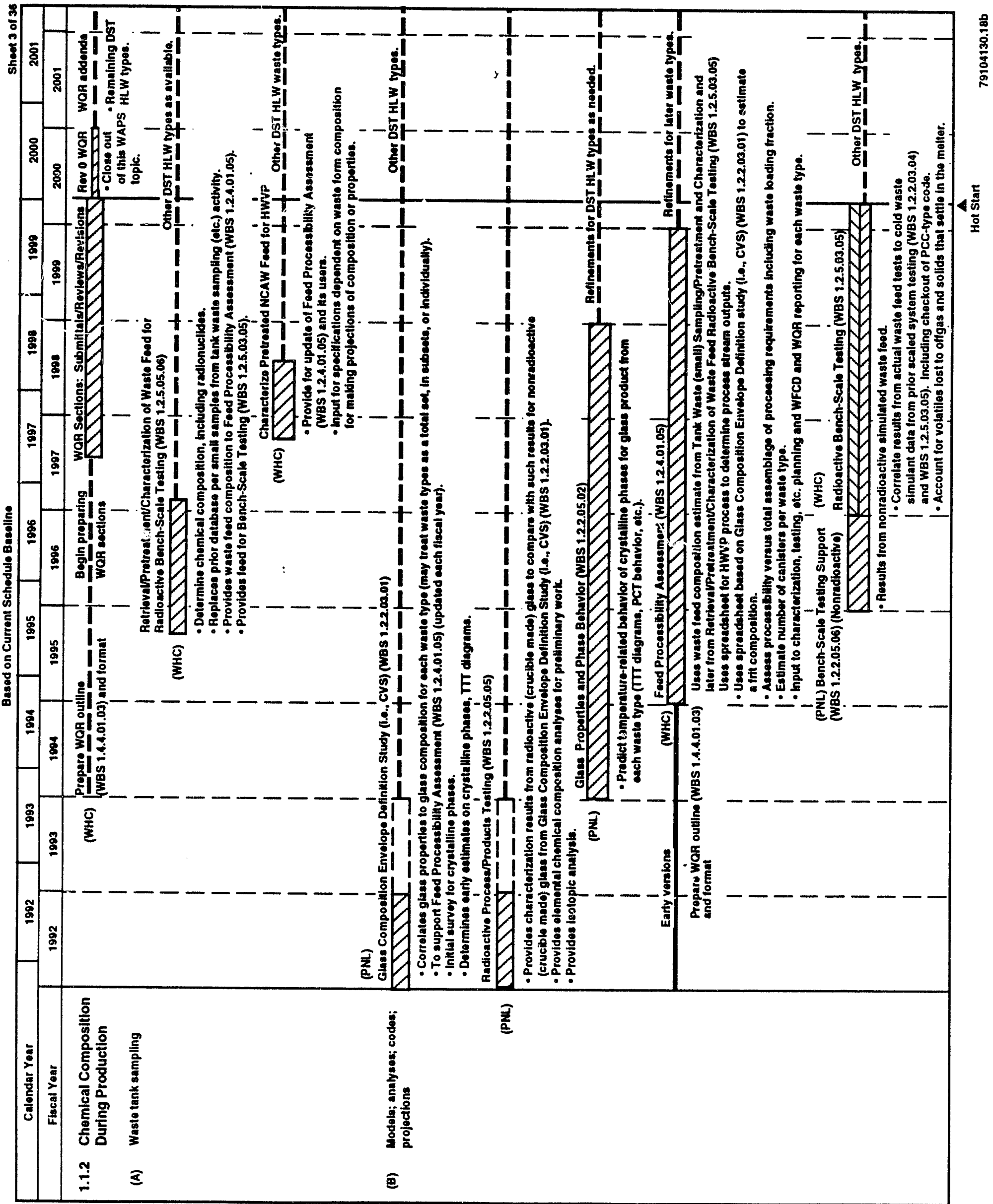


WHC-EP-0522

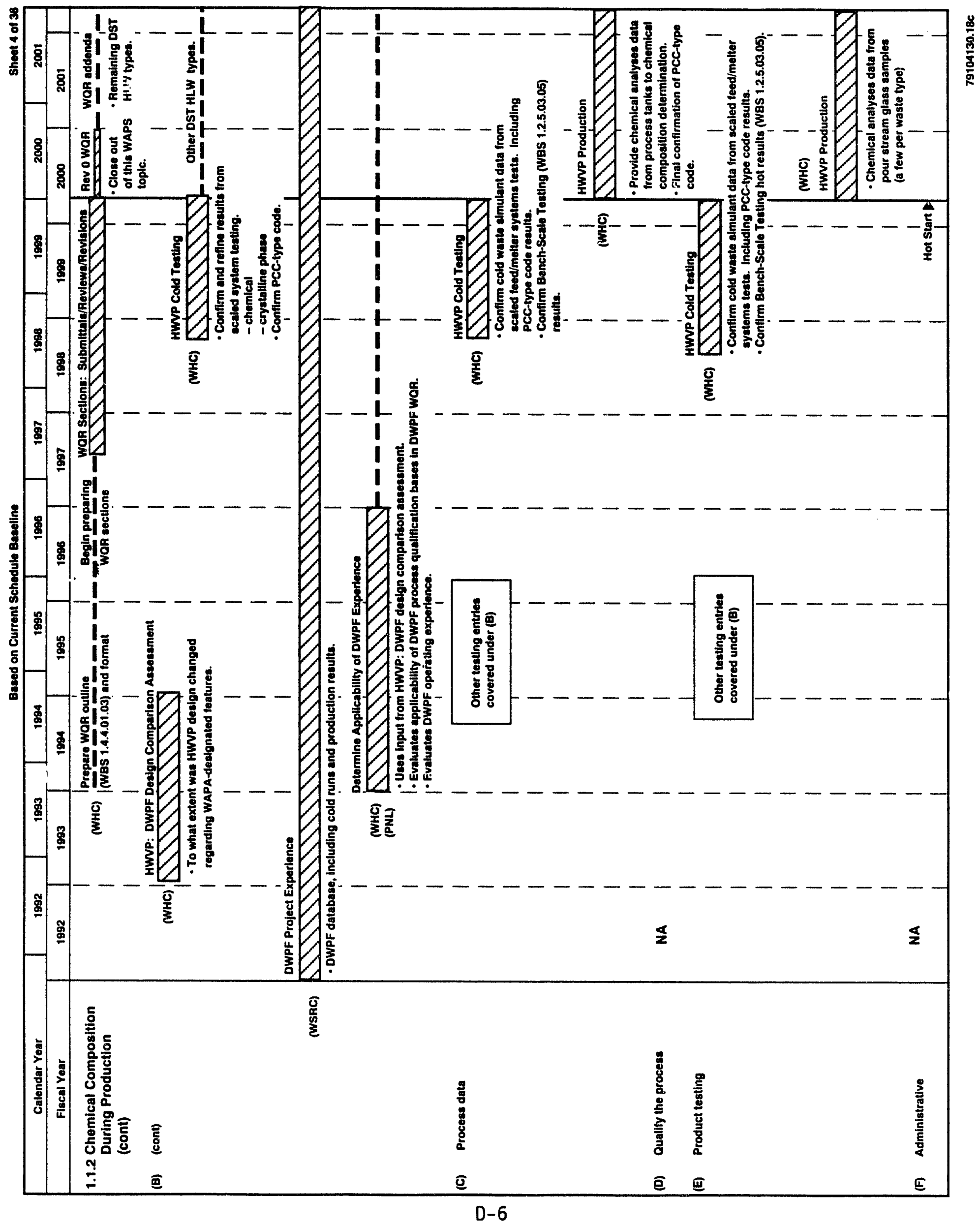


WHC-EP-0522

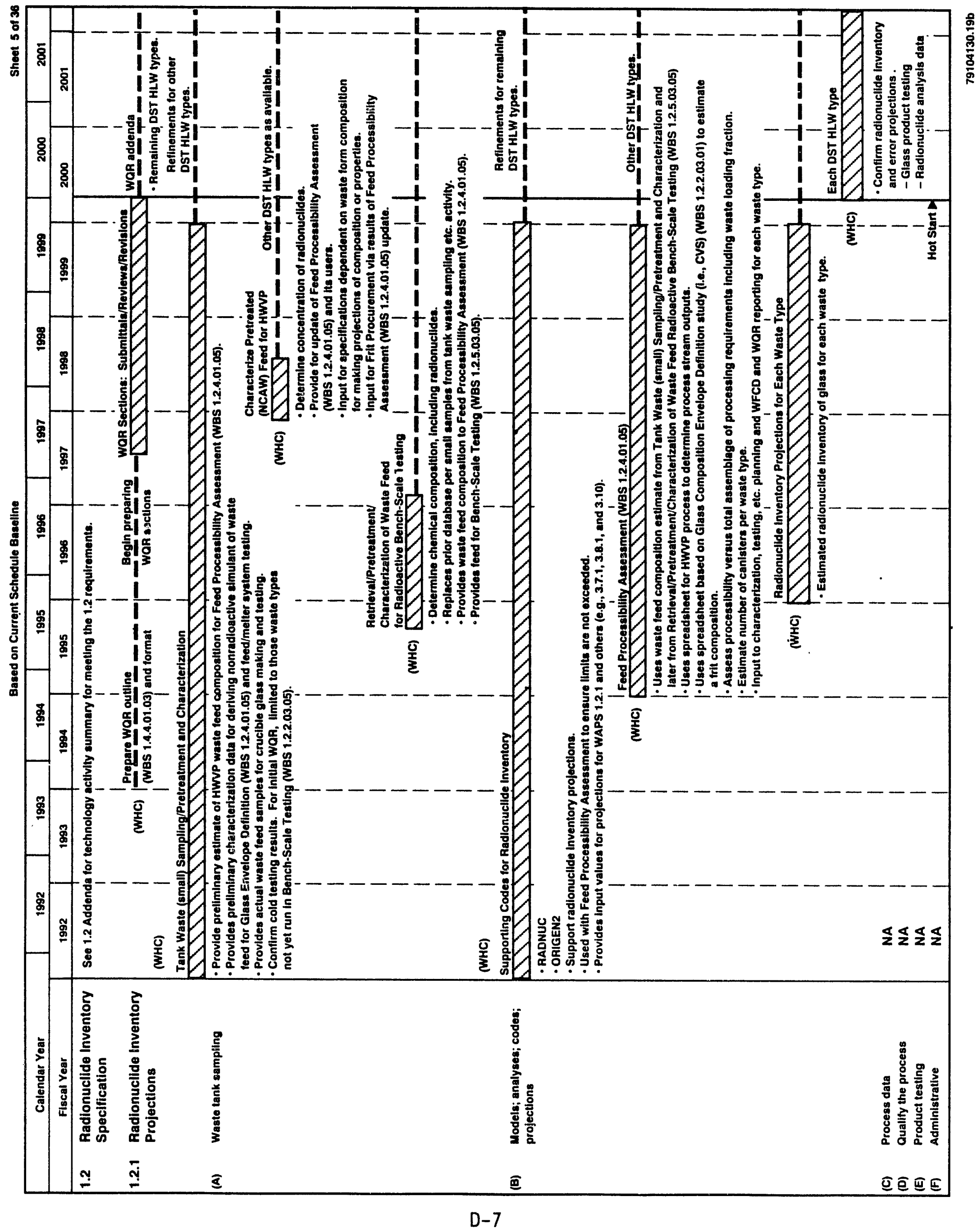


WHC-EP-0522

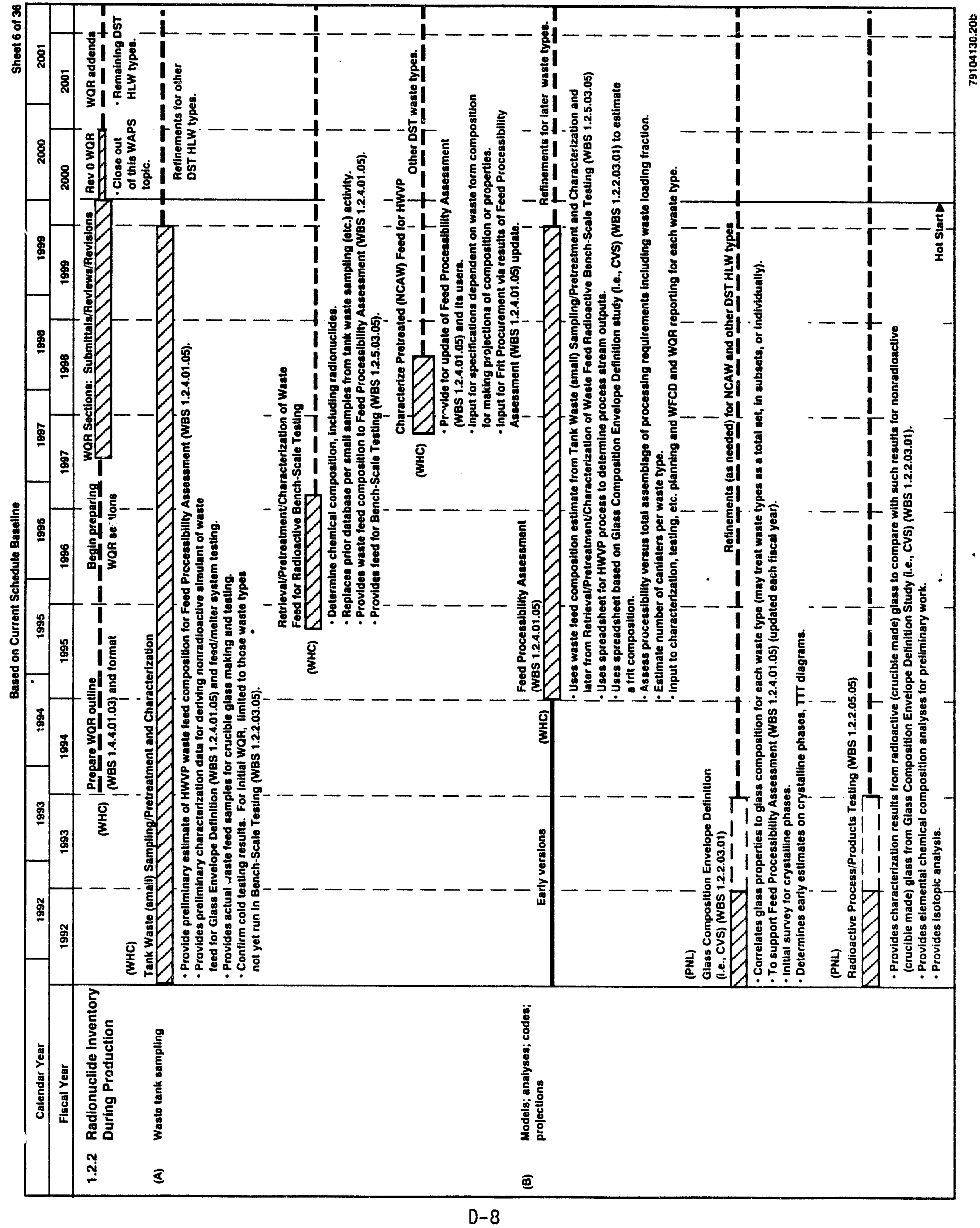


WHC-EP-0522

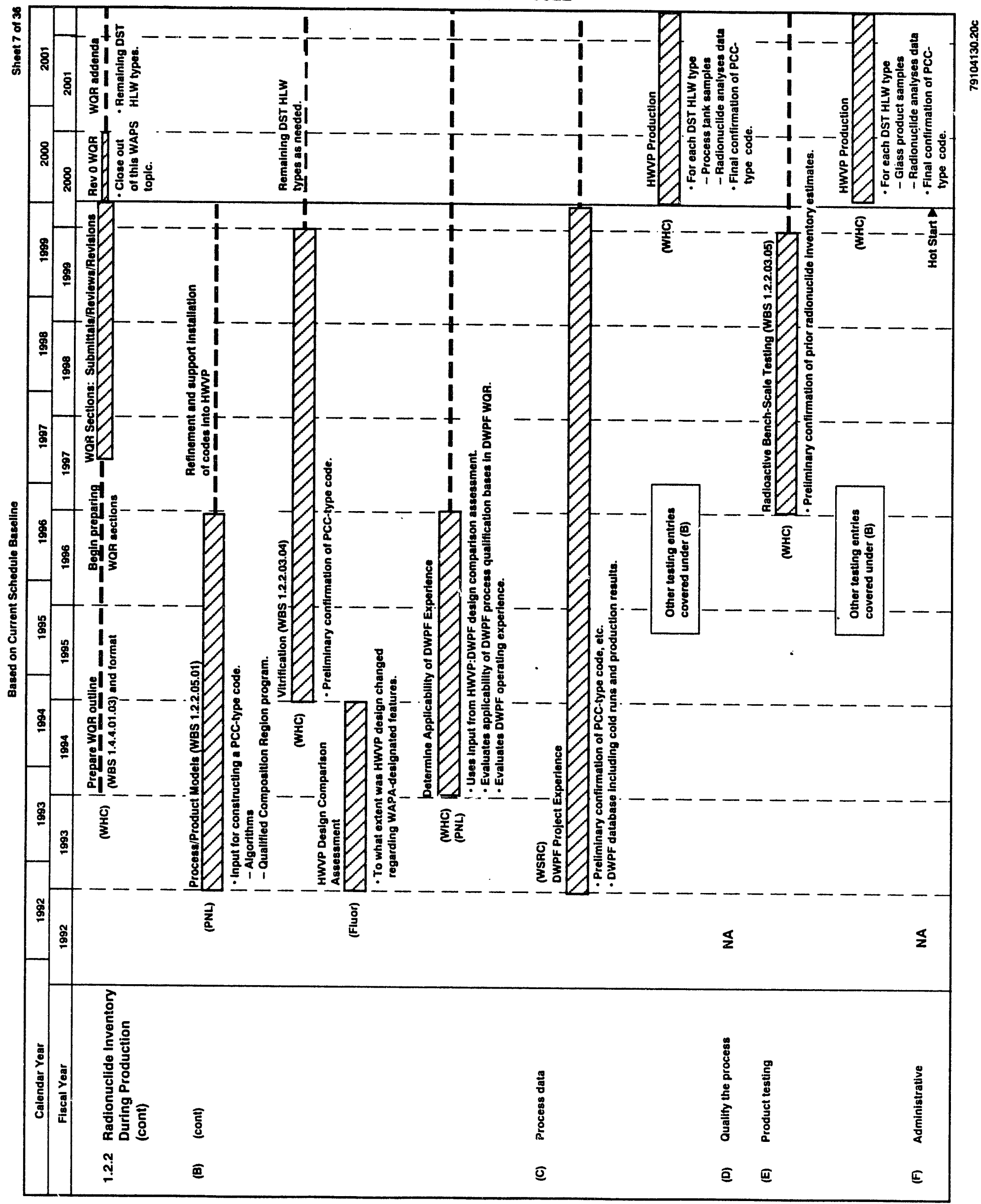

D-9 


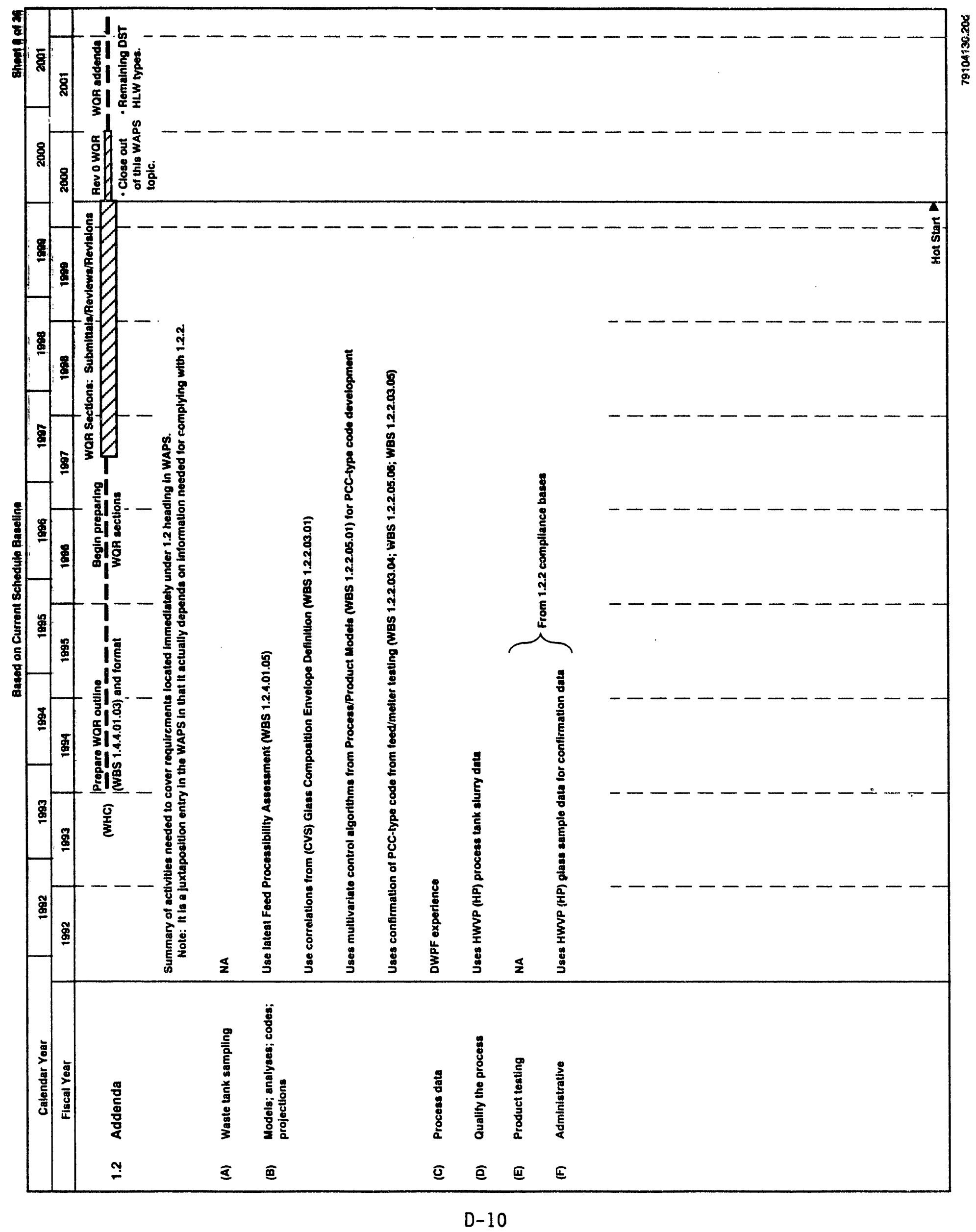


WHC-EP-0522

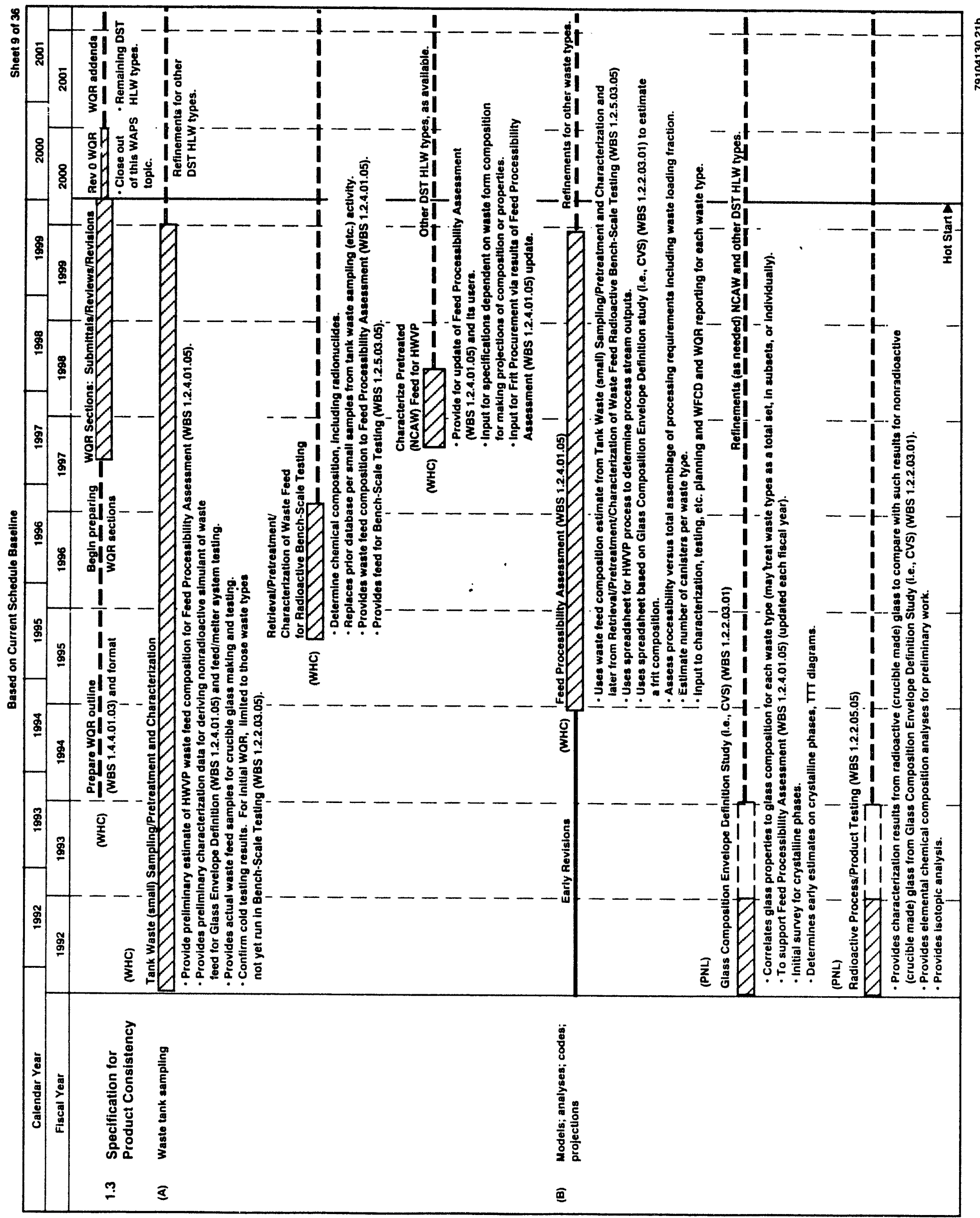

D-11 
WHC-EP-0522

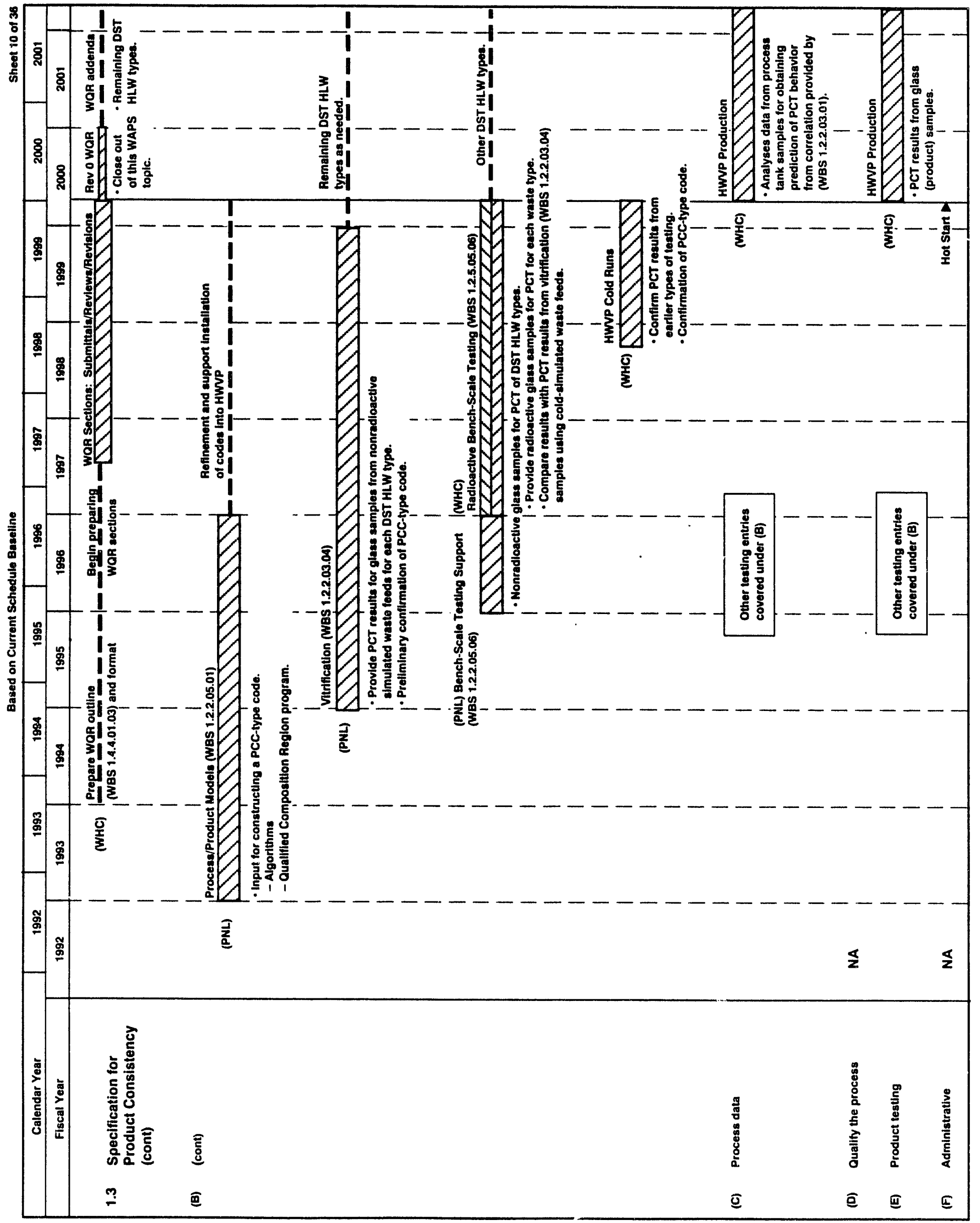

D-12 
WHC-EP-0522

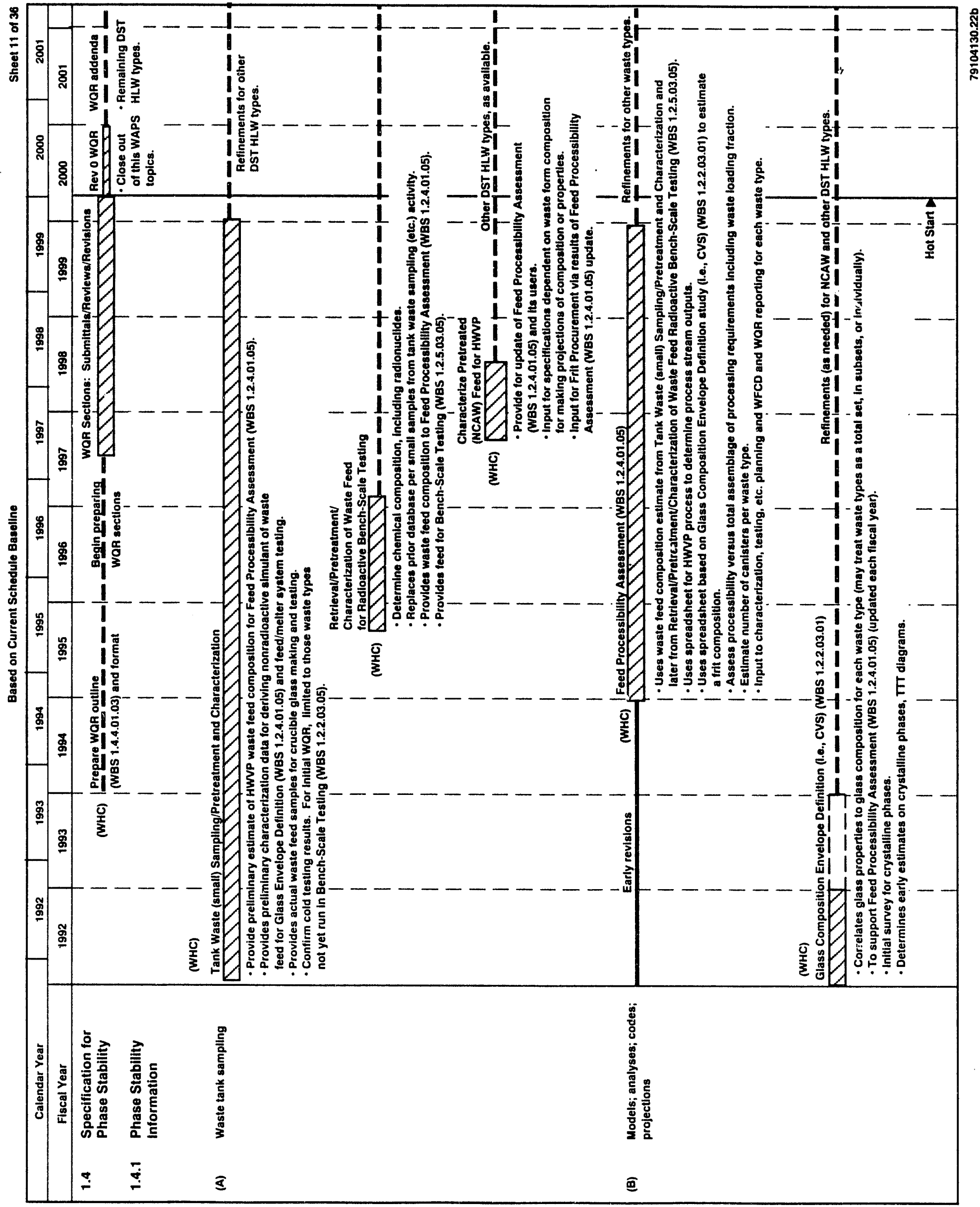

D-13 


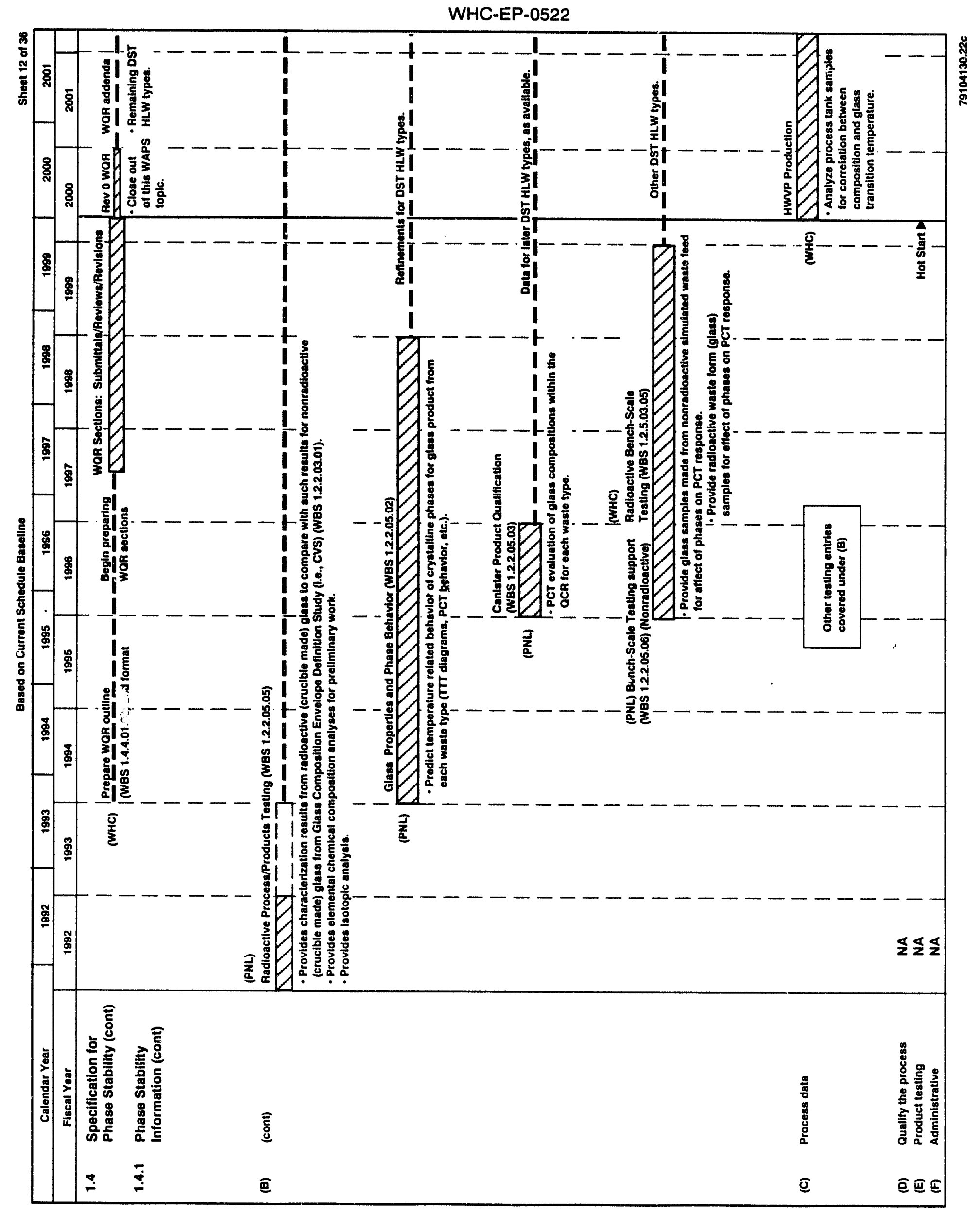

D-14 
WHC-EP-0522

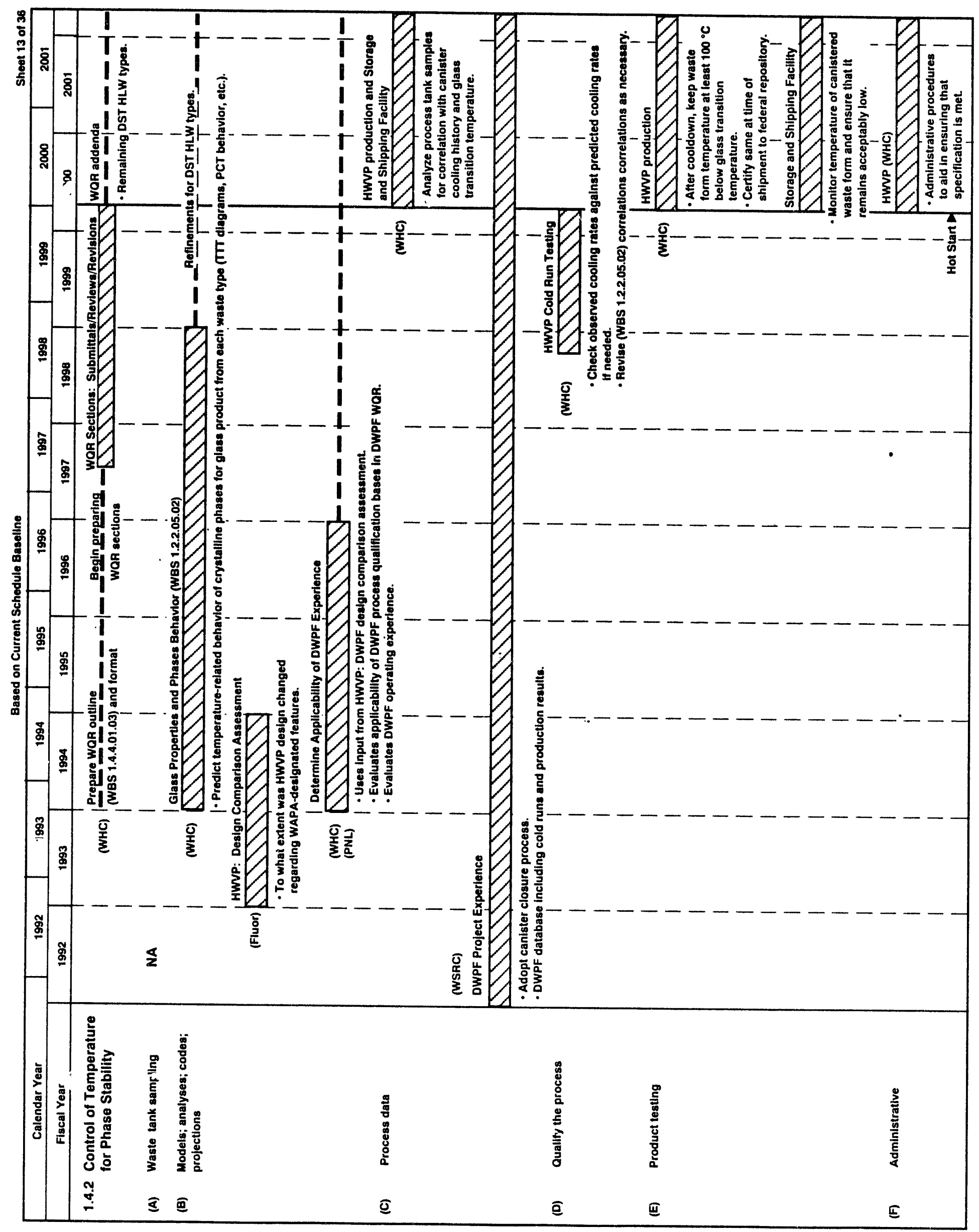




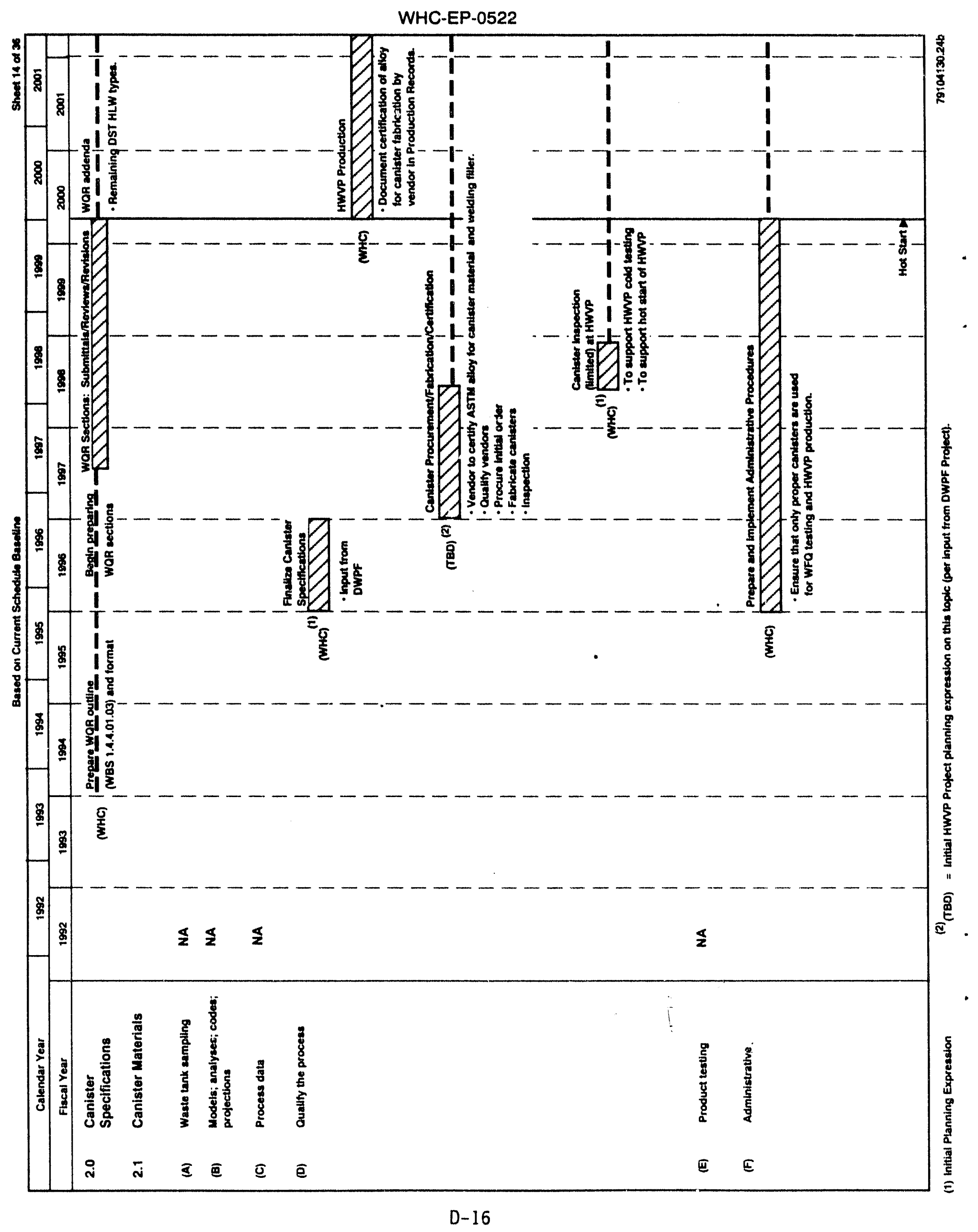


WHC-EP-0522

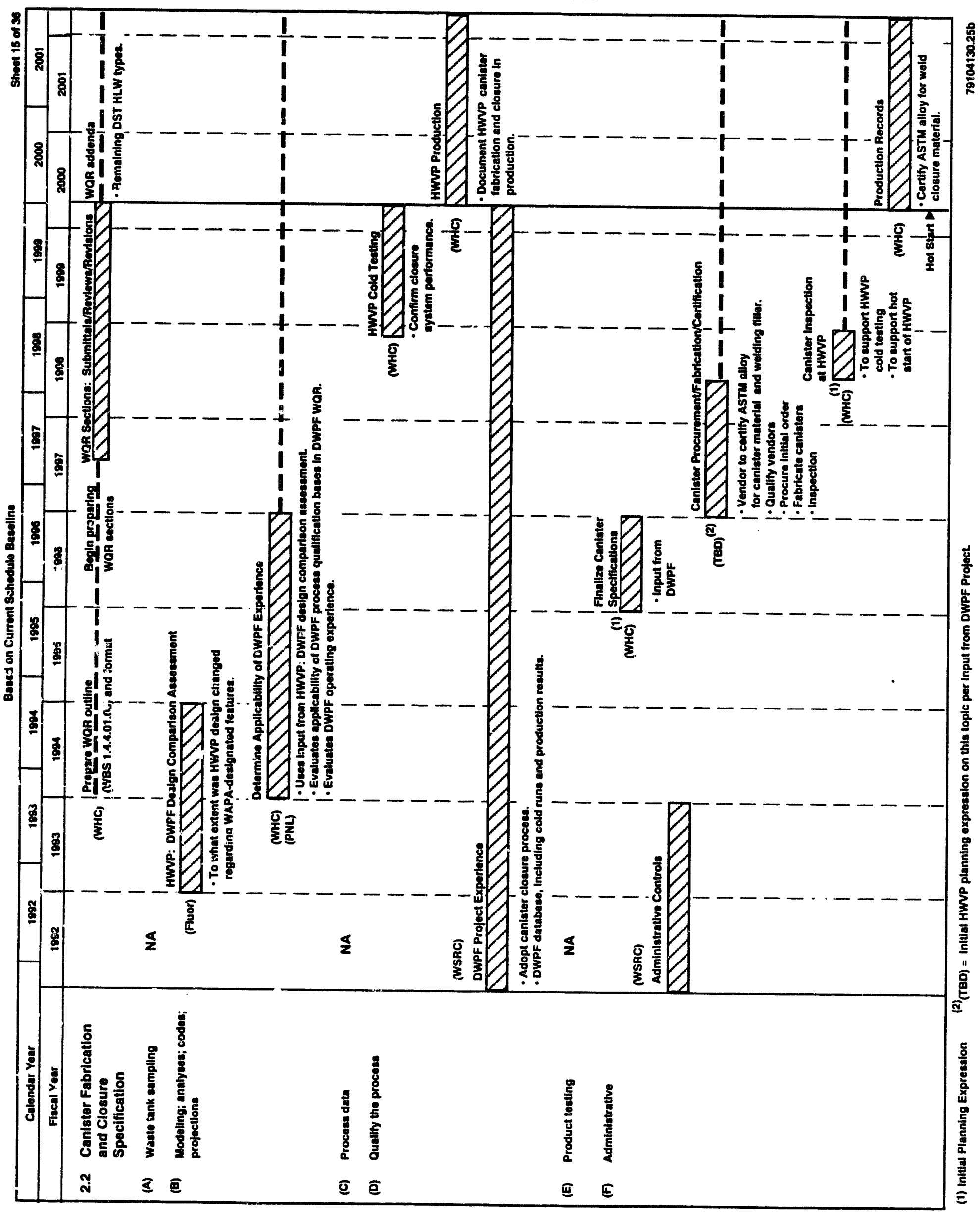


WHC-EP-0522

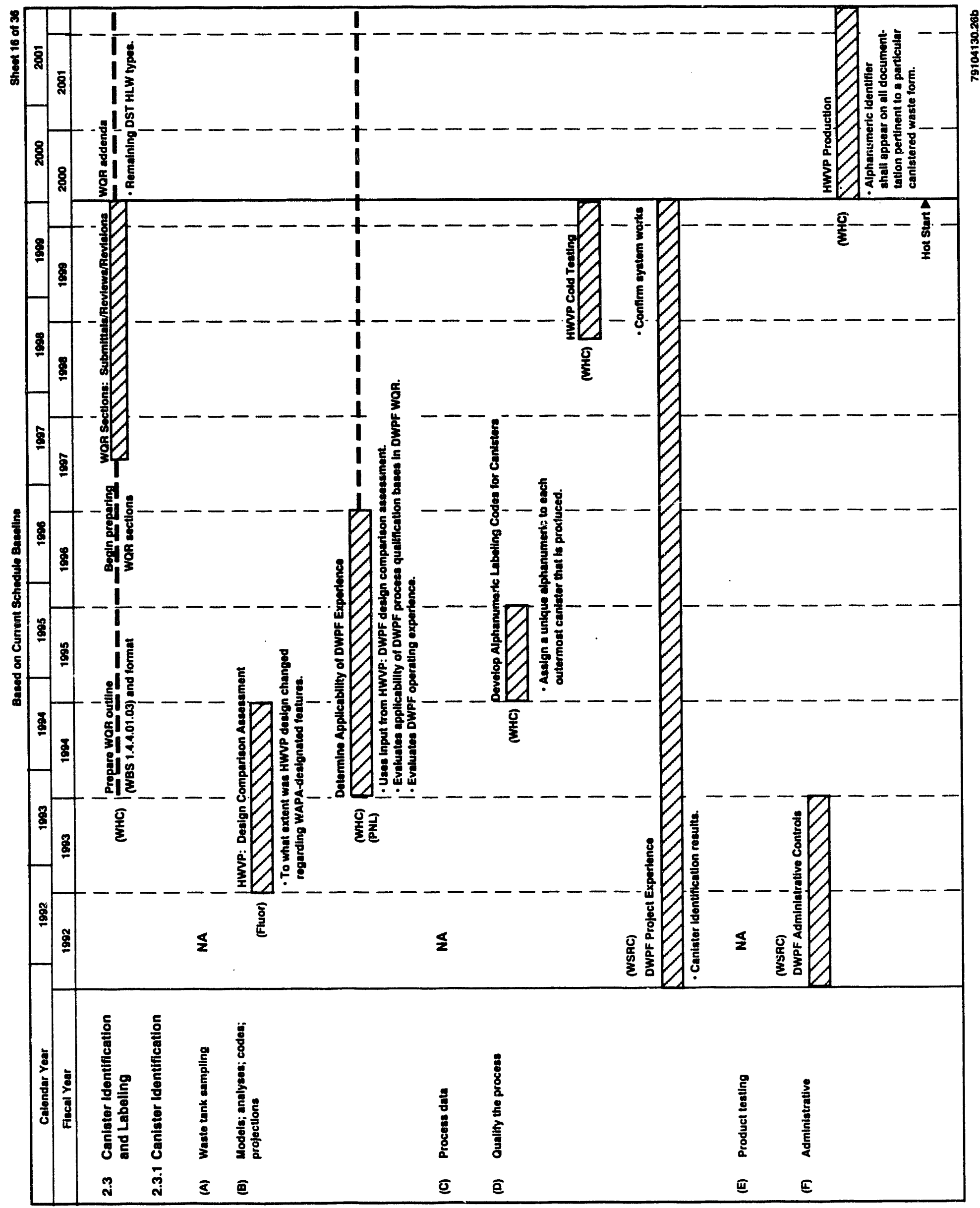


WHC-EP-0522

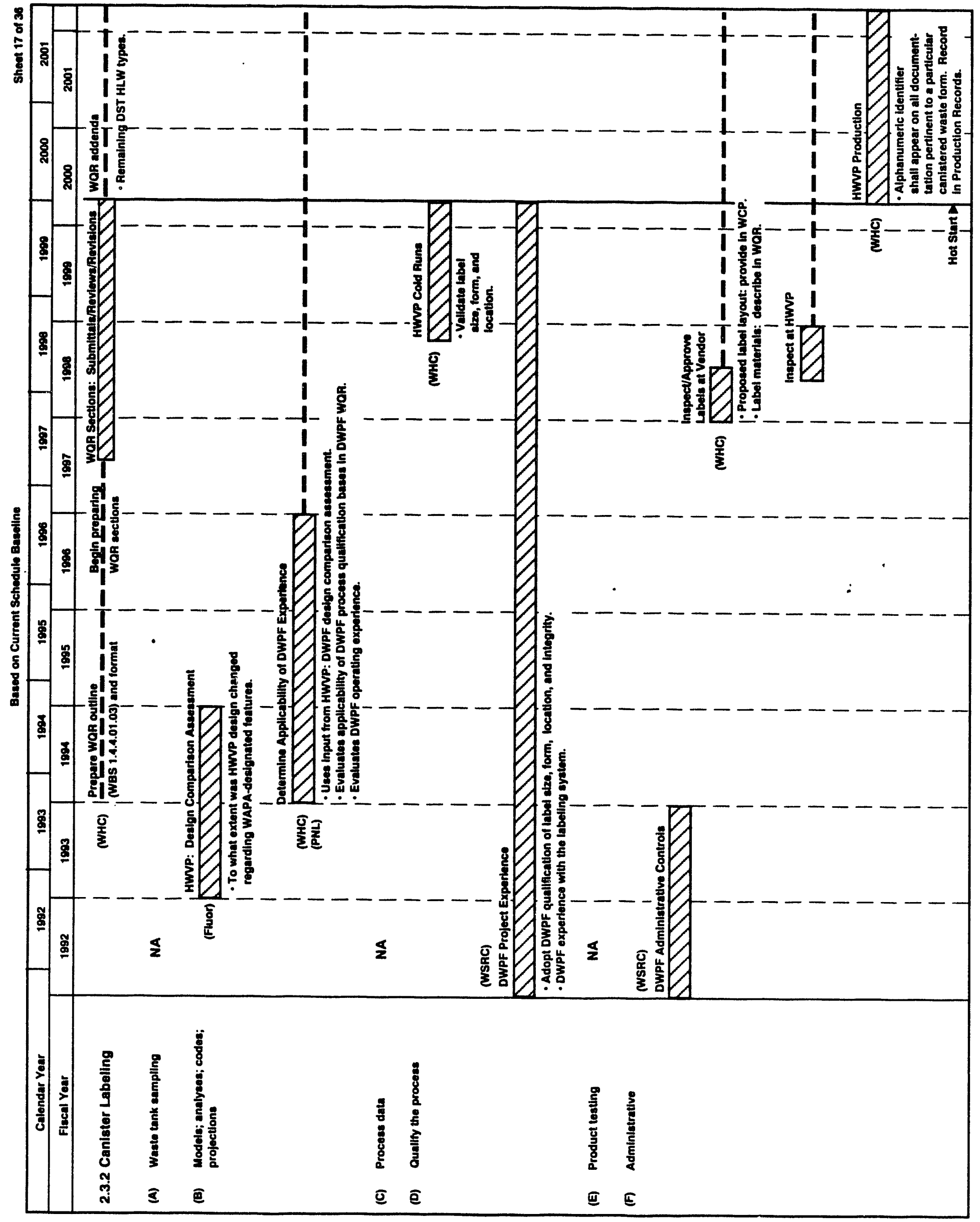


WHC-EP-0522

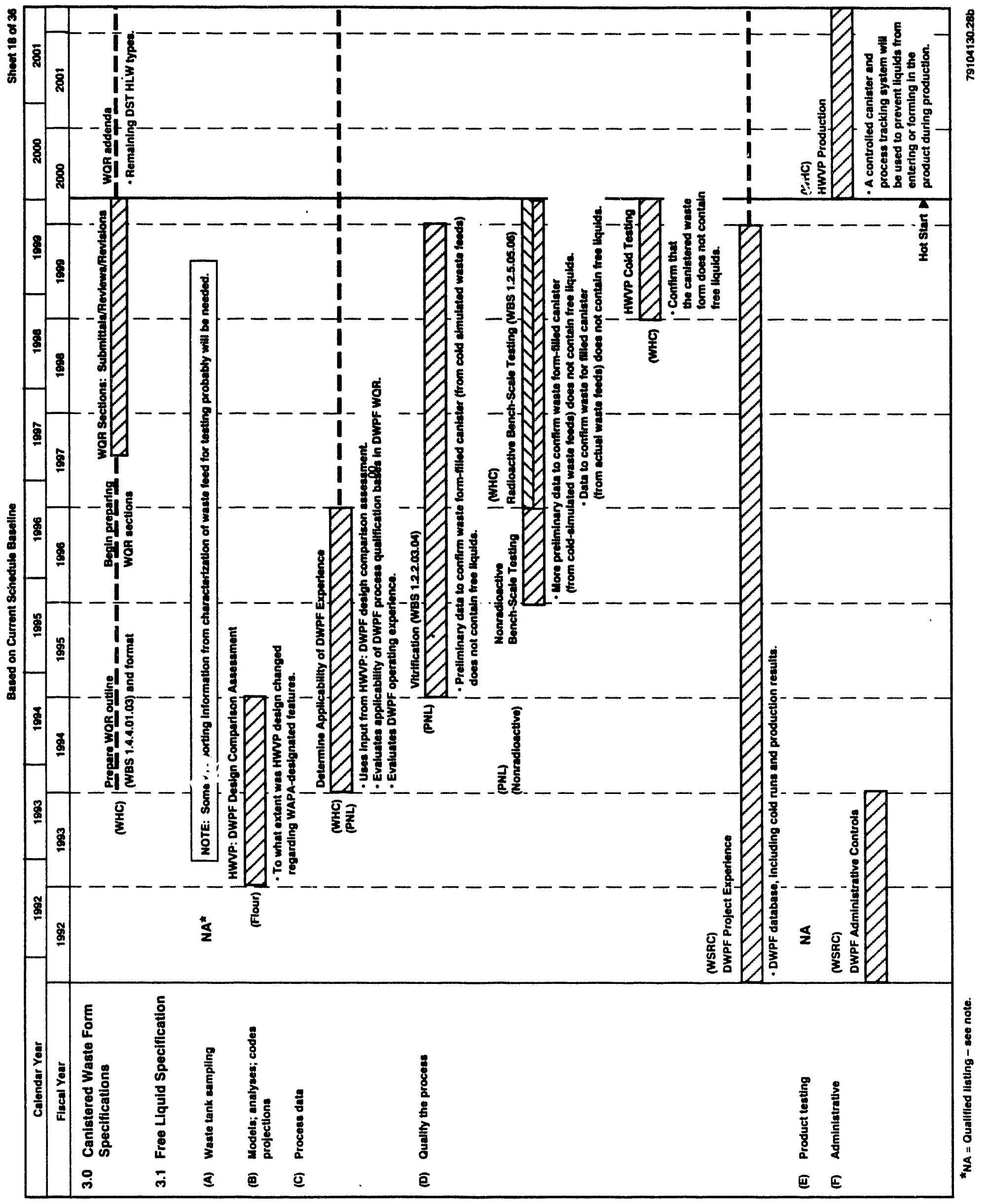


WHC-EP-0522

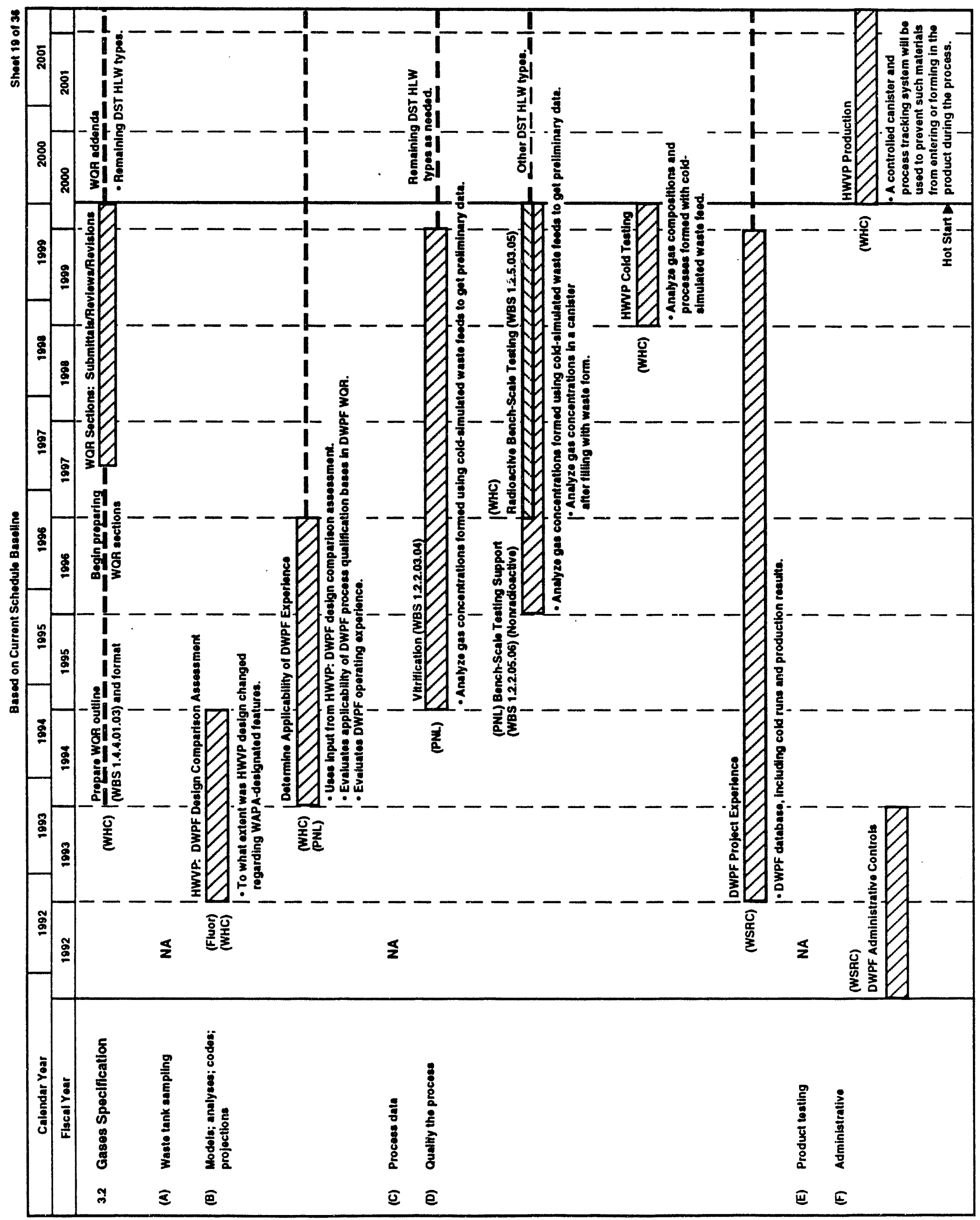


WHC-EP-0522

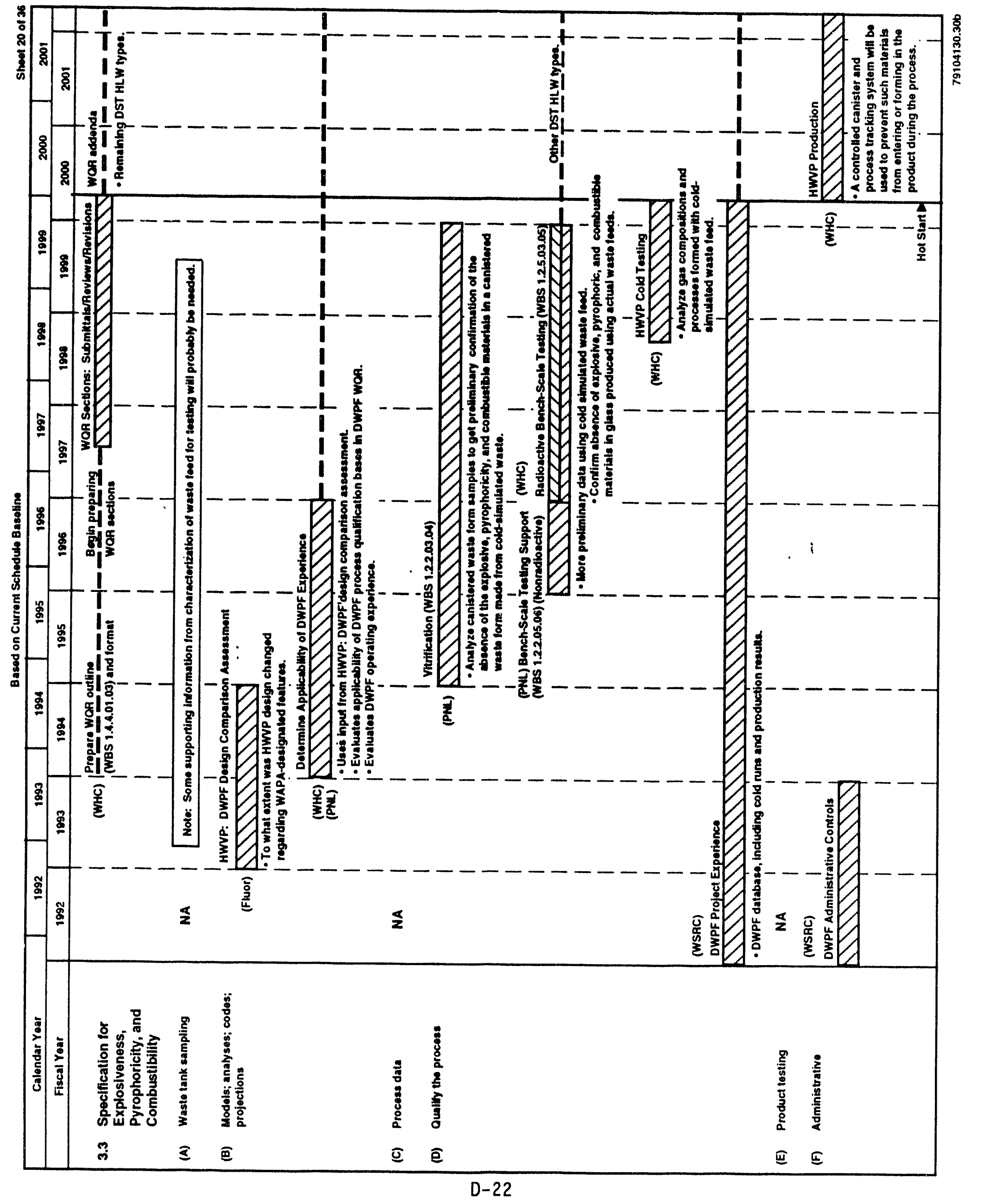


WHC-EP-0522

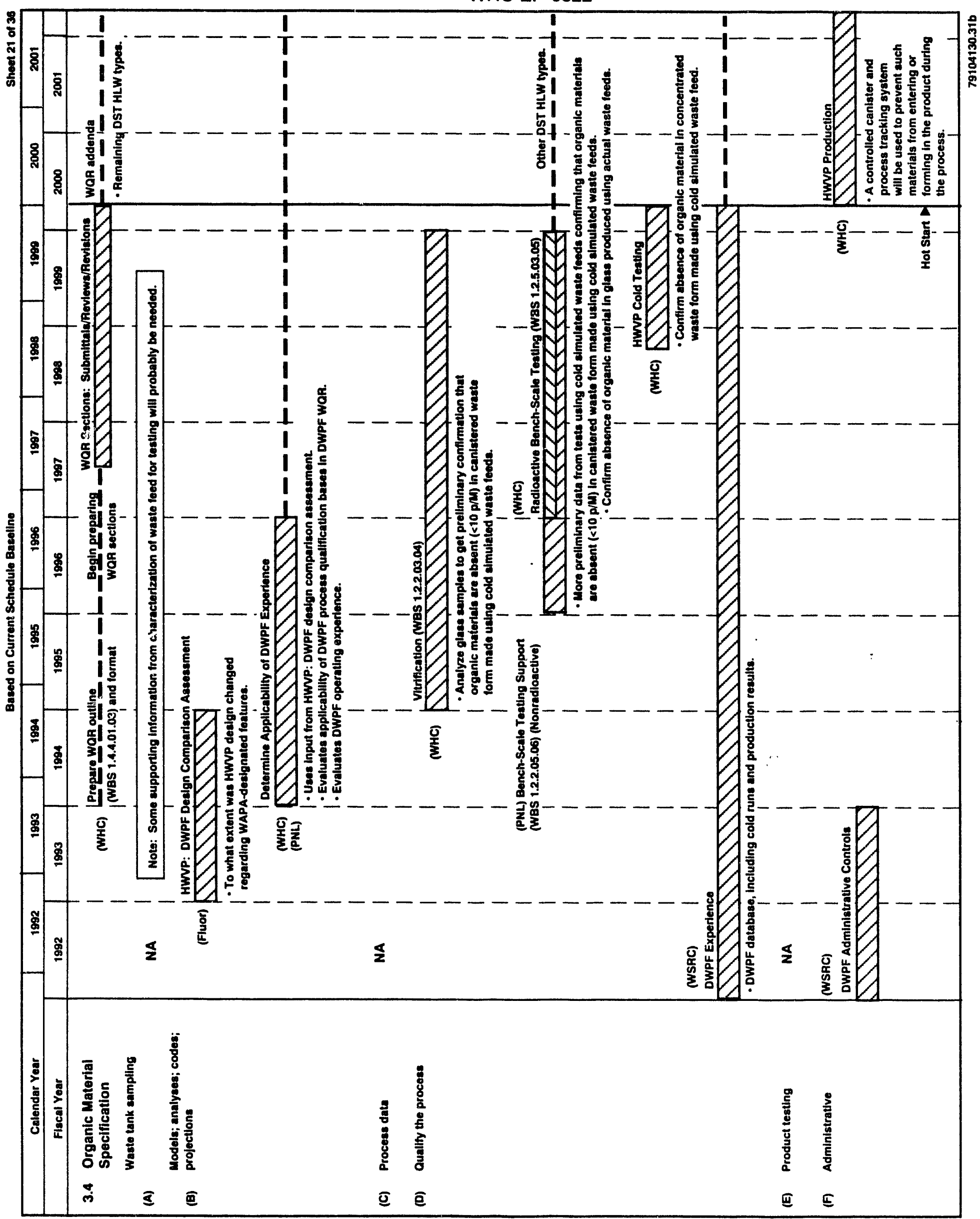


WHC-EP-0522

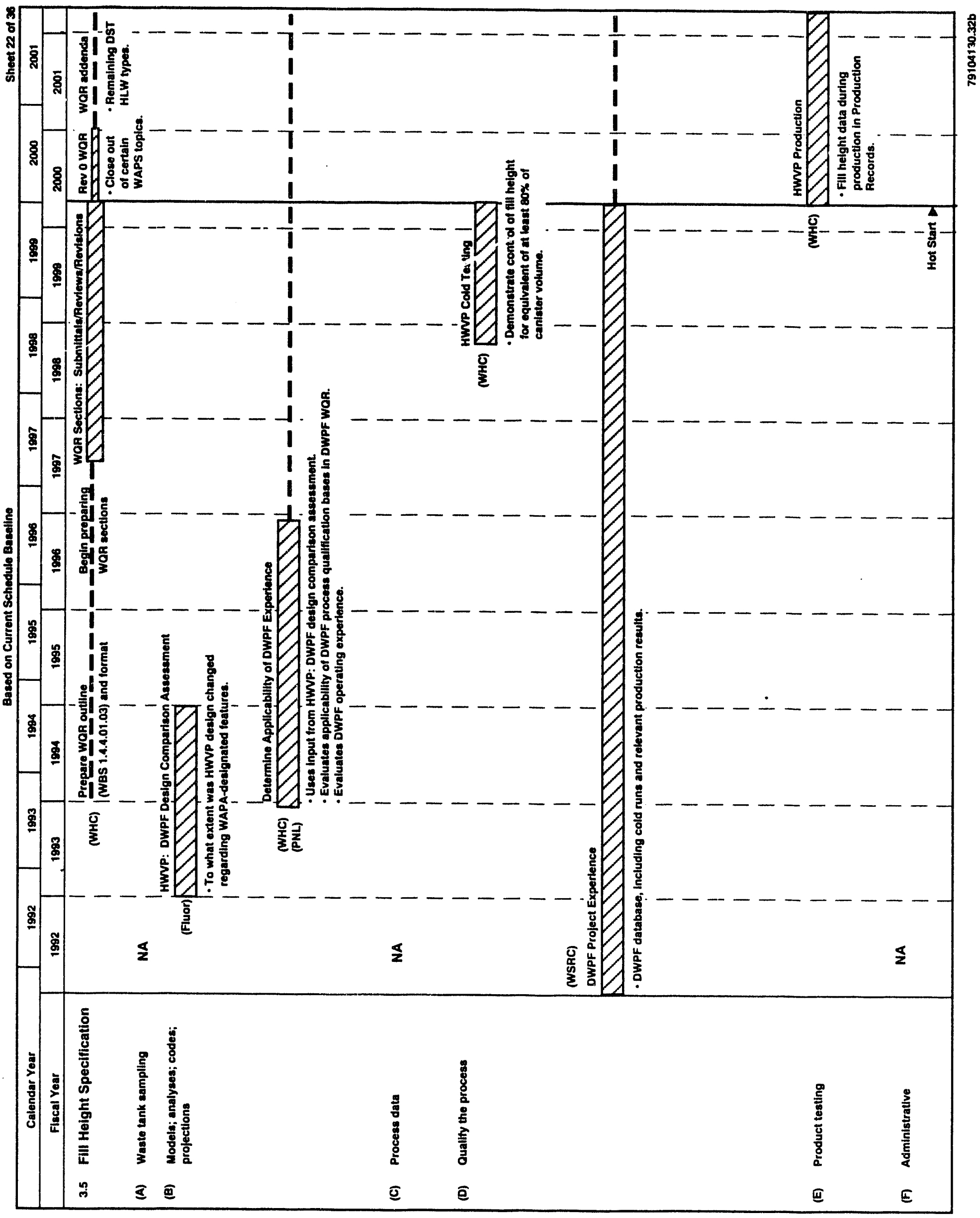


WHC-EP-0522

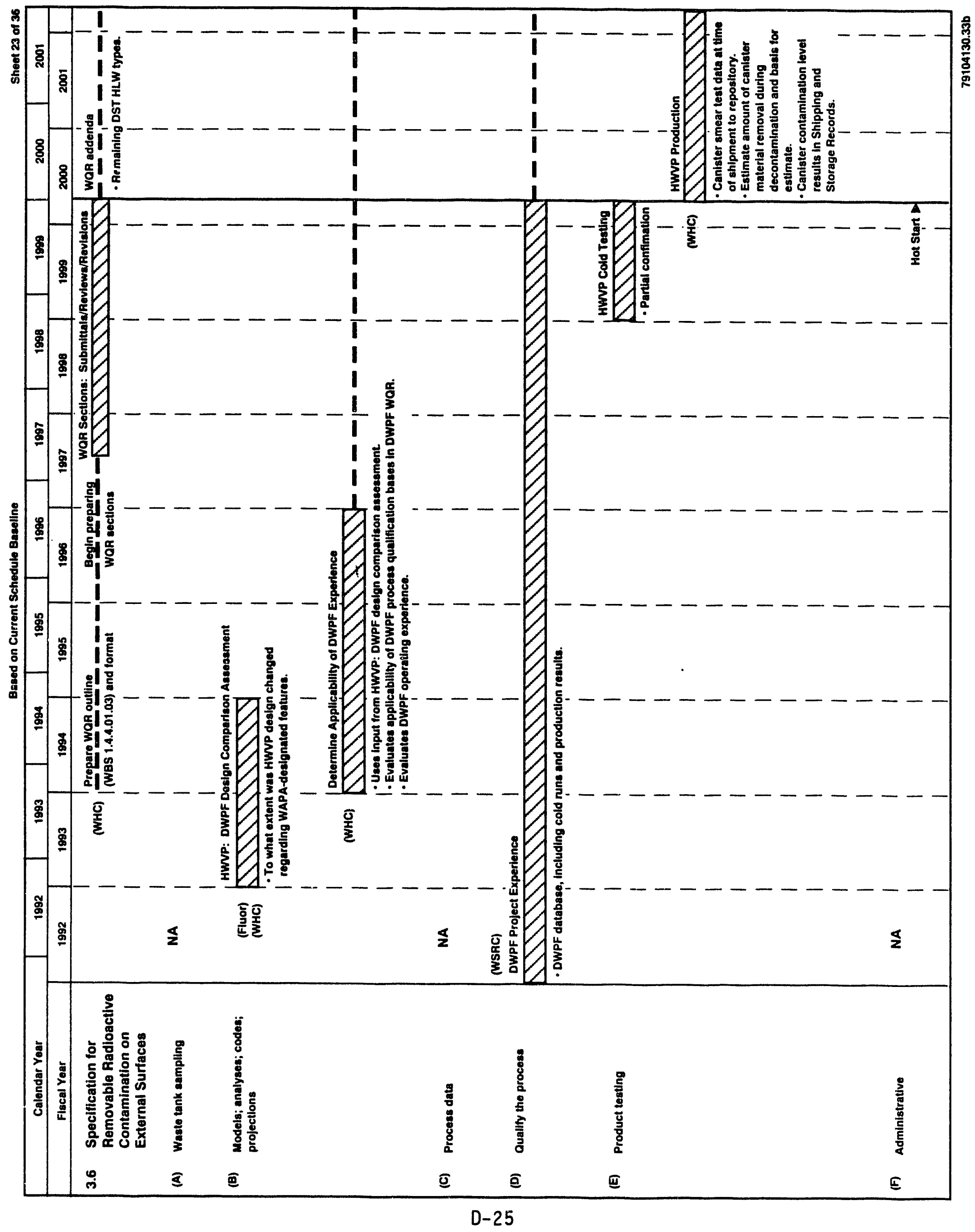


WHC-EP-0522
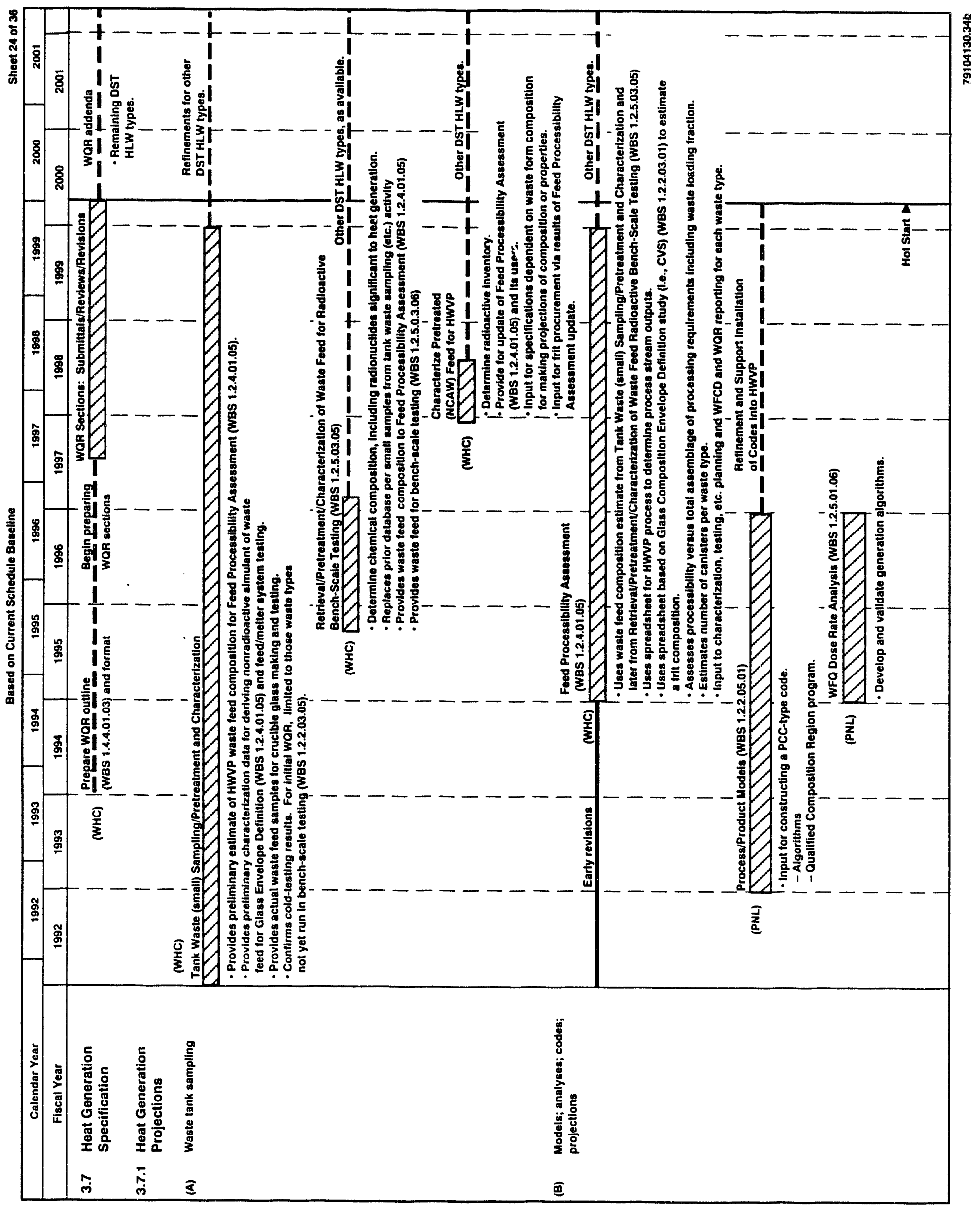
WHC-EP-0522

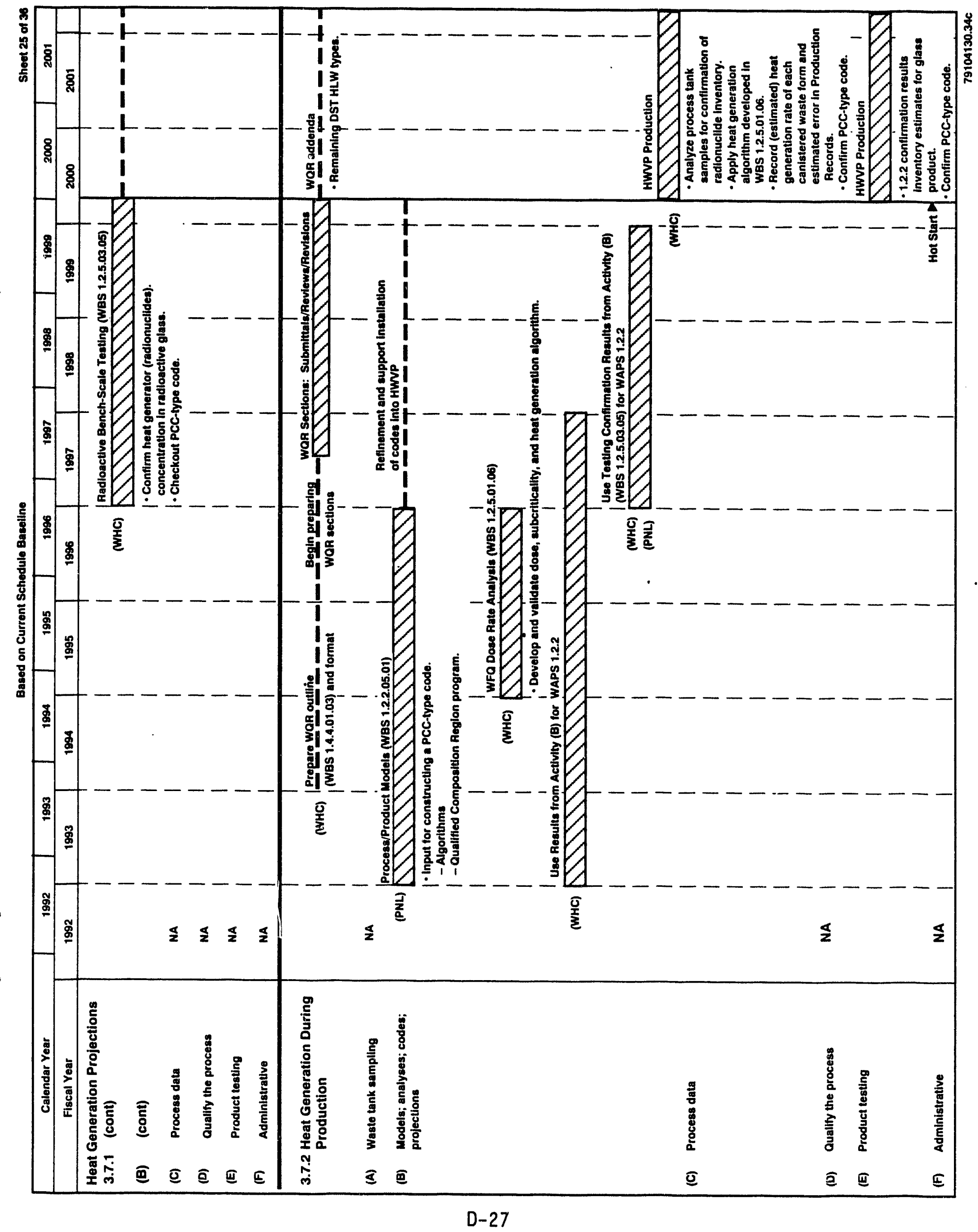


WHC-EP-0522

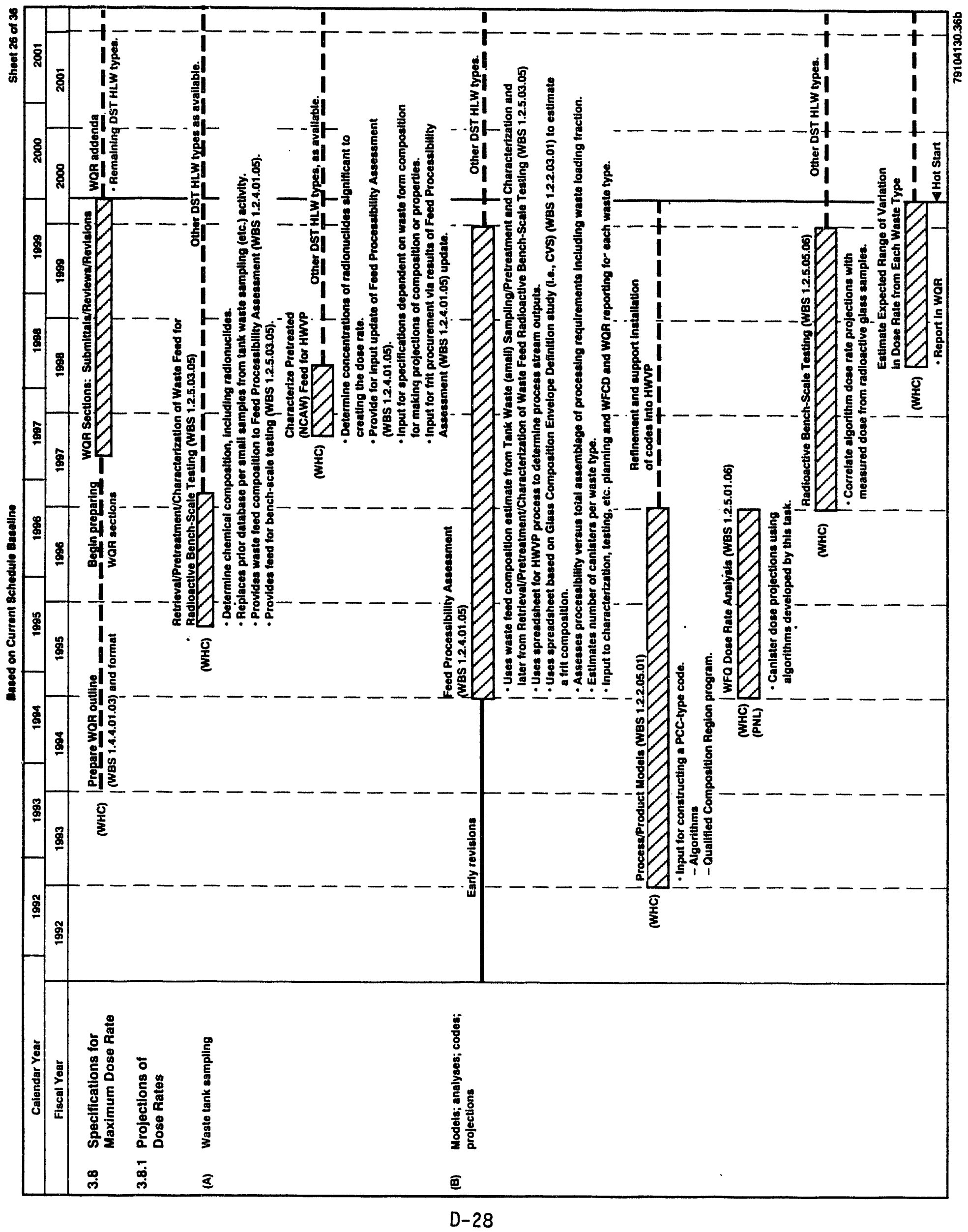


WHC-EP-0522

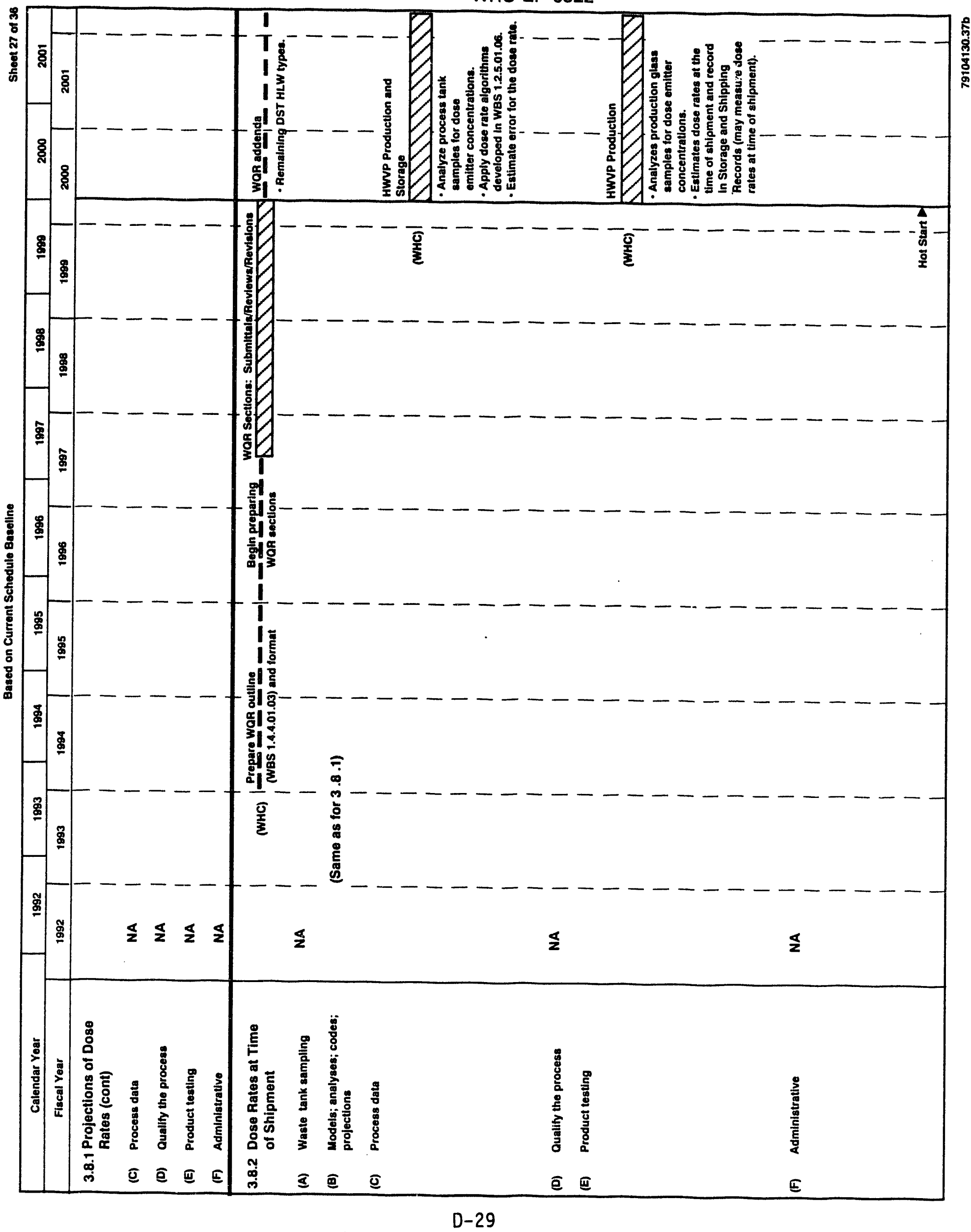




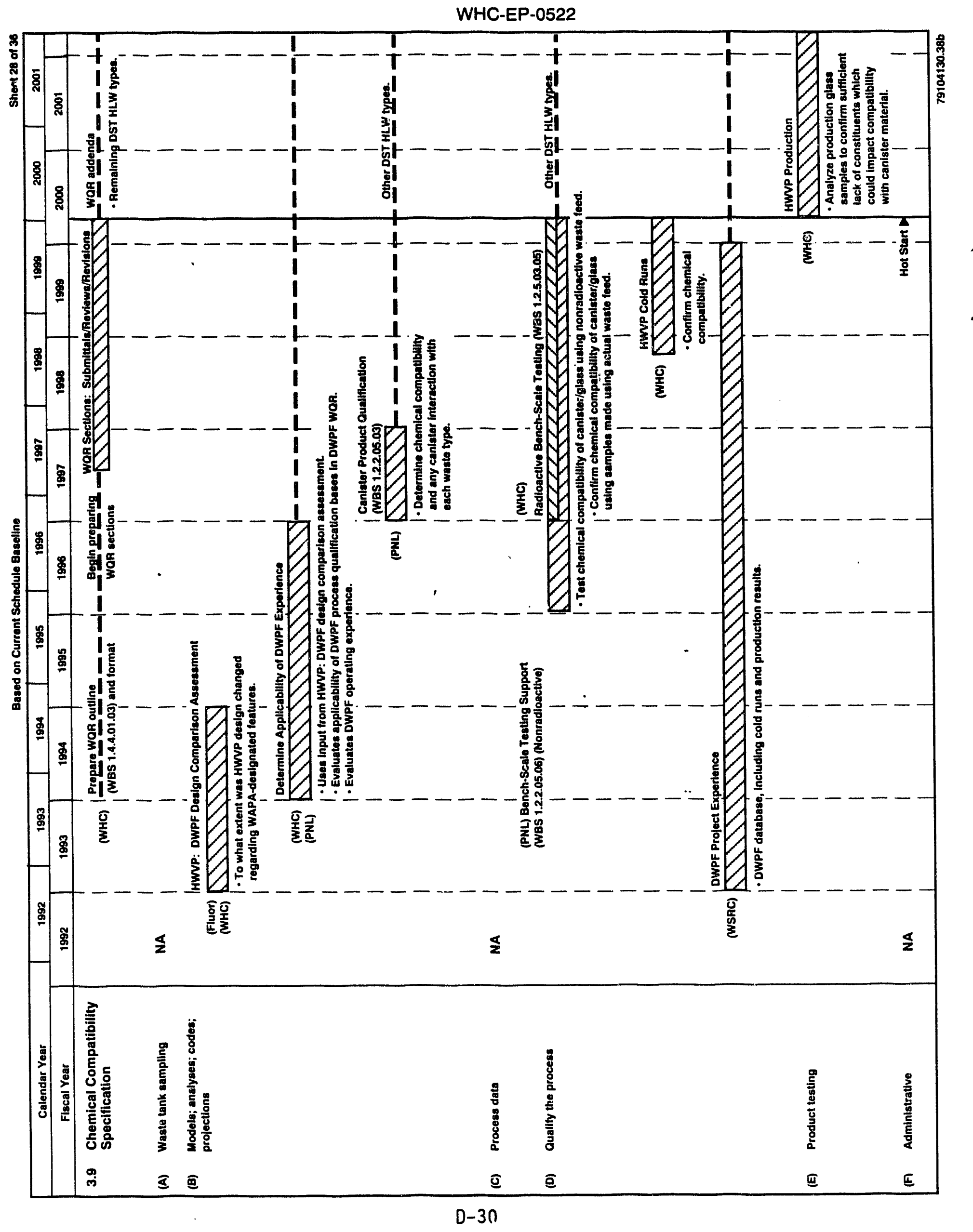


WHC-EP-0522

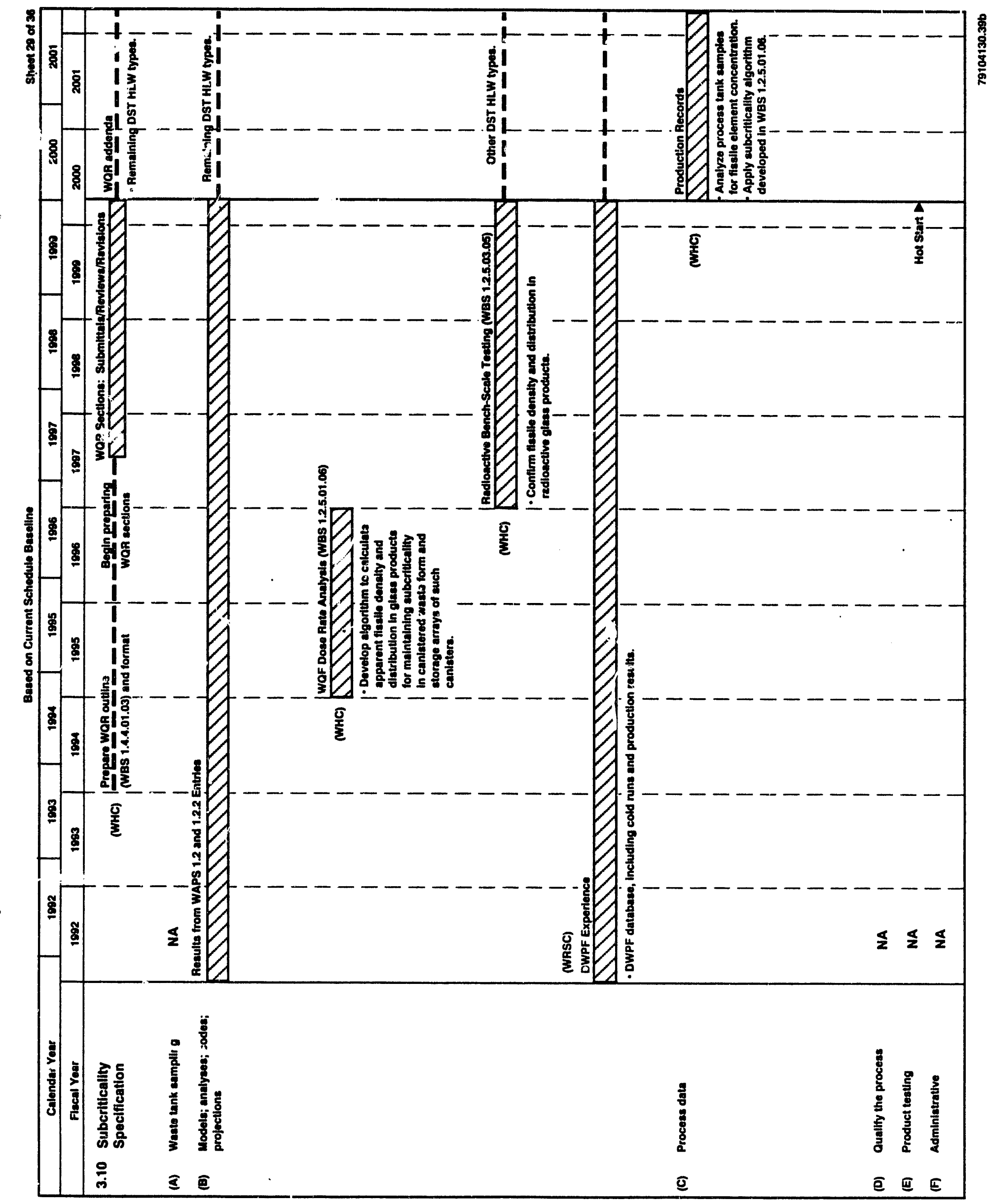


WHC-EP-0522

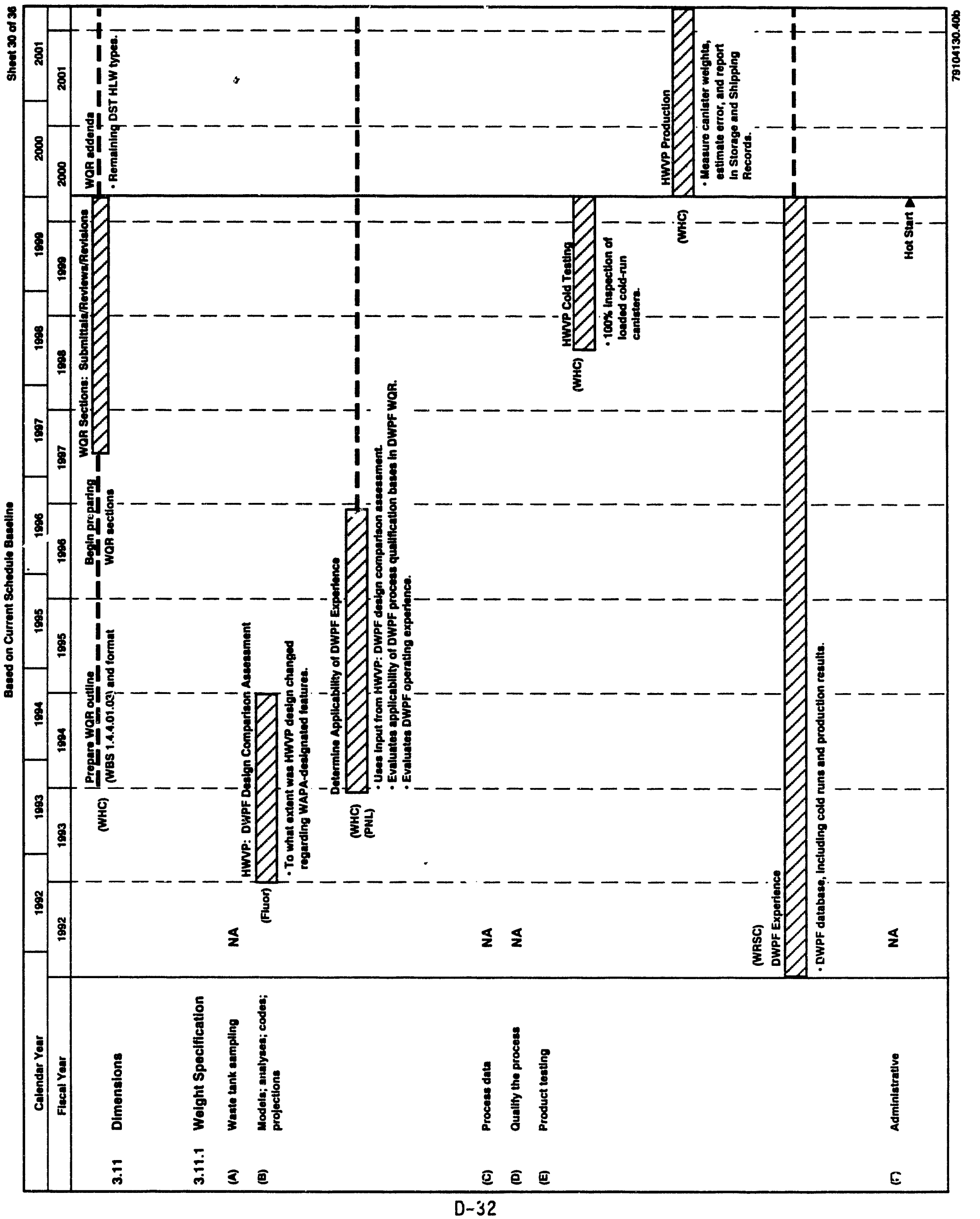


WHC-EP-0522

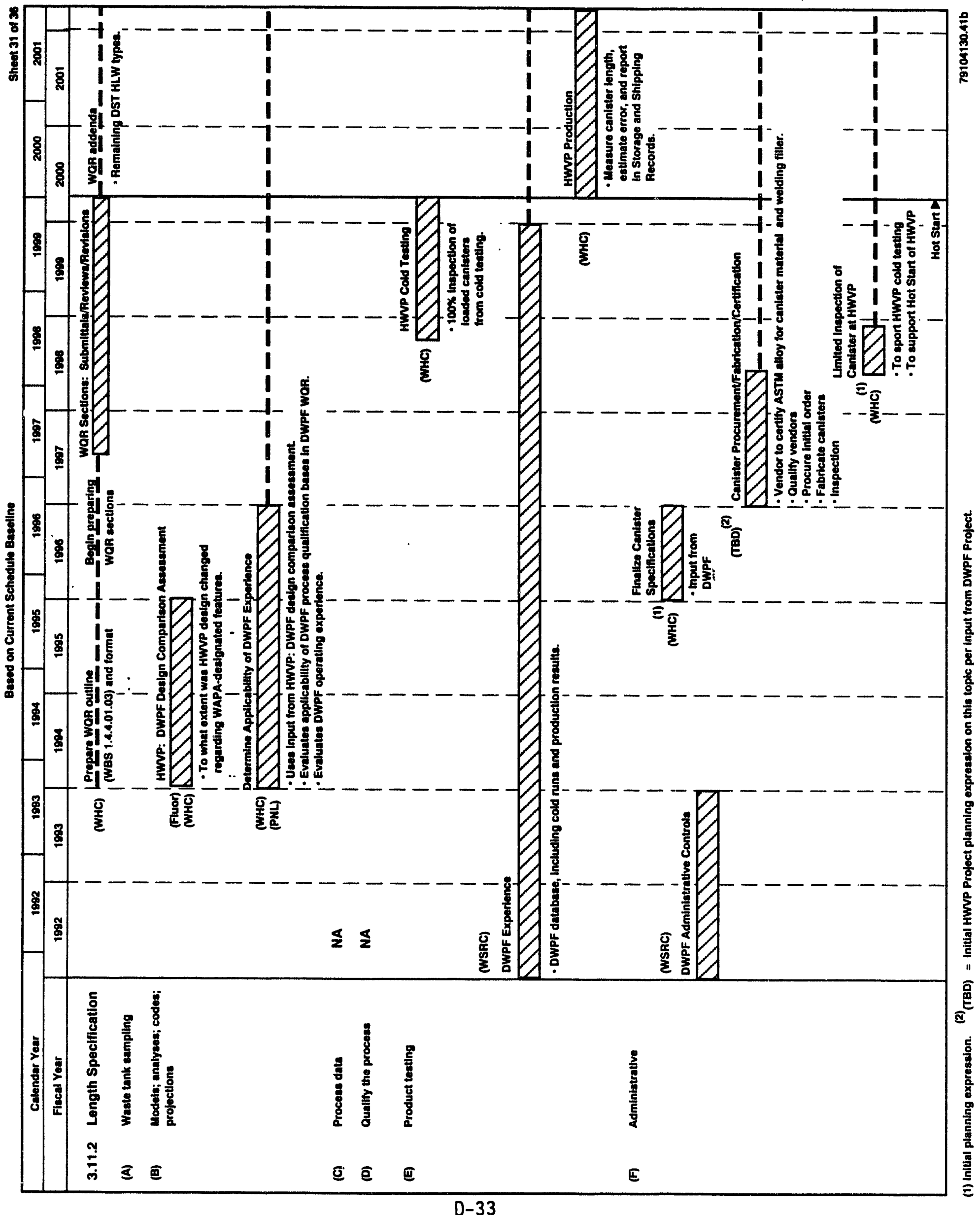


WHC-EP-0522

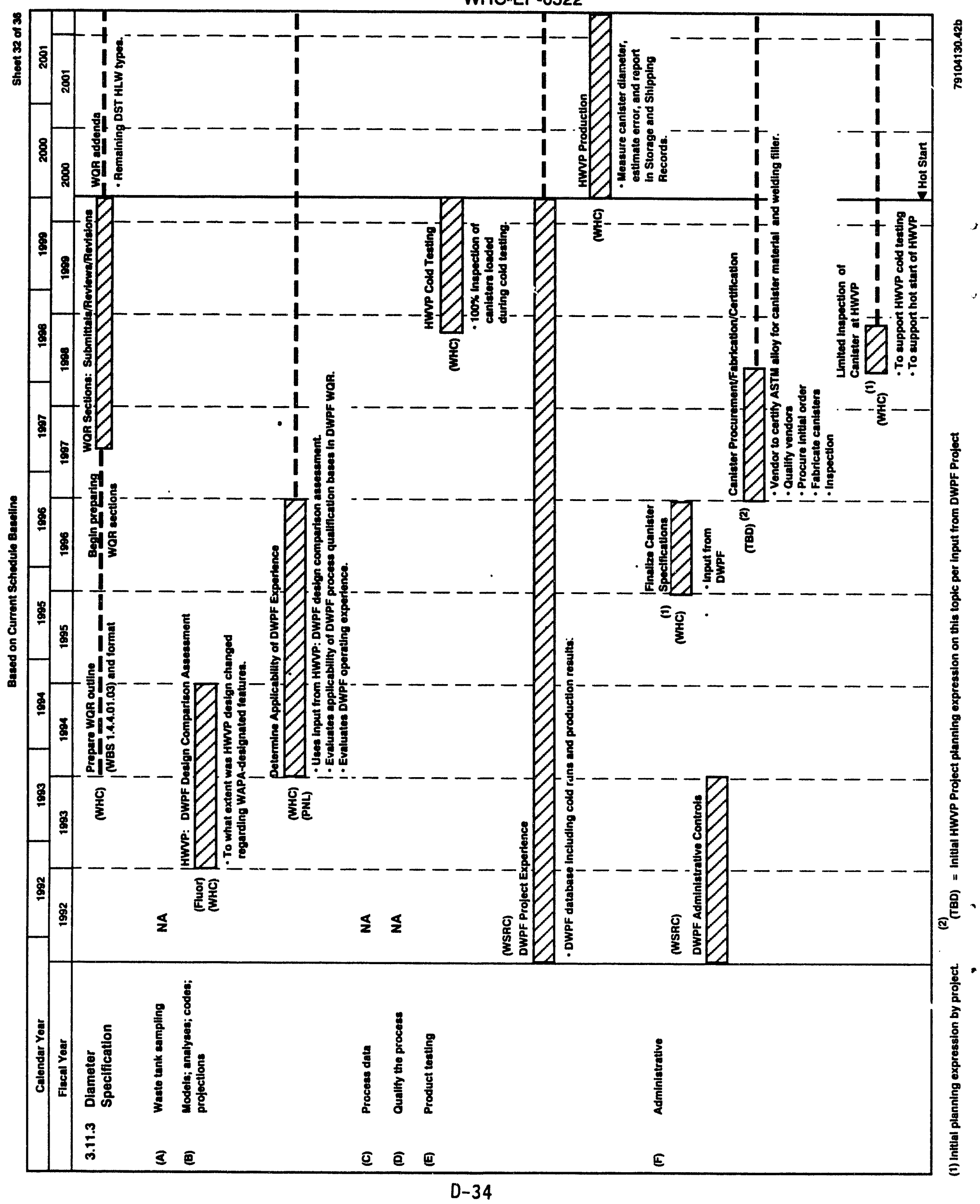


WHC-EP-0522

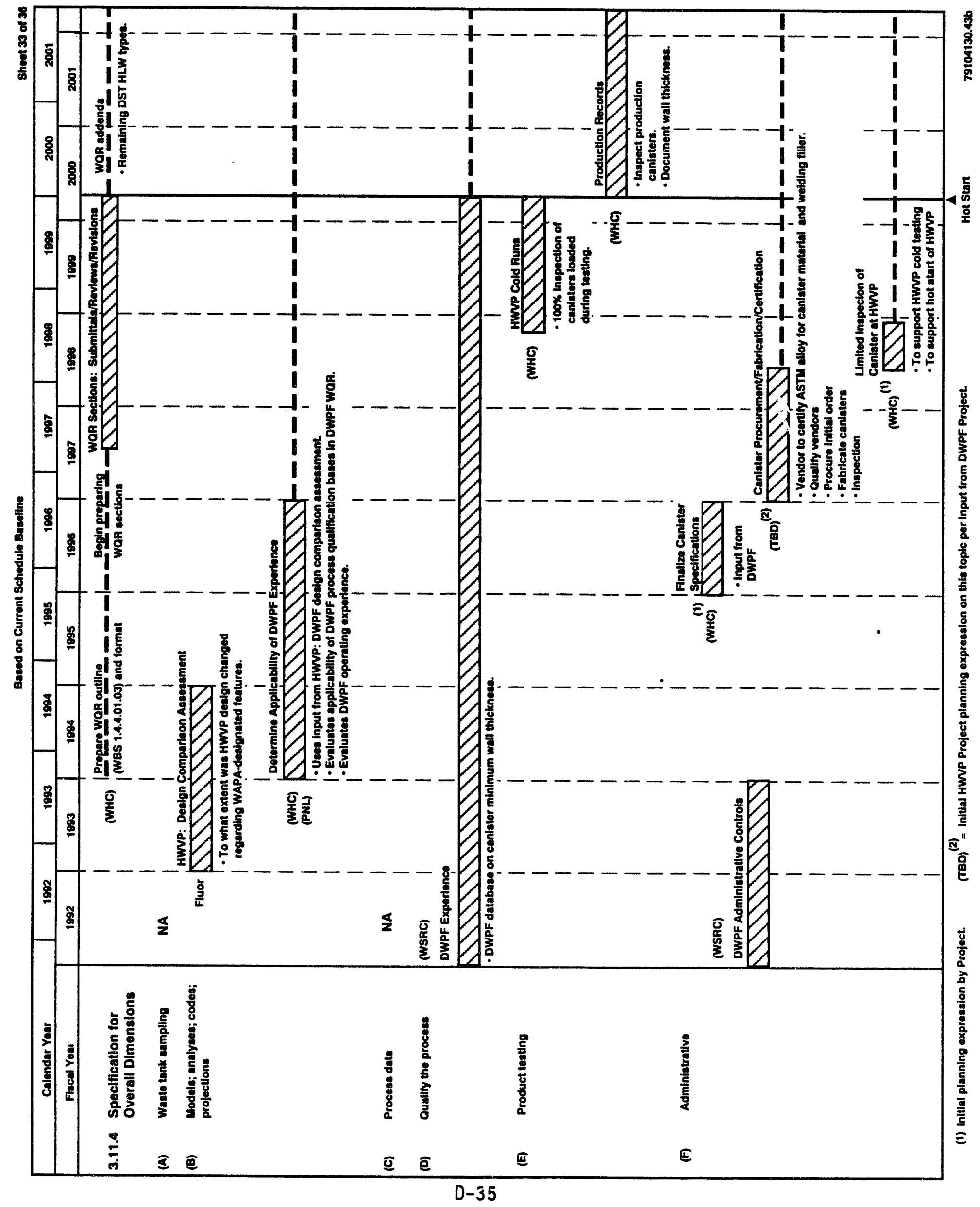




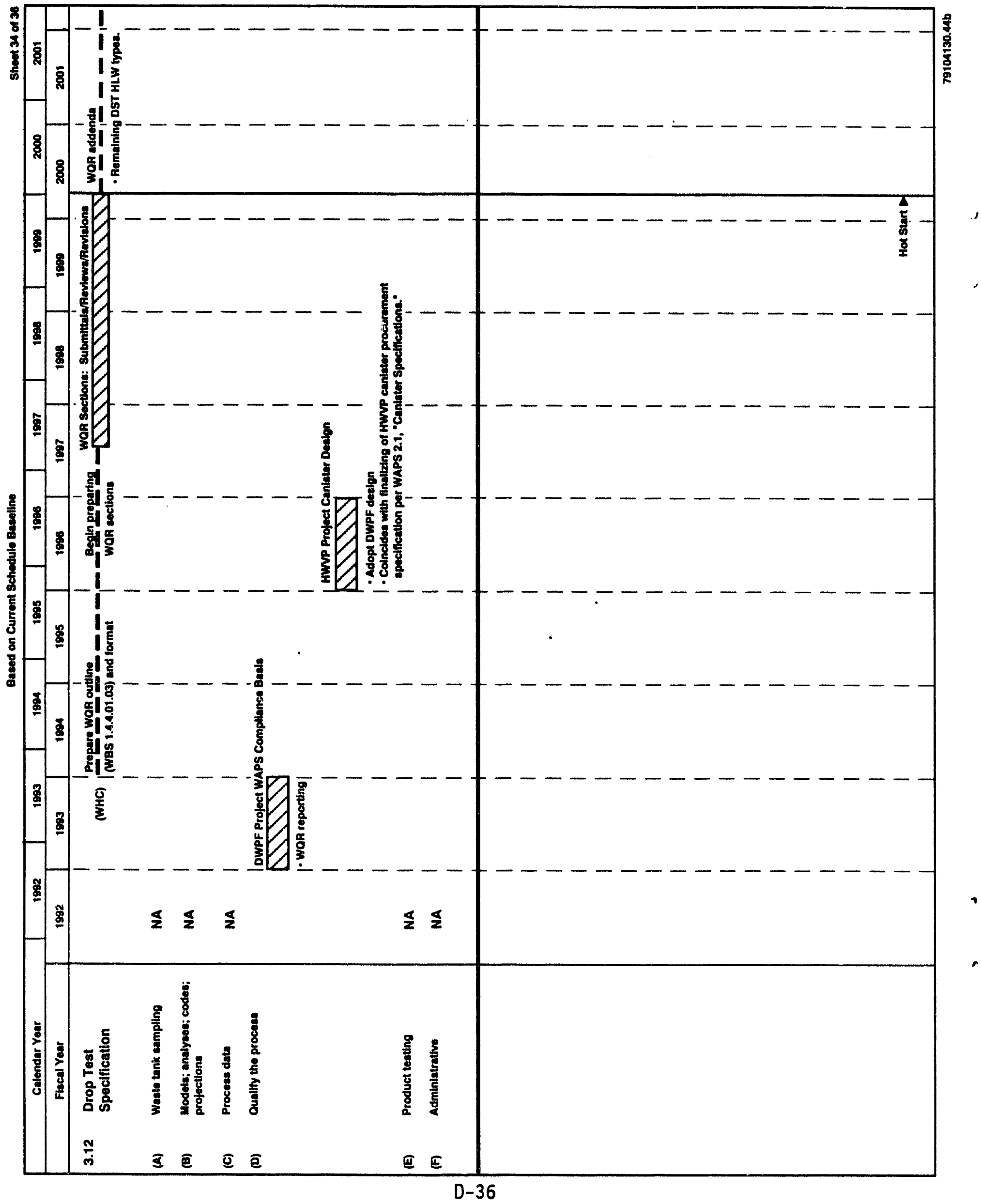


WHC-EP-0522

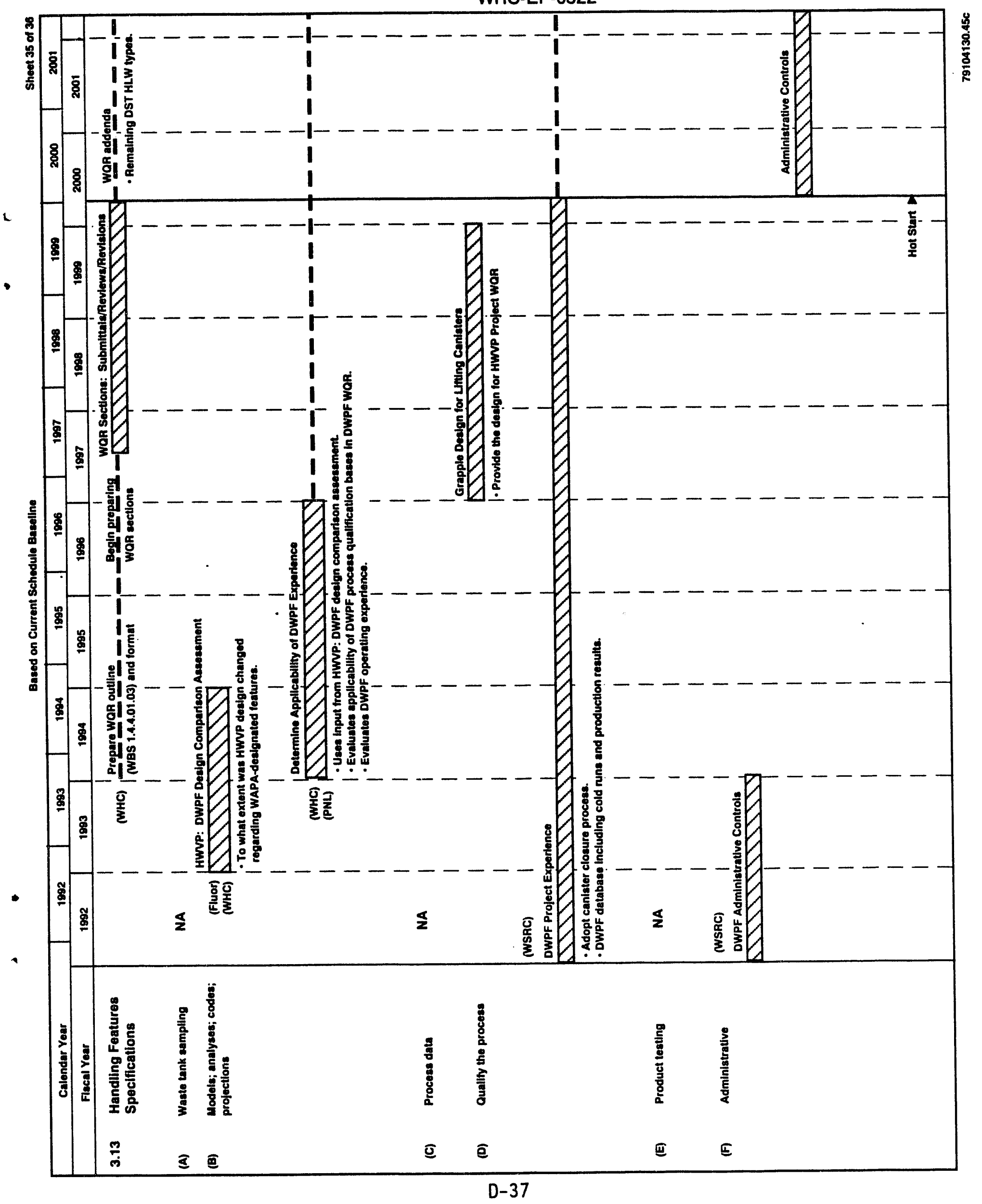




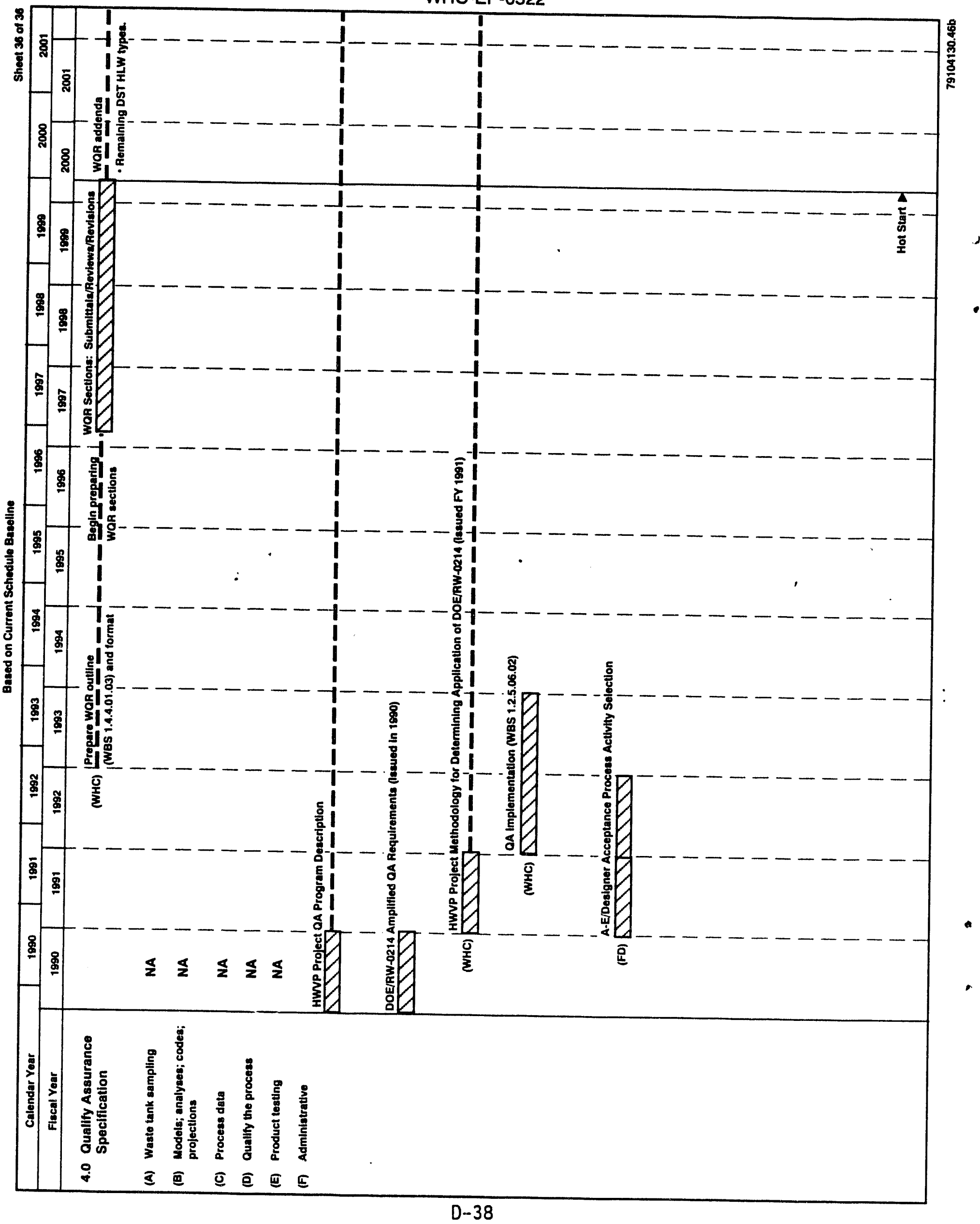


WHC-EP-0522

\section{DISTRIBUTION}

\section{Number of copies}

\section{OFFSITE}

7

U.S. Department of Energy-Headquarters

J. M. Altison

EM-343

K. A. Chacey

EM-36

S. P. Cowan

$E M-30$

R. Erickson

J. Hennesey

EM-343

J. E. Lytle

$E M-343$

J. C. Tseng

EM-30

EM-36

3

Fluor Daniel, Inc.

3333 Michelson Drive

Irvine, California 92730

R. S. Poulter

G. K. Korpi

J. L. Smets

\section{ONSITE}

io

U.S. Department of Energy. Richland Operations Office

R. W. Brown (5)

A5-10

S. T. Burnum

A5-16

L. Erickson

A5-16

P. E. LaMont

R3-73

E. C. Norman

A5-16

Public Reading Room

H2-53

9

Pacific Northwest Laboratory

J. M. Creer

G6-01

P. R. Hrma

P8-37

G. A. Jensen

G6-01

W. L. Kuhn

P8-38

D. E. Larson

J. M. Perez

G6-01

G. F. Piepel

P7-41

R. J. Robertus

K7-34

Technical Files

P8-38

$\mathrm{K} 1-11$

UE\&C-Catalytic Inc.

F. D. Pettit

$\mathrm{N} 1-04$ 


\section{DISTRIBUTION (cont)}

Number of copies

J. N. Appe 1

C. A. August ine

D. G. Baide

J. R. Baker

W. B. Barton

J. F. Bores

R. B. Calmus

R. P. Colburn

D. W. Duncan

P. Felise

R. L. Gibby

M. L. Grygiel

D. W. Hamilton

J. M. Henderson

G. P. Janicek

R. E. Johnson

S. E. Kelly

S. L. Lambert

L. W. Lamm

W. C. Miller

S. R. Nelson

L. E. Nilsen

A. F. Noonan

J. D. Phillips

J. G. Propson

E. H. Randklev (15)

C. K. Rosnick

P. S. Schaus

R. G. Seymour

K. R. Shah

R. A. Smith

G. E. Stegen

L. D. Swenson

D. J. Trimble

D. V. Vo

R. A. Watrous

E. T. Weber

J. Weber

L. 0 . Westphal

C. N. Wilson

D. D. Wodrich

G. Woodcock

Central Files

Document Clearance

Administration (3)

HWVP Project Document

Processing Center
S4-58

G6-02

G6-16

G6-06

L4-75

G6-07

G6-08

G6-08

G6-07

G6-06

G6-08

B 1-58

G6-04

S4-55

G6-04

G6-08

G6-08

G6-08

G6-07

S4-55

G6-14

G6-12

R2-12

G6-06

R2-18

G6-08

G6-06

B1-59

G6-08

G6-06

G6-02

G6-06

G6-06

L5-02

G6-06

G6-08

G6-08

S1-57

G6-06

G6-08

B1-59

G6-08

L8-04

A3-36

G6-51 

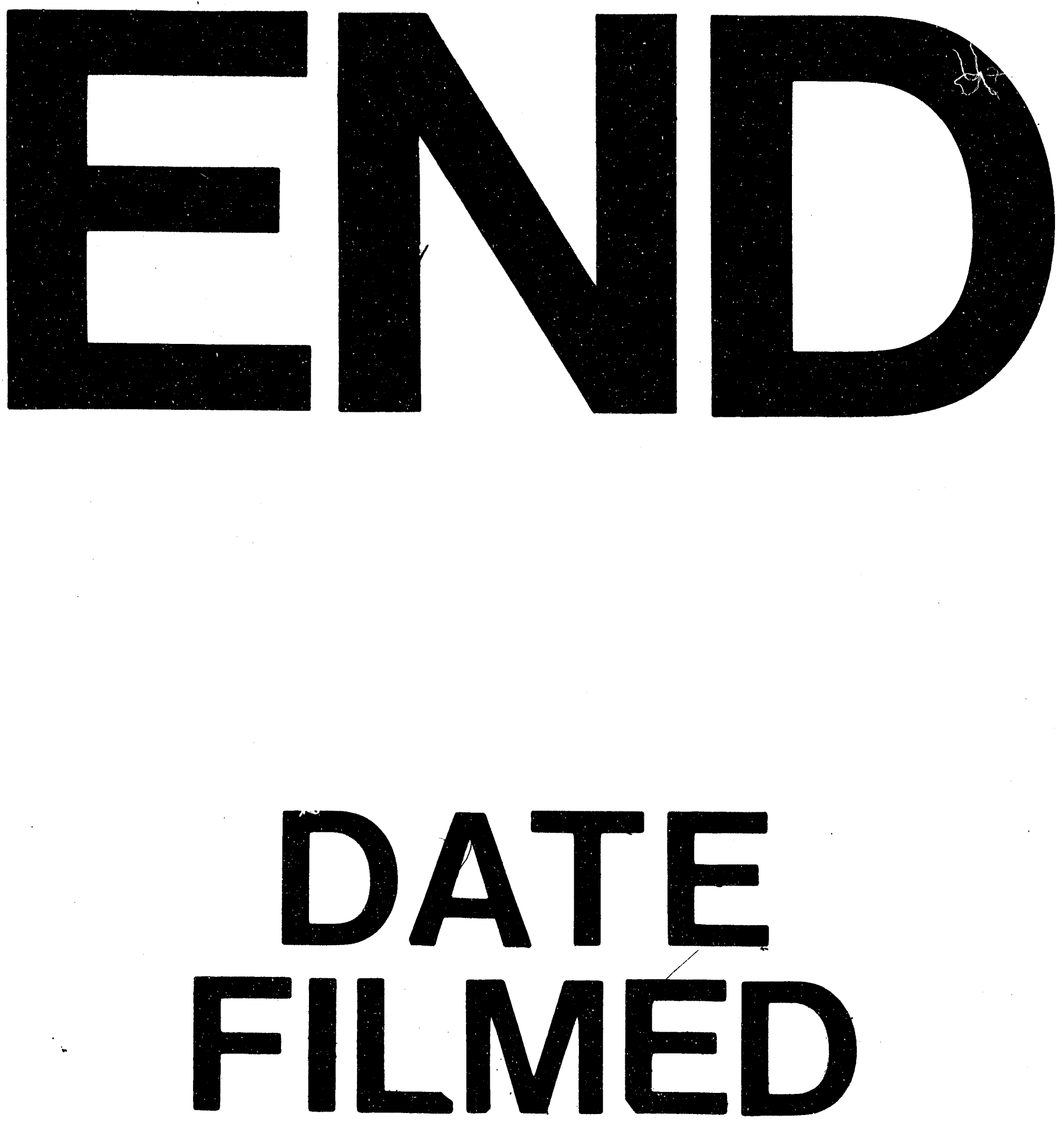

1

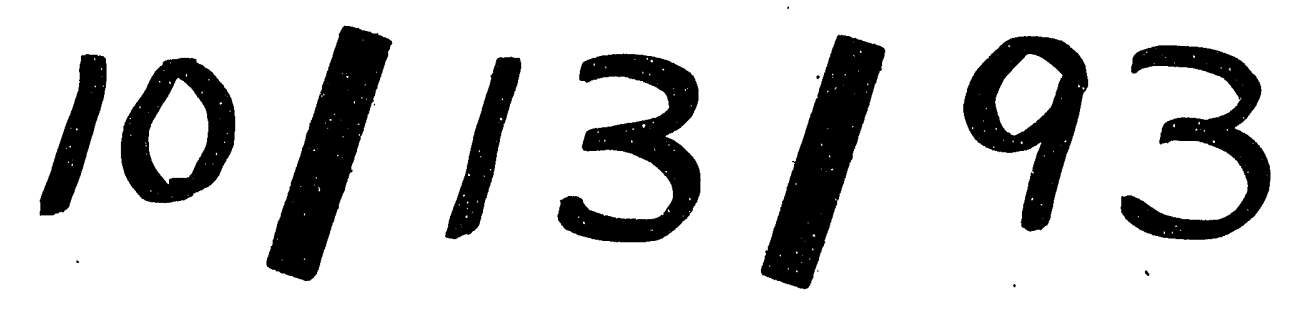


